Florida International University FIU Digital Commons

$11-12-2014$

\title{
Factors of Inflammation in Haitian Americans and African Americans with and without Type 2 Diabetes
}

Janet Antwi

Florida International University, jantw001@fiu.edu

DOI: $10.25148 /$ etd.FI14110719

Follow this and additional works at: https://digitalcommons.fiu.edu/etd

Part of the Dietetics and Clinical Nutrition Commons

\section{Recommended Citation}

Antwi, Janet, "Factors of Inflammation in Haitian Americans and African Americans with and without Type 2 Diabetes" (2014). FIU Electronic Theses and Dissertations. 1587.

https://digitalcommons.fiu.edu/etd/1587 


\title{
FLORIDA INTERNATIONAL UNIVERSITY
}

Miami, Florida

\section{FACTORS OF INFLAMMATION IN HAITIAN AMERICANS AND AFRICAN AMERICANS WITH AND WITHOUT TYPE 2 DIABETES}

A dissertation submitted in partial fulfillment of

\author{
the requirements for the degree of \\ DOCTOR OF PHILOSOPHY \\ in \\ DIETETICS AND NUTRITION
}

by

Janet Antwi

2014 
To: Dean Michele Ciccazzo

R.Stempel College of Public Health and Social Work

This dissertation, written by Janet Antwi, and entitled Factors of Inflammation in Haitian Americans and African Americans with and without Type 2 Diabetes, having been approved in respect to style and intellectual content, is referred to you for judgment.

We have read this dissertation and recommend that it be approved.

Zisca Dixon

Vijaya Narayanan

Tan Li

Fatma G. Huffman, Major Professor

Date of Defense: November 12, 2014

The dissertation of Janet Antwi is approved.

Dean Michele Ciccazzo

R.Stempel College of Public Health and Social Work

Dean Lakshmi N. Reddi

University Graduate School

Florida International University, 2014 


\section{DEDICATION}

This dissertation is dedicated to the Lord my God without whose matchless grace, strength, guidance and wisdom I would not have been able to come this far. I give Him all the glory due His Holy Name: The Lord, Almighty!

To my parents and siblings, I say a big thank you for all your love, unflinching support, encouragement and prayers for me throughout these years to achieve this goal. 


\section{ACKNOWLEDGMENT}

I want to express my heartfelt gratitude to my Major Professor, Dr. Fatma G. Huffman for taking me on as her student. This is a token of my appreciation for all the days you dedicated to teach me, gave me opportunities to develop myself and also for all your advice and guidance. To Dr. Zisca Dixon I say that God bless not only for your prayers, but your help and encouragement each step of the way. For all the lab ideas you gave me and accommodating me when I would not let you have peace with the kits, Dr. Vijaya Narayanan, our own Dr. Viji, thank you. Dr. Tan Li, I want to thank you for all your statistical advice and help. I'm grateful to you all for your time, efforts, patience and help. 
ABSTRACT OF THE DISSERTATION

FACTORS OF INFLAMMATION IN HAITIAN AMERICANS AND AFRICAN

AMERICANS WITH AND WITHOUT TYPE 2 DIABETES

by

Janet Antwi

Florida International University, 2014

Miami, Florida

\section{Professor Fatma G. Huffman, Major Professor}

Chronic low-grade inflammation has been implicated in the processes leading to the development of type 2 diabetes (T2D) and its progression. Non-Hispanic Blacks bear a disproportionate burden of T2D and are highly susceptible to inflammation. This crosssectional study assessed and compared the serum levels of established adipocytokines; interleukin-6 (IL-6), C-reactive protein (CRP), leptin, and novel adipocytokines; chemerin and omentin in Haitian and African Americans with and without T2D. The relationships of these adipocytokines with metabolic syndrome (MetS), anthropometric and HOMA2 measures by ethnicity and diabetes status were also assessed. Serum levels of IL-6, CRP, leptin, chemerin and omentin were determined by the ELISA method. HOMA2 measures were calculated for insulin sensitivity (HOMA2-IS) and insulin resistance (HOMA2-IR).

Analyses of available data for 230 Haitian Americans and 241 African Americans (240 with and 231 without T2D) for the first study showed that Haitian Americans with and without MetS had lower levels of IL-6 and CRP compared to African Americans with and without MetS $(\mathrm{P}<0.05)$. MetS was found to be associated with CRP $(\beta=0.34, \mathrm{P}$ 
$=0.012)$, but not with IL-6. In the second study $(n=429)$, Haitian Americans with T2D had significantly lower serum chemerin levels $(\mathrm{P}<0.001)$ and higher serum omentin levels $(\mathrm{P}=0.023)$ compared to African Americans with T2D. Diabetes status was negatively associated with chemerin $(B=-41.35, P=0.024)$, but not associated with omentin ( $\mathrm{B}=-85.02, \mathrm{P}=0.136)$. HOMA2-IS was inversely associated with chemerin ( $\mathrm{B}$ $=-0.229, \mathrm{P}=0.030)$. Leptin levels in the third study $(\mathrm{n}=413)$ were lower in Haitian American males and females than African American males and females, regardless of diabetes status $(\mathrm{P}<0.05)$. Leptin levels were significantly associated with $\mathrm{BMI}(\mathrm{P}<0.001)$ and HOMA2-IR $(\mathrm{P}=0.015)$ in males without T2D.

Ethnic-specific diabetes intervention and treatment programs must be designed to target Haitian Americans and African Americans as separate unique groups, in order to reduce the burden of T2D among the non-Hispanic Black community. Further research is needed to gain better understanding of the role of inflammation and T2D in this population. 


\section{TABLE OF CONTENTS}

CHAPTER

PAGE

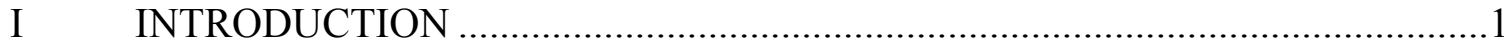

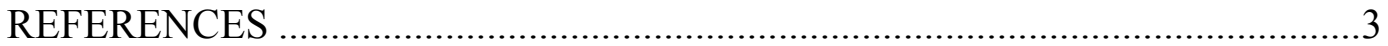

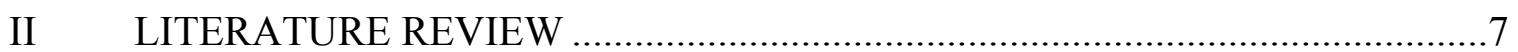

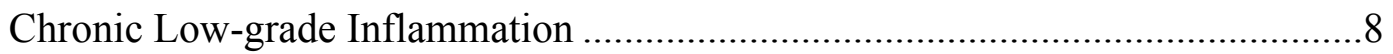

Adipose Tissue as a Major Source of Adipocytokines ..........................................10

Adipocytokines, Insulin Signaling and Insulin Resistance....................................13

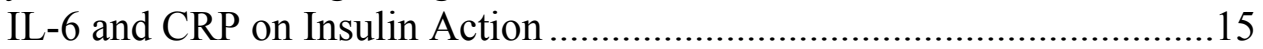

Leptin on Insulin Action ..............................................................................

Chemerin and Omentin on Insulin Action .................................................17

Role of Adipocytokines in Metabolic Syndrome and Type 2 Diabetes..................18

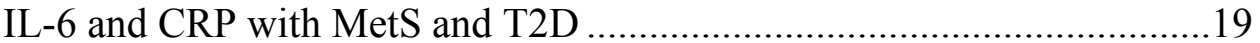

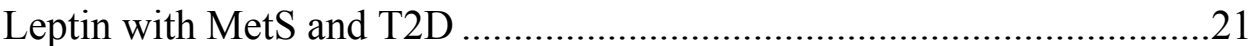

Chemerin and Omentin with MetS and T2D ........................................22

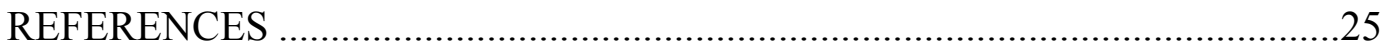

Specific Aims and Hypotheses ……………………..........................................

III INFLAMMATORY ADIPOCYTOKINES AND METABOLIC SYNDROME IN HAITIAN AND AFRICAN AMERICANS WITH AND WITHOUT TYPE 2 DIABETES

IV SERUM CHEMERIN AND OMENTIN IN HAITIAN AND AFRICAN AMERICANS WITH AND WITHOUT TYPE 2 DIABETES ...............................70

V ASSOCIATION OF LEPTIN WITH BMI AND INSULIN RESISTANCE IN HAITIAN AND AFRICAN AMERICANS WITH AND WITHOUT TYPE 2 DIABETES .96

VI SUMMARY AND FUTURE RESEARCH ………......................................121

VITA .125 


\section{LIST OF TABLES}

TABLE

PAGE

CHAPTER III

Table 1. Characteristics of the Participants by Ethnicity and Diabetes Status .64

Table 2. Partial Correlations of log IL-6 and $\log$ CRP with MetS and Components of MetS by Ethnicity and Diabetes Status

Table 3. Multiple Linear Regression with log IL-6 as Dependent Variable......................68

Table 4. Multiple Linear Regression with log CRP as Dependent Variable

\section{CHAPTER IV}

Table 1. Characteristics of the Participants by Diabetes Status

Table 2. Characteristics of the Participants by Ethnicity and Diabetes Status

Table 3. Comparison of Serum Chemerin and Omentin of Participants with and without T2D by BMI Categories.

Table 4. Association between Chemerin and Diabetes Status - Multiple Linear Regression Analysis.

Table 5. Association between Omentin and Diabetes Status - Multiple Linear Regression Analysis

\section{CHAPTER V}

Table 1. Characteristics of the Participants by Sex and Ethnicity

Table 2. Characteristics of the Participants by Sex and Diabetes Status 118

Table 3. Relationship of Leptin with BMI and HOMA2-IR in Participants with T2D - Multiple Linear Regression Analysis

Table 4. Relationship of Leptin with BMI and HOMA2-IR in Participants without T2D - Multiple Linear Regression Analysis 


\section{CHAPTER I: INTRODUCTION}

Type 2 diabetes (T2D) is a major public health concern among ethnic minority groups in the United States and non-Hispanic Blacks in particular, are disproportionately

affected. ${ }^{1-3}$ The disparities in the incidence and prevalence of T2D among non-Hispanic Blacks are estimated to be 2 to 6 times of that observed in Caucasians. ${ }^{2,4}$ While reasons for these disparities have not been fully understood, increased prevalence of disease risk factors among this population are considered as the cause. ${ }^{5-6}$ One such risk factor which is receiving increased attention is inflammatory processes, since T2D is considered to be a state of chronic low-grade inflammation. ${ }^{7}$

Chronic low-grade inflammation, as characterized by increased circulating levels of pro-inflammatory adipocytokines, is a key feature of chronic diseases including obesity, T2D and cardiovascular diseases (CVD). ${ }^{8-10}$ Several studies have associated plasma levels of pro-inflammatory adipocytokines such as tumor necrosis factor- $\alpha$ (TNF$\alpha$ ), interleukin-6 (IL-6), C reactive protein (CRP) and leptin with metabolic risk factors such as obesity and insulin resistance. ${ }^{13-14}$ The levels of the anti-inflammatory adipocytokine, adiponectin are however reduced in these disease conditions. ${ }^{15-17}$ Similar observations have also been made between these markers and metabolic syndrome (MetS) in individuals with and without T2D. ${ }^{8,18}$

Previous studies that found an association between inflammation and the pathogenesis and progression of T2D also reported on ethnic differences in the levels of established adipocytokines such as, TNF- $\alpha$, IL-6, CRP, leptin and adiponectin. ${ }^{5-6,19}$ Chemerin and omentin are recently identified novel adipocytokines that have been shown to have reciprocal effects in inflammatory processes and chronic disorders. ${ }^{20-22}$ The levels 
of pro-inflammatory chemerin are increased in obesity, insulin resistance, metabolic syndrome, T2D and cardiovascular diseases, while the anti-inflammatory omentin is down-regulated in these disorders. ${ }^{23-27}$

In a recent study, BMI, fasting serum insulin, triglycerides and high density lipoprotein cholesterol (HDL-C) were significantly correlated with plasma chemerin levels in 969 Mexican-Americans with T2D compared to 173 without T2D. ${ }^{28}$ Similar relationships have been observed in various other populations. ${ }^{23,29}$ However, the roles of chemerin and omentin as novel candidates to link inflammation with T2D in other ethnic minority subgroups such as Haitian and African Americans have not been studied. Furthermore, recent studies have associated chemerin and omentin with several established pro-inflammatory and anti-inflammatory adipocytokines, ${ }^{24,26}$ but data on their interactions among Haitian and African Americans is scarce. The study of novel adipocytokines may provide better understanding of the disparities in T2D that exist among non-Hispanic Blacks.

Therefore, the aims of this study were to characterize adipocytokines in Haitian and African Americans with and without T2D and determine the relationships of these adipocytokines with metabolic syndrome (MetS), anthropometric and HOMA2 measures by ethnicity and diabetes status controlling for socio-demographic variables, dietary and lifestyle factors and other health status variables. 


\section{REFERENCES:}

1. Center for Disease Control and Prevention. Diabetes Data and Trends. Diabetes Complications. 2008. Available at:

http://www.cdc.gov/diabetes/statistics/complications national.html. Accessed on August 18, 2014.

2. Center for Disease Control and Prevention. Diabetes Public Health Resource. 2010. Available at: http://www.cdc.gov/diabetes/consumer/groups.html. Accessed on August 18, 2014.

3. Lanting LC, Joung IM, Mackenbach JP, Lamberts SW, Bootsma AH. Ethnic differences in mortality, end-stage complications, and quality of care among diabetic patients: a review. Diabetes Care. 2005;28(9):2280-2288.

4. Diabetes Disparities Among Racial and Ethnic Minorities: Fact Sheet. November 2001. Agency for Healthcare Research and Quality, Rockville, MD.

http://www.ahrq.gov/research/findings/factsheets/diabetes/diabdisp/index.html. Accessed on August 18, 2014.

5. Albert MA, Glynn RJ, Buring J, Ridker PM. C-reactive protein levels among women of various ethnic groups living in the United States (from the Women's Health Study). Am J Cardiol. 2004;93(10):1238-1242.

6. Paalani M, Lee JW, Haddad E, Tonstad S. Determinants of inflammatory markers in a bi-ethnic population. Ethn Dis. 2011;21(2):142-149.

7. Shoelson SE, Goldfine AB. Getting away from glucose: fanning the flames of obesity-induced inflammation. Nat Med. 2009;15(4):373-4.

8. Moon YS, Kim DH, Song DK. Serum tumor necrosis factor-alpha levels and components of the metabolic syndrome in obese adolescents. Metabolism. 2004;53(7):863-867.

9. Duncan BB, Schmidt MI, Pankow JS, Ballantyne CM, Couper D, Vigo A, Hoogeveen R, Folsom AR, Heiss G; Atherosclerosis Risk in Communities Study. Low-grade systemic inflammation and the development of type 2 diabetes: the atherosclerosis risk in communities study. Diabetes. 2003;52(7):1799-1805.

10. Pai JK, Pischon T, Ma J, Manson JE, Hankinson SE, Joshipura K, Curhan GC, Rifai N, Cannuscio CC, Stampfer MJ, Rimm EB. Inflammatory markers and the 
risk of coronary heart disease in men and women. N Engl J Med. 2004;351(25):2599-2610.

11. Hu FB, Meigs JB, Li TY, Rifai N, Manson JE. Inflammatory markers and risk of developing type 2 diabetes in women. Diabetes. 2004;53(3):693-700.

12. Kanaya AM, Wassel Fyr C, Vittinghoff E, Harris TB, Park SW, Goodpaster BH, Tylavsky F, Cummings SR. Adipocytokines and incident diabetes mellitus in older adults: the independent effect of plasminogen activator inhibitor 1. Arch Intern Med. 2006;166(3):350-356.

13. Abbatecola AM, Ferrucci L, Grella R, Bandinelli S, Bonafè M, Barbieri M, Corsi AM, Lauretani F, Franceschi C, Paolisso G. Diverse effect of inflammatory markers on insulin resistance and insulin-resistance syndrome in the elderly. J Am Geriatr Soc. 2004;52(3):399-404.

14. Yudkin JS, Stehouwer CD, Emeis JJ, Coppack SW. C-reactive protein in healthy subjects: associations with obesity, insulin resistance, and endothelial dysfunction: a potential role for cytokines originating from adipose tissue? Arterioscler Thromb Vasc Biol. 1999;19(4):972-978.

15. Lihn AS, Pedersen SB, Richelsen B. Adiponectin: action, regulation and association to insulin sensitivity. Obes Rev. 2005;6(1):13-21.

16. Shehzad A, Iqbal W, Shehzad O, Lee YS. Adiponectin: regulation of its production and its role in human diseases. Hormones (Athens). 2012;11(1):8-20.

17. Ryan AS, Berman DM, Nicklas BJ, Sinha M, Gingerich RL, Meneilly GS, Egan JM, Elahi D. Plasma adiponectin and leptin levels, body composition, and glucose utilization in adult women with wide ranges of age and obesity. Diabetes Care. 2003;26(8):2383-2388.

18. You T, Ryan AS, Nicklas BJ. The metabolic syndrome in obese postmenopausal women: relationship to body composition, visceral fat, and inflammation. J Clin Endocrinol Metab. 2004;89(11):5517-5522.

19. Olson NC, Callas PW, Hanley AJ, Festa A, Haffner SM, Wagenknecht LE, Tracy RP. Circulating levels of TNF- $\alpha$ are associated with impaired glucose tolerance, increased insulin resistance, and ethnicity: the Insulin Resistance Atherosclerosis Study. J Clin Endocrinol Metab. 2012;97(3):1032-1040. 
20. Hart R, Greaves DR. Chemerin contributes to inflammation by promoting macrophage adhesion to VCAM-1 and fibronectin through clustering of VLA-4 and VLA-5. J Immunol. 2010;185(6):3728-3739.

21. Goralski KB, McCarthy TC, Hanniman EA, Zabel BA, Butcher EC, Parlee SD, Muruganandan S, Sinal CJ. Chemerin, a novel adipokine that regulates adipogenesis and adipocyte metabolism. J Biol Chem. 2007;282(38):2817528188.

22. Yang RZ, Lee MJ, Hu H, Pray J, Wu HB, Hansen BC, Shuldiner AR, Fried SK, McLenithan JC, Gong DW. Identification of omentin as a novel depot-specific adipokine in human adipose tissue: possible role in modulating insulin action. Am J Physiol Endocrinol Metab. 2006;290(6):E1253-E1261.

23. Bozaoglu K, Bolton K, McMillan J, Zimmet P, Jowett J, Collier G, Walder K, Segal $\mathrm{D}$. Chemerin is a novel adipokine associated with obesity and metabolic syndrome. Endocrinology. 2007;148(10):4687-4694.

24. Chu SH, Lee MK, Ahn KY, Im JA, Park MS, Lee DC, Jeon JY, Lee JW. Chemerin and adiponectin contribute reciprocally to metabolic syndrome. PLoS One. 2012;7(4):e34710.

25. de Souza Batista CM, Yang RZ, Lee MJ, Glynn NM, Yu DZ, Pray J, Ndubuizu K, Patil S, Schwartz A, Kligman M, Fried SK, Gong DW, Shuldiner AR, Pollin TI, McLenithan JC. Omentin plasma levels and gene expression are decreased in obesity. Diabetes. 2007;56(6):1655-1661.

26. Moreno-Navarrete JM, Ortega F, Castro A, Sabater M, Ricart W, Fernández-Real JM. Circulating omentin as a novel biomarker of endothelial dysfunction. Obesity (Silver Spring). 2011;19(8):1552-1559.

27. Yoo HJ, Hwang SY, Hong HC, Choi HY, Yang SJ, Seo JA, Kim SG, Kim NH, Choi KM, Choi DS, Baik SH. Association of circulating omentin-1 level with arterial stiffness and carotid plaque in type 2 diabetes. Cardiovasc Diabetol. 2011;10:103-111.

28. Bozaoglu K, Segal D, Shields KA, Cummings N, Curran JE, Comuzzie AG, Mahaney MC, Rainwater DL, VandeBerg JL, MacCluer JW, Collier G, Blangero $\mathrm{J}$, Walder K, Jowett JB. Chemerin is associated with metabolic syndrome phenotypes in a Mexican-American population. J Clin Endocrinol Metab. 2009;94(8):3085-3088. 
29. Stejskal D, Karpisek M, Hanulova Z, Svestak M. Chemerin is an independent marker of the metabolic syndrome in a Caucasian population--a pilot study.

Biomed Pap Med Fac Univ Palacky Olomouc Czech Repub. 2008;152(2):217221. 


\section{CHAPTER II: LITERATURE REVIEW}

Diabetes is a metabolic disorder that has emerged as a global epidemic and is estimated to be the seventh leading cause of death by the year $2030 .{ }^{1}$ According to estimates by the World Health Organization, as of 2011, there were approximately 347 million people with diabetes worldwide. ${ }^{1}$ In the United States, an estimated 29 million people have diabetes, of which $90-95 \%$ of cases are attributed to type 2 diabetes (T2D). ${ }^{2}$ The burden of T2D is increasing in parallel to increasing cases of obesity and metabolic syndrome (MetS). ${ }^{3}$ Clinical data show that of the people diagnosed with T2D, about 80 $90 \%$ are highly likely to be diagnosed as obese. ${ }^{4}$ Mozumdar and Liguori ${ }^{3}$ compared the National Health and Nutrition Examination Survey (NHANES) data from 1988-1994 and 1999-2006 and revealed that there was a 5\% increase in MetS prevalence among US adults between the two periods. The authors also reported that Mexican-Americans had the highest prevalence of MetS and there was a significant increase in prevalence among non-Hispanic Blacks compared with non-Hispanic Whites.

Non-Hispanic Blacks are particularly at a greater risk of T2D and its

complications compared to Hispanics and Non-Hispanic Whites. ${ }^{5-8}$ Apart from higher prevalence rates of $\mathrm{T} 2 \mathrm{D}$, ethnic minority groups also have poorer diabetes control and worse diabetes-related complications. Lanting et al. ${ }^{7}$ examined ethnic differences in quality of care, end-stage complications and mortality among patients with diabetes. The results showed that non-Hispanic Blacks and Hispanics have 2 to 4 times the rate of blindness, kidney disease and amputation-related mortality of non-Hispanic Whites. Diabetes data and trends for 2010, available at the Centers for Disease Control and 
Prevention indicated that diabetes-related heart disease and myocardial infarction was $34 \%$ in non-Hispanic Blacks, $24.7 \%$ in Hispanics and $32.9 \%$ in non-Hispanic Whites. ${ }^{5}$

Compelling evidence from recent studies suggest that observed ethnic differences in inflammation may provide major explanation to the disparities in T2D prevalence and health outcomes. ${ }^{9-11}$ Various analyses of the association between ethnicity and inflammation showed that non-Hispanic Blacks have higher IL-6 and CRP than Hispanics and non-Hispanic Whites. Further, TNF- $\alpha$ levels were higher among nonHispanic Blacks compared to non-Hispanic Whites. ${ }^{12}$ There is the need to understand the molecular mechanisms that underlie inflammatory processes to relate to their pathogenic role in metabolic disease development in order to establish strategies to effectively combat T2D and its complications among non-Hispanic Blacks.

\section{Chronic Low-grade Inflammation}

Inflammation is a complex defense mechanism induced by the body to various injuries and foreign stimuli. ${ }^{13-15}$ The process of inflammation is a normal immune response, which may be innate or adaptive. This often self-regulatory and short-term response is a crucial part of tissue repair and involves the combination of several complex signals in particular cells and organs. ${ }^{15}$ The presence of an injury or stimuli initiates the migration of leucocytes (mainly neutrophils) from circulation into the affected tissues to attack the agents that possibly can cause tissue injury. ${ }^{14,16}$ Neutrophils secrete proinflammatory cytokines including tumor necrosis factor-alpha (TNF- $\alpha$ ) and interleukin-6 (IL-6) to induce an immune response and return the body to a homeostatic state. ${ }^{17-19}$ Additionally, IL-6 in particular, stimulates production of the acute-phase reactant, C- 
reactive protein (CRP) from the liver. ${ }^{20-21}$ This form of inflammatory response referred to as acute inflammation is actively terminated within the first few hours of inflammatory response. ${ }^{22}$ The resolution of inflammation involves mainly eliminating neutrophils by the phagocytic and destructive actions of monocytes and macrophages and also through the release of anti-inflammatory cytokines such as IL-10. ${ }^{22-23}$ Thus, acute inflammation is considered as a limited, often beneficial response. However, in the presence of an ongoing stimuli, the immune response may be persistently triggered and lead to chronic low-grade inflammation.

Chronic low-grade inflammation, in contrast to acute inflammation is associated with infiltration of mainly monocytes and macrophages of the immune response. ${ }^{14,16}$ Chronic low-grade inflammation is considered as a chronic activation of the innate immune system than the adaptive. ${ }^{24}$ The mechanisms that control the transition from neutrophil to monocyte/macrophage recruitment during the transformation from acute to chronic inflammation is poorly understood. However, the body's own process used to resolve inflammation, whereby monocytes/macrophages or fibroblasts are recruited to phagocytize neutrophils has been implicated. ${ }^{22,25}$ A disruption in control of neutrophils trafficking by a continuous stimuli, may cause the resolution phase to be disordered. This may be significant at increased recruitment of monocytes/macrophages and the overproduction of pro-inflammatory cytokines resulting in a perpetual pro-inflammatory state. ${ }^{22,25}$ The long-term consequences of this prolonged inflammation which favors the production of pro-inflammatory cytokines and decreased levels of anti-inflammatory cytokines are often detrimental. ${ }^{26-32}$ The hallmark of chronic low-grade inflammation is systemic inflammation, which is the involvement of the endothelial, circulatory, 
lymphatic and other organs systems, rather than restricted to a specific tissue. As a result, chronic low-grade inflammation is characterized by 2 to 3 fold increase in circulating levels of TNF- $\alpha$, IL-6 and CRP and decreased levels of IL-10. ${ }^{26}$ The altered circulating levels of these pro- and anti-inflammatory cytokines have been observed in various chronic diseases and it is suggested that chronic low-grade inflammation may be crucial in the pathogenesis and progression of chronic diseases. ${ }^{26-32}$ For example, the levels of circulating TNF- $\alpha$, IL-6 and CRP have consistently correlated with obesity and insulin resistance and has provided the basis for an intense area of research into other metabolic disorders such as metabolic syndrome, type 2 diabetes and cardiovascular diseases. ${ }^{33-34}$ The discovery of the adipose tissue as an endocrine organ is expected to provide better insight into the processes underlying the onset and progression of these metabolic conditions.

\section{Adipose Tissue as a Major Source of Adipocytokines}

For many decades, adipose tissue was considered as a fat storage organ and also known to possess thermogenic properties. In human and animal models, brown adipose tissue has been shown to be responsible for thermogenesis, whereas white adipose tissue plays the essential role of being a fat storage site. ${ }^{35}$ Recently, however, adipose tissue has been established as an active endocrine organ that produces several bioactive molecules collectively termed adipocytokines. ${ }^{36-40}$ They are so named because they are cytokines produced by the adipose tissue. The most abundant sites are visceral and subcutaneous adipose tissues, ${ }^{41}$ which produce bonafide adipocytokines such as leptin and adiponectin known to elicit pro-inflammatory and anti-inflammatory responses, respectively. ${ }^{42-43}$ 
Adipocytokines have diverse autocrine, panacrine and endocrine functions and as such are crucial mediators of metabolic processes including glucose and lipid homeostasis. ${ }^{41-42}$ For example, leptin and adiponectin have the ability to cross the blood-brain barrier and reach their main site of action in the hypothalamus to regulate the balance of hunger and satiety. ${ }^{38}$ Thus, these adipocytokines play a major role in the control of energy metabolism, the nutrient status of the organism and energy expenditure. ${ }^{44}$ Several investigations have also highlighted the importance of TNF- $\alpha$ and IL-6, as adipocytokines which activate inflammatory signaling cascades in adipose tissue. ${ }^{33-34}$ The adipose tissue is known to produce about $10-35 \%$ of the body's IL-6 levels. ${ }^{45}$ Moreover, in a recent in vivo study, human adipocyte cell lines were found to have the capacity to also produce CRP. ${ }^{46}$ It is important to know the initiating factors responsible for induction of adipose tissue inflammation and the mechanism that continue to amplify the pro-inflammatory state.

Chronic disruption of metabolic homeostasis, such as occurs in overnutrition could lead to irregular immune responses. ${ }^{47}$ In the presence of a continuous nutritional oversupply, excessive lipid accumulation in adipose tissues results in obesity. ${ }^{48}$ Since the bulk of accumulated lipid is stored in adipocytes, the excess nutrition overload causes adipocytes to rapidly proliferate and expand resulting in cellular stress. ${ }^{47-48}$ With excess adiposity, monocytes and macrophages are chronically recruited to adipose tissue which enhance the secretory capacity of adipose tissue and results in overproduction of proinflammatory TNF- $\alpha$, IL- 6 and leptin and decreased production of anti-inflammatory, adiponectin. ${ }^{39,49}$ Consistent with the evidence of a link between the adipose tissue and inflammation, studies have shown serum levels of adiponectin to inversely correlate with 
fatness, whereas the levels of TNF- $\alpha$, IL-6, CRP and leptin increase with increasing adiposity. ${ }^{34,50}$ Thus, it is firmly established that obese individuals display a characteristic imbalance of their adipocytokine profile. ${ }^{50}$ The role of adipocytokines as modulators of whole body energy balance and inflammatory processes has been demonstrated in most clinical studies. ${ }^{51}$ Weight loss due to long-term caloric restriction was associated with reduced levels of pro-inflammatory adipocytokines and increased levels of antiinflammatory adipocytokines. ${ }^{51}$ However, some studies have also demonstrated that dysregulation of these adipocytokines may be observed under conditions associated with a lack of adipose tissue. ${ }^{52}$ This is with reference to individuals who though are lean, usually have increased levels of pro-inflammatory adipocytokines and develop MetS and T2D. It has been well-established that metabolic changes related to obesity are principally attributable to abdominal or visceral fat mass rather than subcutaneous fat mass. ${ }^{53}$ These fat masses vary by cell size, metabolic activity and potential role in inflammatory processes. ${ }^{54}$ Visceral fat, usually measured by waist circumference (WC) is more pathogenic. ${ }^{53-54}$ Thus, supposedly, lean individuals may have abnormal distribution of body fat with more stores in the visceral area.

Adipose tissue function in inflammatory processes and the development of metabolic disorders in both human and animal systems is unprecedented and continues to expand. The works of Bazaoglu et al. ${ }^{55}$ and Yang et al. ${ }^{56}$ have led to the discovery of the novel adipocytokines chemerin and omentin. Chemerin is a recently discovered adipocytokine that is highly expressed in white adipose tissue and liver. ${ }^{55}$ It is a ligand activator for G-protein coupled receptor, chemokine-like receptor 1 (CMKLR1) and thought to modulate innate and adaptive immunity by binding to this receptor found on 
immune cells. ${ }^{57-59}$ Importantly, chemerin has been shown to have effects on adipose tissue development, metabolism and inflammation in both human and animal adipocytes. ${ }^{60}$ Chemerin mediates inflammatory processes as it is a chemokine to promote the migration of macrophages and immature dendritic cells and adhesion of macrophages to the endothelium. ${ }^{57-61}$

Yang et al. ${ }^{56}$ described omentin as a novel adipocytokine with insulin-sensitizing effects. Omentin is a soluble galactofuranose-binding lectin preferentially expressed by visceral omental adipose tissue but not by subcutaneous adipose tissue. ${ }^{56,62}$ Omentin is recognized as an anti-inflammatory adipocytokine that has similar functions as adiponectin, and thus reduced in disorders involving inflammatory processes. ${ }^{63-66}$ Moreover, omentin attenuated CRP and TNF- $\alpha$ induced nuclear factor kappa-B (NF-kB) activation in human endothelial cells. ${ }^{65}$ Because of the key role that adipocytokines play in the regulation of glucose and lipid metabolism, they have been suggested to provide the link between obesity, inflammation and impaired insulin signaling which lead to the development of obesity-related disorders including MetS and T2D. The association of chronic low-grade inflammation with insulin resistance is a growing area of research interest.

\section{Adipocytokines, Insulin Signaling and Insulin Resistance}

Insulin is a hormone secreted from the cells localized to the pancreatic $\beta$ islets and is necessary for the regulation of metabolic processes and maintenance of normal glucose levels. ${ }^{67}$ Thus, insulin secretion is enhanced in response to increased glucose levels, fatty acids and amino acids. In addition, insulin stimulates glucose uptake in the muscle and 
adipose tissue. Insulin also increases fatty acid synthesis in hepatocytes and adipocytes and reduces adipocyte free fatty acid production. ${ }^{67}$ Usually, insulin signaling involves the binding of insulin to its receptor, composed of two substrates (insulin receptor substrates 1 and 2 (IRS1/2) with two $\alpha$ and two $\beta$ subunits). ${ }^{68}$ The binding activates tyrosine kinase activity which results in autophosphorylation of the receptors on specific tyrosine residues and formation of binding sites for the recruitment of IRS1/2. Subsequent phosphorylation of IRS1/2 by the insulin receptor stimulate the phosphatidylinositol 3kinase (PI3K)-AKT/protein kinase B (PKB) pathway which regulates metabolic functions of insulin including glucose homeostasis and fat regulation. ${ }^{68}$ Many cell lines have shown that the PI3K-AKT/protein kinase B (PKB) activation is essential for the translocation of the glucose transporter 4 (GLUT 4) to the plasma membrane for glucose uptake in skeletal muscle and adipose tissue. ${ }^{69}$ Thus, a disturbance of insulin-mediated signaling pathway may result in systemic hyperglycemia which is known as insulin resistance.

An imbalance between circulating pro- and anti-inflammatory adipocytokines may promote insulin resistance in the liver and muscle. Adipocytokines circulate as signaling molecules to communicate not only with adipose tissue itself but also other organs such as liver and muscle. ${ }^{36-38}$ Their interaction with these other insulin sensitive organs, in particular the liver have been shown to activate key inflammatory signaling pathways such as the cJun N-terminal kinase (JNK) and inhibitor of nuclear factor kappaB kinase subunit beta/nuclear factor $\kappa \mathrm{B}(\mathrm{IKK} \beta / \mathrm{NF}-\kappa \mathrm{B}) \cdot{ }^{70-71} \mathrm{IKK} \beta / \mathrm{NF}-\kappa \mathrm{B}$ pathways promote the expression of numerous genes involved in inflammatory processes which contribute to impaired insulin signaling and induce insulin insensitivity, insulin resistance 
and increased insulin levels. ${ }^{33,70-72}$ In addition, serine/threonine (Ser) residues on IRS1/2 may be phosphorylated instead of tyrosine residues to suppress downstream processes of insulin signaling leading to insulin resistance. JNK is a stress kinase that has been shown to phosphorylate IRS on Ser-307 residues to promote insulin resistance. ${ }^{70}$ Because the effects of insulin are blunted in insulin resistance as a result of ineffectiveness of insulin receptors, pancreatic $\beta$ cells are persistently stimulated to produce and secrete insulin, and this eventually results in the development of T2D.

Persistent increased fat deposition off-sets a vicious cycle, where the adipocyte/macrophage system activates JNK and IKK $\beta / \mathrm{NF}-\kappa \mathrm{B}$ pathways which leads to increased secretion of pro-inflammatory adipocytokines and these in turn act directly on both adipocyte/macrophage system and JNK and IKK $\beta / N F-\kappa B$ pathways. ${ }^{33}$ Adiponectin on the other hand exhibits its anti-diabetic beneficial properties in insulin sensitivity through activation of AMP-dependent protein kinase (AMPK) to enhance glucose uptake. ${ }^{73}$ Adiponectin also inhibits production of pro-inflammatory adipocytokines in macrophages through suppression of NF- $\mathrm{kB}$ activation. ${ }^{74}$ Besides acting in concert to activate the cJun N-terminal kinase (JNK) and inhibitor of nuclear factor $\mathrm{\kappa B}$ kinase $\beta /$ nuclear factor $\kappa \mathrm{B}(\mathrm{IKK} \beta / \mathrm{NF}-\mathrm{\kappa B})$ inflammatory pathways, pro- and anti-inflammatory adipocytokines may act individually through other pathways to affect insulin resistance.

\section{IL-6 and CRP on Insulin Action:}

IL-6 is a pleiotropic adipocytokine that is reported to regulate the activities of several tissues and cells including proliferation of hematopoietic cells, induction of acute phase response in the liver and inflammation in tissue injury. ${ }^{75}$ IL- 6 is considered to possess both pro- and anti-inflammatory properties. ${ }^{76}$ Research has associated IL-6 to the 
modulation of glucose and lipid metabolism through pathways connected to insulin action. ${ }^{77-78}$ IL-6 inhibits insulin receptor signal transduction in hepatic cells by enhancing the expression of the suppression of cytokine signaling-3 (SOCS-3) pathway to induce insulin resistance. ${ }^{79}$ However, in a study using animal models, mice that had developed hepatic inflammation due to IL-6 deficiency showed improvement in insulin sensitivity upon administration of IL- $6 .{ }^{80}$ Moreover, the role of IL-6 in insulin resistance in other tissues such as skeletal muscle and adipose tissue is inconsistent. ${ }^{81}$ In humans, the administration of IL-6 to healthy individuals increased fasting blood glucose levels, potentially by inducing insulin resistance. ${ }^{82}$ While IL- 6 has been generally considered to play a role in insulin resistance, some investigators have suggested that IL-6 prevents insulin resistance.$^{83}$ The discrepancies in reports linking IL-6 to insulin resistance has been attributed to the likely dependence on the site, level and duration of IL-6 expression and its anti-inflammatory properties. ${ }^{76,80-81}$ C-reactive protein is induced by IL- 6 and is synthesized by the liver. ${ }^{20} \mathrm{CRP}$ acts as part of the innate immune system and induces phagocytosis of macrophages. In acute inflammation, CRP marks damaged cells to make them easier to be recognized by macrophages ${ }^{84}$ Several studies have associated insulin resistance with increased CRP levels depicting its role in chronic low-grade inflammation and metabolic disease processes. ${ }^{85-87}$ The mechanism through which CRP may induce insulin resistance is unclear. However, it is possible that CRP propagates the inflammatory and insulin resistance effects of IL-6.

\section{Leptin on Insulin Action:}

Leptin is the first adipocytokine to be isolated from the adipose tissue ${ }^{88}$ Leptin is a product of the human obese $(o b)$ gene located on chromosome $7 .{ }^{89}$ Human leptin is a 
$16 \mathrm{kDa}$ protein of 167 amino acids. It is released into circulatory from the adipose tissue and acts in the hypothalamus to control hunger and energy expenditure and thus regulates body weight. ${ }^{90}$ Thus, leptin deficient mice display marked obesity and insulin resistance.$^{88}$ Until decades ago, leptin had been considered to only play a role in regulation of energy balance. More recent data shows that leptin is a pro-inflammatory adipocytokine and also seems to play a role in inflammatory response. Leptin has structural properties similar to IL-6 and is indicated to also induce insulin resistance through the SOCS-3 pathway. ${ }^{91}$ In addition, leptin interacts with the immune system to enhance the release of pro-inflammatory IL- 6 and TNF- $\alpha$ by macrophages. ${ }^{92-93}$ This integrated system of pro-inflammatory adipocytokines augments the resistant effect of leptin on insulin action. It is also suggested that leptin may directly regulate the secretion of insulin by pancreatic $\beta$ cells. ${ }^{94}$ Leptin levels increase with increasing BMI due to leptin resistance and this is attributable to impaired leptin transport in blood brain barrier which is induced by SOCS-3. ${ }^{91}$

\section{Chemerin and Omentin on Insulin Action:}

In vivo and in vitro studies have demonstrated that chemerin may influence glucose homeostasis through reduction of insulin sensitivity ${ }^{95-96}$ The effect of chemerin on insulin action is suggested to be elicited through alteration of GLUT2 expression and/or activity. ${ }^{97-98}$ GLUT2 promotes insulin secretion in pancreatic $\beta$ cells by increasing the intracellular levels of glucose. ${ }^{98}$ Evidence supporting the reduction of glucoseinduced insulin secretion was demonstrated in chemerin deficient mice. Chemerin and its receptor signaling positively modulated the expression of the pancreatic $\beta$-cell-specific transcriptional factor, MafA, expressed in pancreatic $\beta$ cells that positively influence 
GLUT2 activity. ${ }^{98}$ Thus, reduction of MafA and subsequently GLUT2 expression may be the explanation for the reduced insulin release. Omentin is an anti-inflammatory adipocytokine that is inversely associated with obesity and insulin resistance. ${ }^{63}$ Omentin has therefore been shown to enhance insulin sensitivity by increasing the Akt/PkB phosphorylation and promoting insulin-facilitated glucose uptake in human omental and subcutaneous adipocytes. ${ }^{65}$ The mechanism by which omentin achieves the positive effect on insulin action remains to be clarified.

The role of insulin resistance in mediating adiposity induced-inflammation and the development of MetS and T2D is recognized as an interplay between the metabolic and immune pathways. ${ }^{34}$ Insulin has pleitropic functions and as such, insulin resistance and insulin deficiency result in hyperglycemia. The hyperglycemia state is closely linked with other metabolic derangement such as hypertension and hyperlipidemia due to further activation of inflammatory pathways. ${ }^{99}$ Taken together, the balance of animal and human studies support a role for all these adipocytokines as regulators of insulin resistance, the core defect that underlies the development of MetS and T2D.

\section{Roles of Adipocytokines in Metabolic Syndrome and Type 2 Diabetes}

Various cross-sectional studies, longitudinal studies and randomized control trials conducted to investigate the association between obesity and the effects of adipocytokines in the development of insulin resistance and subsequently MetS and T2D have shown conflicting results. While some studies demonstrated positive associations, others found no significant associations. 


\section{IL-6 and CRP with MetS and T2D:}

Abbatecola et al. ${ }^{100}$ used a cross-sectional study design to evaluate the association between pro-inflammatory adipocytokines, insulin resistance and components of the MetS, which the researchers termed as insulin resistance syndrome. Insulin resistance was calculated with the homeostatic model assessment (HOMA-IR). This large population-based study conducted in 1146 older persons without T2D, showed a positive correlation between plasma levels of TNF- $\alpha$, IL-6, CRP, interleukin-1 receptor antagonist (IL-1 ra) and soluble IL-6 receptor (sIL-6R) and insulin resistance. Moreover, as the degree of insulin resistance increased, the levels of TNF- $\alpha$, IL-6, CRP, and IL-1ra also increased. In addition, body mass index (BMI), a measure of obesity, triglycerides (TG) and IL-6 were associated with higher insulin resistance.

A study that measured the levels of TNF- $\alpha$, IL-6, and CRP, and their soluble receptors, in obese postmenopausal women with and without MetS showed significantly higher levels of soluble TNF- $\alpha$ receptor 1 (sTNFR1) in those with MetS. The number of MetS components significantly correlated with plasma concentrations of sTNFR1, but was not related to plasma TNF $\alpha$, sTNFR1, IL-6, IL-6sR, or CRP. The authors concluded that the severity of the MetS is associated with body composition, visceral adiposity, and inflammation. $^{101}$

The Women's Health Initiative study prospectively investigated the relationships of plasma levels of tumor necrosis factor $\alpha$ receptor 2 (TNF- $\alpha-\mathrm{R} 2)$, IL-6, and CRP with the incidence of T2D. The study included non-Hispanic white, Hispanic, non-Hispanic Black and Asian/Pacific Islander women aged 50 to 79 years. After a follow-up period of 5.9 years, 1584 women who developed T2D were matched with 2198 women who did 
not have T2D. The results of the study showed that all three pro-inflammatory adipocytokines were significantly associated with increased T2D risk, however CRP had the highest estimated relative risk. Moreover, mutual adjustment for each adipocytokine did not attenuate the consistent and significant associations of IL-6 and CRP with increased risk of T2D in all ethnic groups. Subgroup analysis indicated more evident interactions of TNF- $\alpha-R 2$, IL-6, and CRP with T2D risk in women with BMI $\geq 25$ $\mathrm{kg} / \mathrm{m}^{2} \cdot{ }^{12}$

Han et al. ${ }^{102}$ have also considered the role of CRP in the development of both MetS and T2D in the same study. The researchers studied 515 men and 729 women who were free of diabetes at baseline, but had one or none of other metabolic condition including hypertension and dyslipidemia. Serum levels of CRP, indices of adiposity, insulin resistance, plasma glucose concentrations, lipid profile and blood pressure were measured at baseline and at the end of the study (6 years). CRP correlated significantly with components of the MetS in both men and women. Men had a lower risk to develop MetS compared to women and this corresponded with lower BMI, waist circumference, lower concentrations of CRP, HOMA-IR, high density lipoprotein cholesterol (HDL-C), TG, lower levels of systolic blood pressure (SBP) and diastolic blood pressure (DBP) in men. Subjects with the highest risk to develop MetS and T2D also had the highest levels of CRP at baseline. A comparison of the clinical value of CRP with adiposity and insulin resistance measures as a risk factor for the development of MetS showed that the combined effects of CRP, BMI and HOMA-IR had greater predictive power than the individual markers. 


\section{Leptin with MetS and T2D:}

There is abundant data indicating that leptin can impact insulin sensitivity and that hyperleptinaemia may underlie insulin response. Some evidence also exist which provide further insight into possible association between leptin and MetS and T2D. Zimmet et al. ${ }^{103}$ in a population-based study of Western Samoans with and without T2D, determined the relationship of serum leptin with insulin sensitivity measured by HOMA and components of the MetS. While the results indicated higher leptin levels in men with than without T2D, adjustment of BMI made the difference no longer significant. Leptin levels did not differ between women with and without T2D. Leptin was significantly, positively correlated with BMI, insulin levels, and SBP and DBP when age and gender were taken into consideration, irrespective of diabetes status. Moreover, in regression models, leptin was associated with insulin sensitivity independent of age, BMI, waist/hip ratio, TG, HDL-C, SBP and DBP levels. Furthermore, evidence supporting the relationship of leptin with insulin action in T2D was demonstrated by Ozata et al. ${ }^{104}$ who found that improvement in glycemic control following a 4 month treatment with sulfonylurea in a group of poorly controlled obese women with T2D matched with those without T2D was associated with reduced serum leptin levels. However, this was not associated with correction of lipid abnormalities.

In Mexican Americans, the serum leptin levels were analyzed in relation to obesity and T2D. The results of the study indicated that leptin resistance is prevalent in this Hispanic ethnic minority subgroup. In addition, higher leptin levels were associated with obesity irrespective of diabetes status. ${ }^{105}$ In 144 Saudi Arabian men, higher leptin levels were associated with T2D and coronary heart disease risk factors. Moreover, leptin 
levels were positively associated with TG and SBP when individuals were obese and had insulin resistance and findings were also associated with MetS. ${ }^{106}$ Conversely, Abdelgadir and colleagues. ${ }^{107}$ found that higher levels of leptin were not associated with T2D in 104 indigenous Africans from Sudan with T2D. Despite the finding of no association, serum leptin levels positively correlated with HOMA of both beta-cell function and insulin resistance in individuals with T2D and only insulin resistance in those without T2D.

\section{Chemerin and Omentin with MetS and T2D:}

There is limited research on the relationship of chemerin and omentin with MetS and T2D, but available data have shown positive associations.

Bozaoglu et al. ${ }^{55}$ found that in an animal model of obesity and T2D, gene expression of chemerin was significantly higher in the adipose tissue of obese and T2D models than lean and normoglycemic models. When the investigators measured serum levels of chemerin in human samples, there was no significant difference between those with compared to without T2D. However, chemerin levels were significantly associated with BMI, TG and blood pressure measures in individuals without T2D. In a cohort of 55 healthy non-obese Caucasians and 181 at risk for the MetS, chemerin was evaluated as a marker of MetS and its predictive accuracy was determined. Chemerin levels were higher in individuals with the MetS than in healthy controls. Moreover, serum chemerin levels positively correlated with age, serum glucose, HDL-C, TG, blood pressure and the number of metabolic risk factors. With a cut-off value of $240 \mu \mathrm{g} / \mathrm{L}$, chemerin predicted presence of MetS with a $75 \%$ sensitivity and $67 \%$ specificity. ${ }^{108}$ 
Available data have shown that circulating levels of omentin are significantly decreased in obese individuals and those with T2D. ${ }^{109}$ Additionally, circulating omentin levels are reduced in association with BMI, leptin, waist circumference (WC), HOMA-IR and increased with adiponectin and HDL-C. ${ }^{110}$ Clinical studies have also revealed a positive association between omentin levels and vascular health, suggesting an important role for omentin in cardiovascular diseases. ${ }^{63,66}$

Pan et al. ${ }^{64}$ utilized a cohort with impaired glucose tolerance, newly diagnosed and untreated T2D individuals and healthy controls. Serum omentin levels were assayed and their relationship with BMI, glycated hemoglobin (A1C), plasma glucose, fasting insulin, HOMA-IR, TNF- $\alpha$ and IL-6 levels were determined. The results indicated that serum omentin levels were lower in those with glucose tolerance and T2D than in the control group. There was a negative correlation between omentin levels and BMI, HOMA-IR, plasma glucose, fasting insulin, TNF- $\alpha$ and IL-6. Further, HOMA-IR and BMI were the independent predictors of serum omentin levels. A similar research undertaken by Shibata and colleagues ${ }^{111}$ using Japanese men without diabetes further demonstrated the role of omentin in MetS. The authors investigated the association of omentin with the metabolic risk factors. In this study, subjects were categorized according to omentin levels as group 1 (those having $<2.59 \mathrm{ng} / \mathrm{ml}$ ); group 2 (those having $\geq 2.59 \mathrm{ng} / \mathrm{ml}$ ); group 3 (those having $\geq 2.66 \mathrm{ng} / \mathrm{ml}$ ) and group 4 (those having $\geq 2.72$ $\mathrm{ng} / \mathrm{ml})$. The results of the investigation showed an inverse correlation between omentin levels and the number of metabolic risk factors including WC, dyslipidemia, high blood pressure and glucose intolerance. 
Existing studies that examined ethnic differences in established adipocytokines such as TNF- $\alpha$, IL-6 and CRP have focused on general ethnic categories and not individual subgroups of ethnicities. ${ }^{12,112-114}$ Haitian and African Americans are two distinct ethnic minority subgroups but are commonly classified as non-Hispanic Blacks. As a result, it is unclear whether adipocytokines may differ between Haitian and African Americans and whether this difference may distinguish risk for T2D and related health outcomes between the two ethnic subgroups. Despite having a better diet quality, Haitian Americans have the worse glycemic control compared to African Americans. ${ }^{15-116}$ Such an important difference supports the need to treat each ethnicity as distinct in diabetes studies and specifically target ethnic minority subgroups in order to identify and reduce disease risks typical for each ethnicity. 


\section{REFERENCES}

1. World Health Organization. Diabetes. (2013). Fact Sheet \#312. Available at: http://www.who.int/mediacentre/factsheets/fs312/en/. Accessed August 04, 2014.

2. American Diabetes Association. National Diabetes Statistics Report, 2014. Statistics About Diabetes. Available at: http://www.diabetes.org/diabetesbasics/statistics/. Accessed on August 04, 2014.

3. Mozumdar, A., Liguori, G. Persistent increase of prevalence of metabolic syndrome among U.S. adults: NHANES III to NHANES 1999-2006. Diabetes Care. 2011;34:216-219.

4. Center for Disease Control and Prevention. (2010). Overweight and Obesity. Adult Obesity Facts. Available at: http://www.cdc.gov/diabetes/consumer/groups.html. Accessed on August 04, 2014.

5. Center for Disease Control and Prevention. (2008). Diabetes Data and Trends. Diabetes Complications. Available at: http://www.cdc.gov/diabetes/statistics/complications national.html. Accessed on August 04, 2014.

6. Center for Disease Control and Prevention. (2010). Diabetes Public Health Resource. Available at: http://www.cdc.gov/diabetes/consumer/groups.html. Accessed on August 04, 2014.

7. Lanting LC, Joung IM, Mackenbach JP, Lamberts SW, Bootsma AH. Ethnic differences in mortality, end-stage complications, and quality of care among diabetic patients: a review. Diabetes Care. 2005;28(9):2280-2288.

8. Diabetes Disparities Among Racial and Ethnic Minorities: Fact Sheet. November 2001. Agency for Healthcare Research and Quality, Rockville, MD. http://www.ahrq.gov/research/findings/factsheets/diabetes/diabdisp/index.html. Accessed August 4, 2014.

9. Krakoff J, Funahashi T, Stehouwer CD, Schalkwijk CG, Tanaka S, Matsuzawa Y, Kobes S, Tataranni PA, Hanson RL, Knowler WC, Lindsay RS. Inflammatory markers, adiponectin, and risk of type 2 diabetes in the Pima Indian. Diabetes Care. 2003;26(6):1745-1751. 
10. Paalani M, Lee JW, Haddad E, Tonstad S. Determinants of inflammatory markers in a bi-ethnic population. Ethn Dis. 2011;21(2):142-149.

11. Olson NC, Callas PW, Hanley AJ, Festa A, Haffner SM, Wagenknecht LE, Tracy RP. Circulating levels of TNF- $\alpha$ are associated with impaired glucose tolerance, increased insulin resistance, and ethnicity: the Insulin Resistance Atherosclerosis Study. J Clin Endocrinol Metab. 2012;97(3):1032-1040.

12. Liu S, Tinker L, Song Y, Rifai N, Bonds DE, Cook NR, Heiss G, Howard BV, Hotamisligil GS, Hu FB, Kuller LH, Manson JE. A prospective study of inflammatory cytokines and diabetes mellitus in a multiethnic cohort of postmenopausal women. Arch Intern Med. 2007;167(15):1676-1685.

13. Medzhitov R. Origin and physiological roles of inflammation. Nature. 2008;454(7203):428-435.

14. Ryan GB, Majno G. Acute inflammation. A review. Am J Pathol. 1977;86(1):183-276.

15. Larsen GL, Henson PM. Mediators of inflammation. Annu Rev Immunol. 1983;1:335-359.

16. Doherty DE, Downey GP, Worthen GS, Haslett C, Henson PM. Monocyte retention and migration in pulmonary inflammation. Requirement for neutrophils. Lab Invest. 1988;59(2):200-213.

17. Oishi K, Machida K. Some plasma component is essential for IL-6 secretion by Neutrophils. Environ Health Prev Med. 1997;2(2):89-92.

18. Jaillon S, Galdiero MR, Del Prete D, Cassatella MA, Garlanda C, Mantovani A. Neutrophils in innate and adaptive immunity. Semin Immunopathol. 2013;35(4):377-394.

19. Cassatella MA. The production of cytokines by polymorphonuclear neutrophils. Immunol Today. 1995;16(1):21-26.

20. Heinrich PC, Castell JV, Andus T. Interleukin-6 and the acute phase response. Biochem J. 1990;265(3):621-636. 
21. Gabay C, Kushner I. Acute-phase proteins and other systemic responses to inflammation. N Engl J Med. 1999;340(6):448-454.

22. Serhan CN, Savill J. Resolution of inflammation: the beginning programs the end. Nat Immunol. 2005;6(12):1191-1197.

23. Sato Y, Ohshima T, Kondo T. Regulatory role of endogenous interleukin-10 in cutaneous inflammatory response of murine wound healing. Biochem Biophys Res Commun. 1999;265(1):194-199.

24. Ghanim H, Aljada A, Hofmeyer D, Syed T, Mohanty P, Dandona P. Circulating mononuclear cells in the obese are in a proinflammatory state. Circulation. 2004;110(12):1564-1571.

25. Buckley CD, Pilling D, Lord JM, Akbar AN, Scheel-Toellner D, Salmon M. Fibroblasts regulate the switch from acute resolving to chronic persistent inflammation. Trends Immunol. 2001;22(4):199-204.

26. Petersen AM, Pedersen BK. The anti-inflammatory effect of exercise. J Appl Physiol (1985). 2005;98(4):1154-1162

27. Hu FB, Meigs JB, Li TY, Rifai N, Manson JE. Inflammatory markers and risk of developing type 2 diabetes in women. Diabetes. 2004;53(3):693-700.

28. Moon YS, Kim DH, Song DK. Serum tumor necrosis factor-alpha levels and components of the metabolic syndrome in obese adolescents. Metabolism. 2004;53(7):863-867.

29. Ferrucci L, Semba RD, Guralnik JM, Ershler WB, Bandinelli S, Patel KV, Sun K, Woodman RC, Andrews NC, Cotter RJ, Ganz T, Nemeth E, Longo DL. Proinflammatory state, hepcidin, and anemia in older persons. Blood. 2010;115(18):3810-3816.

30. Kundu JK, Surh YJ. Inflammation: gearing the journey to cancer. Mutat Res. 2008;659(1-2):15-30.

31. Pearson TA, Mensah GA, Alexander RW, Anderson JL, Cannon RO 3rd, Criqui M, Fadl YY, Fortmann SP, Hong Y, Myers GL, Rifai N, Smith SC Jr, Taubert K, Tracy RP, Vinicor F; Centers for Disease Control and Prevention; American 
Heart Association. Markers of inflammation and cardiovascular disease: application to clinical and public health practice: A statement for healthcare professionals from the Centers for Disease Control and Prevention and the American Heart Association. Circulation. 2003;107(3):499-511.

32. Willette AA, Xu G, Johnson SC, Birdsill AC, Jonaitis EM, Sager MA, Hermann BP, La Rue A, Asthana S, Bendlin BB. Insulin resistance, brain atrophy, and cognitive performance in late middle-aged adults. Diabetes Care. 2013;36(2):443449.

33. Shoelson SE, Lee J, Goldfine AB. Inflammation and insulin resistance. J Clin Invest. 2006;116(7):1793-1801.

34. Hotamisligil GS. Inflammation and metabolic disorders. Nature. 2006;444(7121):860-867.

35. Hahn P, Novak M. Development of brown and white adipose tissue. J Lipid Res. 1975;16(2):79-91.

36. Deng Y, Scherer PE. Adipokines as novel biomarkers and regulators of the metabolic syndrome. Ann N Y Acad Sci. 2010;1212:E1-E19.

37. Dulloo AG, Jacquet J, Solinas G, Montani JP, Schutz Y. Body composition phenotypes in pathways to obesity and the metabolic syndrome. Int J Obes (Lond). 2010;34 Suppl 2:S4-17.

38. Ronti T, Lupattelli G, Mannarino E. The endocrine function of adipose tissue: an update. Clin Endocrinol (Oxf). 2006;64(4):355-365.

39. Weisberg SP, McCann D, Desai M, Rosenbaum M, Leibel RL, Ferrante AW Jr. Obesity is associated with macrophage accumulation in adipose tissue. J Clin Invest. 2003;112(12):1796-1808.

40. Hauner H. Secretory factors from human adipose tissue and their functional role. Proc Nutr Soc. 2005;64(2):163-169.

41. Kershaw EE, Flier JS. Adipose tissue as an endocrine organ. J Clin Endocrinol Metab. 2004;89(6):2548-2556. 
42. Waki H, Tontonoz P. Endocrine functions of adipose tissue. Annu Rev Pathol. 2007;2:31-56.

43. Deepa SS, Dong LQ. APPL1: role in adiponectin signaling and beyond. Am J Physiol Endocrinol Metab. 2009;296(1):E22-36.

44. Galic S, Oakhill JS, Steinberg GR. Adipose tissue as an endocrine organ. Mol Cell Endocrinol. 2010;316(2):129-139.

45. Mohamed-Ali V, Goodrick S, Rawesh A, Katz DR, Miles JM, Yudkin JS, Klein S, Coppack SW. Subcutaneous adipose tissue releases interleukin-6, but not tumor necrosis factor-alpha, in vivo. J Clin Endocrinol Metab. 1997;82(12):41964200.

46. Calabro P, Chang DW, Willerson JT, Yeh ET. Release of C-reactive protein in response to inflammatory cytokines by human adipocytes: linking obesity to vascular inflammation. J Am Coll Cardiol. 2005;46(6):1112-1123.

47. Reid J, MacDougall AI, Andrews MM. Aspirin and diabetes mellitus. Br Med J. 1957;2(5053):1071-1074.

48. Kolonin MG, Saha PK, Chan L, Pasqualini R, Arap W. Reversal of obesity by targeted ablation of adipose tissue. Nat Med. 2004;10(6):625-632.

49. Xu H, Barnes GT, Yang Q, Tan G, Yang D, Chou CJ, Sole J, Nichols A, Ross JS, Tartaglia LA, Chen H. Chronic inflammation in fat plays a crucial role in the development of obesity-related insulin resistance. J Clin Invest. 2003;112(12):1821-1830.

50. Ryan AS, Berman DM, Nicklas BJ, Sinha M, Gingerich RL, Meneilly GS, Egan JM, Elahi D. Plasma adiponectin and leptin levels, body composition, and glucose utilization in adult women with wide ranges of age and obesity. Diabetes Care. 2003;26(8):2383-2388.

51. Clément K, Viguerie N, Poitou C, Carette C, Pelloux V, Curat CA, Sicard A, Rome S, Benis A, Zucker JD, Vidal H, Laville M, Barsh GS, Basdevant A, Stich $\mathrm{V}$, Cancello R, Langin D. Weight loss regulates inflammation-related genes in white adipose tissue of obese subjects. FASEB J. 2004;18(14):1657-1669. 
52. Arioglu E, Rother KI, Reitman ML, Premkumar A, Taylor SI. Lipoatrophy syndromes: when 'too little fat' is a clinical problem. Pediatr Diabetes. 2000;1(3):155-168.

53. Krotkiewski M, Björntorp P, Sjöström L, Smith U. Impact of obesity on metabolism in men and women. Importance of regional adipose tissue distribution. J Clin Invest. 1983;72(3):1150-1162.

54. Johnson PR, Hirsch J. Cellularity of adipose depots in six strains of genetically obese mice. J Lipid Res. 1972;13(1):2-11.

55. Bozaoglu K, Bolton K, McMillan J, Zimmet P, Jowett J, Collier G, Walder K, Segal D. Chemerin is a novel adipokine associated with obesity and metabolic syndrome. Endocrinology. 2007;148(10):4687-4694.

56. Yang RZ, Lee MJ, Hu H, Pray J, Wu HB, Hansen BC, Shuldiner AR, Fried SK, McLenithan JC, Gong DW. Identification of omentin as a novel depot-specific adipokine in human adipose tissue: possible role in modulating insulin action. Am J Physiol Endocrinol Metab. 2006;290(6):E1253-1261.

57. Wittamer V, Franssen JD, Vulcano M, Mirjolet JF, Le Poul E, Migeotte I, Brézillon S, Tyldesley R, Blanpain C, Detheux M, Mantovani A, Sozzani S, Vassart G, Parmentier M, Communi D. Specific recruitment of antigen-presenting cells by chemerin, a novel processed ligand from human inflammatory fluids. J Exp Med. 2003;198(7):977-985.

58. Wittamer V, Bondue B, Guillabert A, Vassart G, Parmentier M, Communi D. Neutrophil-mediated maturation of chemerin: a link between innate and adaptive immunity. J Immunol. 2005;175(1):487-493.

59. Zabel BA, Allen SJ, Kulig P, Allen JA, Cichy J, Handel TM, Butcher EC. Chemerin activation by serine proteases of the coagulation, fibrinolytic, and inflammatory cascades. J Biol Chem. 2005;280(41):34661-34666.

60. Goralski KB, McCarthy TC, Hanniman EA, Zabel BA, Butcher EC, Parlee SD, Muruganandan S, Sinal CJ. Chemerin, a novel adipokine that regulates adipogenesi and adipocyte metabolism. J Biol Chem. 2007;282(38):28175-28188. 
61. Hart R, Greaves DR. Chemerin contributes to inflammation by promoting macrophage adhesion to VCAM-1 and fibronectin through clustering of VLA-4 and VLA-5. J Immunol. 2010;185(6):3728-3739.

62. Schäffler A, Neumeier M, Herfarth H, Fürst A, Schölmerich J, Büchler C. Genomic structure of human omentin, a new adipocytokine expressed in omental adipose tissue. Biochim Biophys Acta. 2005;1732(1-3):96-102.

63. Moreno-Navarrete JM, Ortega F, Castro A, Sabater M, Ricart W, Fernández-Real JM. Circulating omentin as a novel biomarker of endothelial dysfunction. Obesity (Silver Spring). 2011;19(8):1552-1559.

64. Pan HY, Guo L, Li Q. Changes of serum omentin-1 levels in normal subjects and in patients with impaired glucose regulation and with newly diagnosed and untreated type 2 diabetes. Diabetes Res Clin Pract. 2010;88(1):29-33.

65. Tan BK, Adya R, Farhatullah S, Chen J, Lehnert H, Randeva HS. Metformin treatment may increase omentin-1 levels in women with polycystic ovary syndrome. Diabetes. 2010;59(12):3023-3031.

66. Yoo HJ, Hwang SY, Hong HC, Choi HY, Yang SJ, Seo JA, Kim SG, Kim NH, Choi KM, Choi DS, Baik SH. Association of circulating omentin-1 level with arterial stiffness and carotid plaque in type 2 diabetes. Cardiovasc Diabetol. 2011;10:103-111.

67. Pessin JE, Saltiel AR. Signaling pathways in insulin action: molecular targets of insulin resistance. J Clin Invest. 2000;106(2):165-169.

68. Taniguchi CM, Emanuelli B, Kahn CR. Critical nodes in signalling pathways: insights into insulin action. Nat Rev Mol Cell Biol. 2006;7(2):85-96.

69. Wang Q, Somwar R, Bilan PJ, Liu Z, Jin J, Woodgett JR, Klip A. Protein kinase B/Akt participates in GLUT4 translocation by insulin in L6 myoblasts. Mol Cell Biol. 1999;19(6):4008-4018.

70. Aguirre V, Uchida T, Yenush L, Davis R, White MF. The c-Jun NH(2)-terminal kinase promotes insulin resistance during association with insulin receptor substrate-1 and phosphorylation of Ser(307). J Biol Chem. 2000;275(12):90479054. 
71. Yuan M, Konstantopoulos N, Lee J, Hansen L, Li ZW, Karin M, Shoelson SE. Reversal of obesity- and diet-induced insulin resistance with salicylates or targeted disruption of Ikkbeta. Science. 2001;293(5535):1673-1677.

72. Hirosumi J, Tuncman G, Chang L, Görgün CZ, Uysal KT, Maeda K, Karin M, Hotamisligil GS. A central role for JNK in obesity and insulin resistance. Nature. 2002;420(6913):333-336.

73. Yamauchi T, Kamon J, Minokoshi Y, Ito Y, Waki H, Uchida S, Yamashita S, Noda M, Kita S, Ueki K, Eto K, Akanuma Y, Froguel P, Foufelle F, Ferre P, Carling D,

Kimura S, Nagai R, Kahn BB, Kadowaki T. Adiponectin stimulates glucose utilization and fatty-acid oxidation by activating AMP-activated protein kinase. Nat Med. 2002;8(11):1288-1295.

74. Yokota T, Oritani K, Takahashi I, Ishikawa J, Matsuyama A, Ouchi N, Kihara S, Funahashi T, Tenner AJ, Tomiyama Y, Matsuzawa Y. Adiponectin, a new member of the family of soluble defense collagens, negatively regulates the growth of myelomonocytic progenitors and the functions of macrophages. Blood. 2000;96(5):1723-1732.

75. Van Snick J. Interleukin-6: an overview. Annu Rev Immunol. 1990;8:253-278.

76. Scheller J, Chalaris A, Schmidt-Arras D, Rose-John S. The pro- and antiinflammatory properties of the cytokine interleukin-6. Biochim Biophys Acta. 2011;1813(5):878-888.

77. Bastard JP, Maachi M, Van Nhieu JT, Jardel C, Bruckert E, Grimaldi A, Robert JJ, Capeau J, Hainque B. Adipose tissue IL-6 content correlates with resistance to insulin activation of glucose uptake both in vivo and in vitro. J Clin Endocrinol Metab. 2002;87(5):2084-2089.

78. Glund S, Krook A. Role of interleukin-6 signalling in glucose and lipid metabolism. Acta Physiol (Oxf). 2008;192(1):37-48.

79. Senn JJ, Klover PJ, Nowak IA, Zimmers TA, Koniaris LG, Furlanetto RW, Mooney RA. Suppressor of cytokine signaling-3 (SOCS-3), a potential mediator of interleukin-6-dependent insulin resistance in hepatocytes. J Biol Chem. 2003;278(16):13740-13746. 
80. Matthews VB, Allen TL, Risis S, Chan MH, Henstridge DC, Watson N, Zaffino LA, Babb JR, Boon J, Meikle PJ, Jowett JB, Watt MJ, Jansson JO, Bruce CR, Febbraio MA. Interleukin-6-deficient mice develop hepatic inflammation and systemic insulin resistance. Diabetologia. 2010;53(11):2431-2441.

81. Carey AL, Febbraio MA. Interleukin-6 and insulin sensitivity: friend or foe? Diabetologia. 2004;47(7):1135-1142.

82. Tsigos C, Papanicolaou DA, Kyrou I, Defensor R, Mitsiadis CS, Chrousos GP. Dose-dependent effects of recombinant human interleukin-6 on glucose regulation. J Clin Endocrinol Metab. 1997;82(12):4167-4170.

83. Febbraio MA, Pedersen BK. Muscle-derived interleukin-6: mechanisms for activation and possible biological roles. FASEB J. 2002 Sep;16(11):1335-1347.

84. Meyer O. Anti-CRP antibodies in systemic lupus erythematosus. Joint Bone Spine. 2010;77(5):384-389.

85. Festa A, Hanley AJ, Tracy RP, D'Agostino R Jr, Haffner SM. Inflammation in the prediabetic state is related to increased insulin resistance rather than decreased insulin secretion. Circulation. 2003;108(15):1822-1830.

86. Festa A, D'Agostino R Jr, Tracy RP, Haffner SM. C-reactive protein is more strongly related to post-glucose load glucose than to fasting glucose in nondiabetic subjects; the Insulin Resistance Atherosclerosis Study. Diabet Med. 2002;19(11):939-943.

87. McLaughlin T, Abbasi F, Lamendola C, Liang L, Reaven G, Schaaf P, Reaven P. Differentiation between obesity and insulin resistance in the association with $\mathrm{C}$ reactive protein. Circulation. 2002;106(23):2908-2912.

88. Zhang Y, Proenca R, Maffei M, Barone M, Leopold L, Friedman JM. Positional cloning of the mouse obese gene and its human homologue. Nature. 1994;372(6505):425-432.

89. Isse N, Ogawa Y, Tamura N, Masuzaki H, Mori K, Okazaki T, Satoh N, Shigemoto M, Yoshimasa Y, Nishi S, et al. Structural organization and chromosomal assignment of the human obese gene. J Biol Chem. 1995;270(46):27728-27733. 
90. Friedman JM, Halaas JL. Leptin and the regulation of body weight in mammals. Nature. 1998;395(6704):763-770.

91. Bjørbaek C, El-Haschimi K, Frantz JD, Flier JS. The role of SOCS-3 in leptin signaling and leptin resistance. J Biol Chem. 1999;274(42):30059-30065.

92. Lam QL, Lu L. Role of leptin in immunity. Cell Mol Immunol. 2007;4(1):1-13.

93. Chen K, Li F, Li J, Cai H, Strom S, Bisello A, Kelley DE, Friedman-Einat M, Skibinski GA, McCrory MA, Szalai AJ, Zhao AZ. Induction of leptin resistance through direct interaction of C-reactive protein with leptin. Nat Med. 2006;12(4):425-432.

94. Spiegelman BM, Flier JS. Obesity and the regulation of energy balance. Cell. 2001;104(4):531-543.

95. Sell H, Laurencikiene J, Taube A, Eckardt K, Cramer A, Horrighs A, Arner P, Eckel J. Chemerin is a novel adipocyte-derived factor inducing insulin resistance in primary human skeletal muscle cells. Diabetes. 2009;58(12):2731-2740.

96. Ernst MC, Haidl ID, Zúñiga LA, Dranse HJ, Rourke JL, Zabel BA, Butcher EC, Sinal CJ. Disruption of the chemokine-like receptor-1 (CMKLR1) gene is associated with reduced adiposity and glucose intolerance. Endocrinology. 2012;153(2):672-682.

97. Ernst MC, Issa M, Goralski KB, Sinal CJ. Chemerin exacerbates glucose intolerance in mouse models of obesity and diabetes. Endocrinology. 2010;151(5):1998-2007.

98. Takahashi M, Okimura Y, Iguchi G, Nishizawa H, Yamamoto M, Suda K, Kitazawa R, Fujimoto W, Takahashi K, Zolotaryov FN, Hong KS, Kiyonari H, Abe T, Kaji H, Kitazawa S, Kasuga M, Chihara K, Takahashi Y. Chemerin regulates $\beta$-cell function in mice. Sci Rep. 2011;1:123-133.

99. Cornier MA, Dabelea D, Hernandez TL, Lindstrom RC, Steig AJ, Stob NR, Van Pelt RE, Wang H, Eckel RH. The metabolic syndrome. Endocr Rev. 2008;29(7):777-822. 
100. Abbatecola AM, Ferrucci L, Grella R, Bandinelli S, Bonafè M, Barbieri M, Corsi AM, Lauretani F, Franceschi C, Paolisso G. Diverse effect of inflammatory markers on insulin resistance and insulin-resistance syndrome in the elderly. J Am Geriatr Soc. 2004;52(3):399-404.

101. You T, Ryan AS, Nicklas BJ. The metabolic syndrome in obese postmenopausal women: relationship to body composition, visceral fat, and inflammation. J Clin Endocrinol Metab. 2004;89(11):5517-5522.

102. Han TS, Sattar N, Williams K, Gonzalez-Villalpando C, Lean ME, Haffner SM. Prospective study of C-reactive protein in relation to the development of diabetes and metabolic syndrome in the Mexico City Diabetes Study. Diabetes Care. 2002;25(11):2016-2021.

103. Zimmet P, Hodge A, Nicolson M, Staten M, de Courten M, Moore J, Morawiecki A, Lubina J, Collier G, Alberti G, Dowse G. Serum leptin concentration, obesity, and insulin resistance in Western Samoans: cross sectional study. BMJ. 1996;313(7063):965-969.

104. Ozata M, Gungor D, Turan M, Ozisik G, Bingol N, Ozgurtas T, Ozdemir IC. Improved glycemic control increases fasting plasma acylation-stimulating protein and decreases leptin concentrations in type II diabetic subjects. J Clin Endocrinol Metab. 2001;86(8):3659-3664.

105. Haffner SM, Stern MP, Miettinen H, Wei M, Gingerich RL. Leptin concentrations in diabetic and nondiabetic Mexican-Americans. Diabetes. 1996;45(6):822-824.

106. Al-Daghri N, Al-Rubean K, Bartlett WA, Al-Attas O, Jones AF, Kumar S. Serum leptin is elevated in Saudi Arabian patients with metabolic syndrome and coronary artery disease. Diabet Med. 2003;20(10):832-837.

107. Abdelgadir M, Elbagir M, Eltom M, Berne C, Ahrén B. Reduced leptin concentrations in subjects with type 2 diabetes mellitus in Sudan. Metabolism. 2002;51(3):304-306.

108. Stejskal D, Karpisek M, Hanulova Z, Svestak M. Chemerin is an independent marker of the metabolic syndrome in a Caucasian population--a pilot study. 
Biomed Pap Med Fac Univ Palacky Olomouc Czech Repub. 2008;152(2):217221.

109. Pan HY, Guo L, Li Q. Changes of serum omentin-1 levels in normal subjects and in patients with impaired glucose regulation and with newly diagnosed and untreated type 2 diabetes. Diabetes Res Clin Pract. 2010;88(1):29-33.

110. de Souza Batista CM, Yang RZ, Lee MJ, Glynn NM, Yu DZ, Pray J, Ndubuizu K, Patil S, Schwartz A, Kligman M, Fried SK, Gong DW, Shuldiner AR, Pollin TI, McLenithan JC. Omentin plasma levels and gene expression are decreased in obesity. Diabetes. 2007;56(6):1655-1661.

111. Shibata R, Ouchi N, Takahashi R, Terakura Y, Ohashi K, Ikeda N, Higuchi A, Terasaki H, Kihara S, Murohara T. Omentin as a novel biomarker of metabolic risk factors. Diabetol Metab Syndr. 2012;4(1):37-41.

112. Albert MA, Glynn RJ, Buring J, Ridker PM. C-reactive protein levels among women of various ethnic groups living in the United States (from the Women's Health Study). Am J Cardiol. 2004 May 15;93(10):1238-1242.

113. Duncan BB, Schmidt MI, Pankow JS, Ballantyne CM, Couper D, Vigo A, Hoogeveen R, Folsom AR, Heiss G; Atherosclerosis Risk in Communities Study. Low-grade systemic inflammation and the development of type 2 diabetes: the atherosclerosis risk in communities study. Diabetes. 2003;52(7):1799-1805.

114. Bertoni AG, Burke GL, Owusu JA, Carnethon MR, Vaidya D, Barr RG, Jenny NS, Ouyang P, Rotter JI. Inflammation and the incidence of type 2 diabetes: the Multi-Ethnic Study of Atherosclerosis (MESA). Diabetes Care. 2010;33(4):804810.

115. Huffman FG, De La Cera M, Vaccaro JA, Zarini GG, Exebio J, Gundupalli D, Shaban L. Healthy Eating Index and Alternate Healthy Eating Index among Haitian Americans and African Americans with and without Type 2 Diabetes. J Nutr Metab. 2011;2011:398324.

116. Vimalananda VG, Rosenzweig JL, Cabral HJ, David MM, Lasser KE. Comparison of diabetes control among Haitians, African Americans, and nonHispanic whites in an urban safety-net hospital. Diabetes Care. 2011;34(1):58-60. 


\section{Specific Aims and Hypotheses}

$\underline{\text { Specific Aim 1: }}$ To evaluate the relationships between metabolic syndrome and inflammation, as measured by serum levels of IL-6 and CRP in Haitian and African Americans with and without T2D.

Hypothesis 1:

a. Metabolic syndrome will be positively associated with IL-6 and CRP levels, independent of diabetes status and ethnicity.

b. Haitian Americans with T2D will have increased levels of IL-6 and CRP, compared to African Americans with T2D.

Rationale: Adipocytokines play important roles in nutrient metabolism and the subsequent development of metabolic syndrome. This aim will provide information on differences in these adipocytokines between Haitian and African Americans and participants with and without T2D and their association with metabolic syndrome.

Specific Aim 2: To investigate the relationships of two novel adipocytokines: chemerin and omentin; diabetes status; and two non-Hispanic Black ethnicities: Haitian and African Americans.

Hypothesis 2:

a. Type 2 diabetes (T2D) will be positively associated with chemerin levels and negatively associated with omentin levels, independent of ethnicity.

b. Haitian Americans with T2D will have increased chemerin levels and reduced omentin levels, compared to African Americans with T2D. 
Rationale: T2D is considered a state of chronic low-grade inflammation. Haitian Americans have been found to have worse glycemic control and T2D outcomes compared to African Americans. This aim will therefore enable us understand these novel adipocytokines and the differences in these markers not only between participants with and without diabetes but between the two ethnicities and further explain those factors which are independently linked with inflammation in this population.

Specific Aim 3: To assess the relationships between BMI, insulin resistance, as measured by homeostatic model of assessment-insulin resistance (HOMA-IR) values and leptin in Haitian and African Americans with and without T2D.

\section{Hypothesis 3 :}

a. BMI and insulin resistance are positively associated with leptin levels, independent of diabetes status and ethnicity.

b. Haitian Americans with T2D will have increased levels of leptin, compared to African Americans with T2D.

Rationale: Leptin, a pro-inflammatory adipocytokine is increased in obesity and is linked to insulin resistance and T2D. This aim will enable us to understand the relationships between leptin, obesity and insulin resistance and how they differ by ethnicity and diabetes status.

Research presented here analyzed secondary data from the parent study conducted by Huffman et al. (2009) which was to compare cardiovascular risk factors of ethnic minorities with and without T2D. In addition, existing serum of participants from the parent study stored at $-70^{\circ} \mathrm{C}$ was used to obtain data on the serum levels of 
adipocytokines. While serum levels of IL-6, leptin, chemerin and omentin were measured in the Human Nutrition Laboratory at Florida International University, CRP levels were obtained from the parent study. TNF- $\alpha$ which was initially proposed to be part of this research was not included in the analyses due to its extremely low detectability in more than $50 \%$ of the samples assayed. For the purposes of this dissertation, discussions will be restricted to IL-6, CRP, leptin, chemerin and omentin. The results of the research will be discussed as three separate manuscripts which will focus on the specific aims and hypotheses described. 
CHAPTER III: INFLAMMATORY ADIPOCYTOKINES AND METABOLIC SYNDROME IN HAITIAN AND AFRICAN AMERICANS WITH AND WITHOUT

TYPE 2 DIABETES

\begin{abstract}
\end{abstract}
Background: Obesity and metabolic syndrome (MetS) often occur jointly and have been associated with type 2 diabetes and cardiovascular diseases. These metabolic processes may partially be explained by a pro-inflammatory state. Ethnic subgroups within the nonHispanic Black population have not been characterized in metabolic disorder studies. The purpose of this study was to assess levels of IL- 6 and CRP by ethnicity and diabetes status; and determine whether MetS will be associated with higher levels of IL-6 or CRP. Methods: Cross-sectional data from 471 participants (230 Haitian Americans and 241 African Americans; 240 with and 231 without T2D) recruited from various community sources in South Florida, were included in this study. Results: African Americans had higher log IL-6 and log CRP levels than Haitian Americans ( $\mathrm{P}<0.001)$. Haitian Americans with and without MetS had lower log IL-6 levels and log CRP than African Americans with and without MetS, respectively $(\mathrm{P}<0.001)$. Log IL-6 and log CRP correlated with higher waist circumference in all groups except for log IL-6 in African Americans without T2D. Log IL-6 and log CRP positively correlated with triglycerides in Haitian Americans with T2D. Log IL-6 was negatively correlated with HDL-C in Haitian Americans with T2D. Higher levels of $\log \mathrm{CRP}(\beta=0.34, \mathrm{SE}=0.14, \mathrm{P}=0.012)$, but not $\log$ IL-6 $(\mathrm{P}=0.727)$ were associated with MetS. Conclusion: Ethnic-centered health interventions that focus on improving these metabolic parameters may be the key to reducing the risk for $\mathrm{T} 2 \mathrm{D}$ and cardiovascular diseases in this population. 


\section{INTRODUCTION}

Metabolic syndrome (MetS), the clustering of complex abnormalities, includes a large waist circumference, dyslipidemia, hypertension, and impaired glucose tolerance. These components of MetS, are a multiplex risk factor for type 2 diabetes (T2D) and cardiovascular diseases (CVD). ${ }^{1-3}$ Population based estimates from the National Health and Nutrition Examination Survey (NHANES) 1999-2006 show that approximately 1 out of every 3 adults $\geq 20$ years has MetS. ${ }^{4}$ Given the dramatic trend in the increasing prevalence of obesity, it is projected that the prevalence of MetS will nearly double in the next 15 years. ${ }^{4}$ The association of MetS with obesity is largely due to chronic low-grade inflammation found in both states. ${ }^{5-9}$ Obesity is associated with dysfunctional adipose tissue which leads to altered physiological balance of adipocytokines and is associated with hyperinsulinemia, insulin resistance, and a pro-inflammatory state. The recognition of the key role of chronic low-grade inflammation in the clinical expression of MetS has developed in the past decade. ${ }^{9}$ Interleukin-6 (IL-6), an important pro-inflammatory adipocytokine released by adipocytes has been found to integrate key metabolic pathways including insulin signaling, glucose and lipid metabolism. ${ }^{10}$ IL-6 regulates hepatic acutephase response and stimulates the production of C-reactive protein (CRP) by the liver. ${ }^{11}$ Recent in vitro studies have demonstrated the extrahepatic production of CRP by human adipocytes, ${ }^{12}$ which elicits the likelihood that CRP may basically be a marker of obesity in individuals who later develop MetS and T2D. Several studies have demonstrated an increase in circulating levels of IL-6 and CRP in subjects with MetS. ${ }^{13-16}$ The graded positive relationships between IL-6 and CRP, and components of the MetS, particularly waist circumference, a measure of obesity, and hyperinsulinemia have also been 
reported. ${ }^{13,16}$ Similarly, high serum IL-6 and CRP have shown significant associations with MetS in individuals with and without T2D in diverse racial and ethnic populations. $^{13,17-18}$

Metabolic syndrome and levels of IL-6 and CRP vary widely across selfdescribed race/ethnic groups in the United States. ${ }^{4,19}$ Studies have consistently shown that African Americans as compared to Mexican Americans and Whites are less likely to be classified as having MetS due to lower prevalence of dyslipidemia. ${ }^{20-22}$ Yet, African Americans exhibit somewhat increased hyperinsulinemia, hypertension, and higher prevalence and risk of T2D and cardiovascular diseases. ${ }^{4,23}$ Moreover, African Americans as compared to Whites have higher levels of IL- 6 and CRP. ${ }^{24-25}$ Whereas a sizeable number of studies have described the associations between MetS, inflammation and long term metabolic disease risks in African Americans, these associations among Haitian Americans are lacking, despite their high susceptibility to develop T2D with poor outcomes. ${ }^{26}$ African Americans as compared to Haitian Americans are found to be more obese and have increased hyperinsulinemia, two major underlying defects associated with MetS. ${ }^{27}$ Considering the fact that these two components of MetS are also strong determinants of IL-6 and CRP levels, the observed differences may have the potential to confer variability in the levels of IL-6 and CRP and their association with MetS among the two ethnic subgroups. Therefore, this study aimed to analyze Haitian and African Americans with and without type 2 diabetes to 1) determine the differences in levels of IL-6 and CRP by ethnicity, diabetes and MetS statuses; 2) assess whether MetS will be associated with higher levels of IL-6 and CRP. 


\section{METHODS}

\section{Research design and Participants}

This was a cross-sectional study conducted to study cardiovascular risk factors in Haitian and African Americans with and without T2D. Study participants were recruited from Miami- Dade and Broward Counties, Florida. African American participants with and without T2D were randomly selected from lists of addresses obtained from the Knowledge Base Marketing, Inc., Richardson, TX, USA. About 7550 letters were mailed to African Americans to request their participation. Of the letters mailed, 4\% $(n=256)$ responded. As a result of unavailability of a similar database of mailing addresses for Haitian Americans, community based sources were used to recruit Haitian Americans (n =259). Recruitment print advertisements were posted in local Haitian supermarkets, churches, and restaurants; and flyers were also distributed to Florida International University (FIU) faculty, staff and students. In addition, local diabetes educators and community health professionals were requested to assist in recruitment efforts and announcements were also aired on a Creole radio station. Interested individuals were interviewed on phone and were fully informed of the study purpose. For all those interviewed, age, gender and self-identified ethnicity (African American and Haitian American) were confirmed. Self-reported T2D status was confirmed based on fasting plasma glucose (FPG) and glycosylated hemoglobin (A1C), diabetes duration and use of diabetes medications. Eligibility also included age $\geq 35$ years and absence of chronic conditions such as kidney failure, hepatitis, HIV and cancer. Eligible respondents were requested to participate in the study at the Human Nutrition Laboratory at FIU. Participants were directed to be in a fasting state, and refrain from smoking and 
exercising 8 hours prior to their visit. This study was approved by the Institutional Review Board at FIU. Signed informed consent in English or Creole was obtained from participants on their initial appointments to the laboratory. Twelve participants (Haitian Americans $=8$; African Americans $=4$ ) were reclassified as having diabetes according to the criteria specified by the American Diabetes Association and referred to their physicians. Participants with missing values $(n=34)$ and outliers $(n=4)$ for IL-6 were excluded. The final data analysis was confined to 230 Haitian Americans and 241 African Americans with complete data on IL-6, CRP and MetS.

\section{Measurement of Study Variables}

\section{a. Socio-demographic}

A validated socio-demographic questionnaire was used to collect information on age, gender, smoking status, and use of lipid, nonsteroidal anti-inflammatory drugs (NSAIDs) and oral hypoglycemic medications.

b. Anthropometric measurement

Height and weight were measured to the nearest $0.5 \mathrm{~cm}$ and $0.1 \mathrm{~kg}$ respectively, using a SECA balance scale (Seca Corp, Columbia, MD). BMI was calculated as weight in $\mathrm{kg} /$ height in $\mathrm{m}^{2}$. Waist circumference was measured with a non-stretchable measuring tape, midway between the lower rib margin and the iliac crest and was reported to the nearest $0.1 \mathrm{~cm}$. Blood pressure was measured twice and averaged with the participants in a sitting position at rest for fifteen minutes with a sphygmomanometer. 
c. Blood sampling and biochemical analysis

Venous blood samples were collected from each participant after an overnight fast of at least 8 hours. A trained and certified phlebotomist was in charge of blood draw and this ensured minimal risk to the participants. Blood samples were collected in a Vaccutainer Serum Separator tube, then coagulated for 30-45 minutes and centrifuged at 2500 RPM for half an hour to obtain serum. The serum was aliquoted into 3 labeled plastic tubes for 1) glucose determination 2) lipid panel analysis and 3) stored at $-70^{\circ} \mathrm{C}$ for subsequent analyses. Glucose levels were determined by hexokinase enzymatic methods, and lipid panel was assayed using enzymatic methods (Laboratory Corporation of America, FL, USA). Glycated hemoglobin (A1C) was measured in whole blood samples via Roche Tina Quant method (Laboratory Corporation of America, FL, USA). Serum fasting insulin levels were determined using a commercially available enzyme-linked immunosorbent assay (ELISA, Millipore, St Charles, MS, USA). Serum C-reactive protein (CRP) was analyzed with the Immulite method (Vascular Disease Intervention and Research Laboratory, OK, USA). Interleukin 6 (IL-6) was measured in serum at the Human Nutrition Laboratory at FIU with the ELISA method (BD Biosciences, San Jose, CA, USA). Briefly, $50 \mu 1$ of ELISA Diluent was pipetted into each well followed by the addition of $100 \mu$ l of standards, blank and samples. After 2 hours of incubation at room temperature followed by washing, $100 \mu 1$ of Working Detector was added and incubated for an hour. After a second washing step, $100 \mu 1$ TMB One-Step Substrate Reagent was added and incubated for half an hour. The reaction process was stopped by addition of 50 $\mu 1$ of Stop Solution. The absorbance of the resulting product was measured at $450 \mathrm{~nm}$ with a spectrophotometer. A microplate reader capable of creating a standard curve plotted the 
mean absorbance values against the IL-6 concentrations of standards. The software used the standard curve to determine the concentrations of the unknown samples. The sensitivity of the ELISA assay was $2.2 \mathrm{pg} / \mathrm{ml}$ and the range was $2.2-300 \mathrm{pg} / \mathrm{ml}$. The intraassay and interassay coefficients of variation were both less than $10 \%$.

d. Metabolic syndrome (MetS) definition

The National Cholesterol Education Program Adult Panel III (NCEP-ATP III) criteria for $\mathrm{MetS}^{1}$ was used to classify participants as having MetS if they met three or more of the following: 1) waist circumference (WC) $>102 \mathrm{~cm}$ for men and $>88 \mathrm{~cm}$ for women; 2) fasting plasma glucose $(\mathrm{FPG}) \geq 110 \mathrm{mg} / \mathrm{dL} ; 3)$ triglyceride $(\mathrm{TG}) \geq 150 \mathrm{mg} / \mathrm{dL} ; 4)$ highdensity lipoprotein cholesterol (HDL-C) $<40 \mathrm{mg} / \mathrm{dL}$ for men and $<50 \mathrm{mg} / \mathrm{dL}$ for women; or 5) systolic blood pressure $\geq 130 \mathrm{mmHg}$ and/or diastolic blood pressure $\geq 85$ $\mathrm{mmHg}$.

\section{Data Analysis}

The IBM Statistical Package for the Social Sciences (SPSS) version 21 (IBM Corporation, Chicago, IL, USA) was used for statistical analyses. Because the distributions of insulin, IL-6 and CRP values were skewed, these variables were logtransformed to approach normality. Descriptive statistics using independent samples t-test and analysis of variance (ANOVA) followed by Tukey post hoc tests, for continuous variables and $\chi^{2}$ tests for categorical variables were used to assess the differences in means stratified by ethnicity, diabetes status and MetS to test the first aim. To evaluate the second aim, partial correlations adjusted for age, gender and BMI, and hierarchical multiple linear regressions were conducted. The log transformed serum concentrations of 
IL-6 and CRP served as dependent variables in separate linear regression equations, and MetS (yes/no), ethnicity (Haitian Americans/African Americans) and diabetes status (yes/no) as independent variables. Regression models were adjusted for age, gender (male/female), BMI, smoking (yes/no), NSAIDs (yes/no), lipid and oral hypoglycemic medications (yes/no). The results were considered statistically significant at P-value $<0.05$.

\section{RESULTS}

The demographic and clinical characteristics of the participants are shown as comparison of means stratified by ethnicity and diabetes status (Table 1). Overall, both Haitian and African Americans had similar prevalence of the MetS and T2D. Haitian Americans as compared to African Americans were significantly older (56.3 \pm 10.5$)$ and had higher A1C and SBP. African Americans had significantly higher mean serum log IL-6 (2.14 \pm .5 vs $1.69 \pm .7)$ and $\log$ CRP levels $(1.23 \pm 1.2$ vs $0.50 \pm 1.1)$ than did Haitian Americans, respectively $(P<0.001)$. Compared with Haitian Americans, African Americans had higher mean BMI $(P<0.001)$, WC $(P<0.001)$, and were more obese $(P<$ 0.001). African Americans also had higher TG levels $(P<0.001)$ and log insulin levels $(P<0.001)$, and lower HDL-C $(P=0.017)$. Current smoking was proportionally higher among African Americans (38.2\%) than among Haitian Americans (6.5\%). African Americans were more likely than Haitian Americans to use NSAIDs (39.4\% vs 27.4\%), whereas the use of lipid medications and oral hypoglycemic medications was not significantly different between the two ethnic subgroups. The mean age of participants with T2D $(n=240)$ was $55.9 \pm 10.2$; where the majority were not current smokers $(78.7 \%)$ 
and used medications (lipid medications $\{41.3 \%\}$, NSAIDs $\{42.5 \%\}$ and oral hypoglycemic medications $\{82.5 \%\})$. A significant difference was observed $(P<0.05)$ between mean BMI, WC, and percentage obesity of participants with and without T2D. Participants with T2D as expected had significantly higher levels of A1C $(P<0.001)$, FPG $(P<0.001)$, SBP $(P=0.024)$, serum log IL-6 $(P=0.028)$ and higher percentage of MetS $(89.6 \%)$. The mean log CRP levels $(P=0.239)$ did not differ significantly between participants with and without T2D. Moreover, no significant difference in the levels of TG, HDL-C, DBP and log insulin was observed between participants with and without T2D.

Figures $1 \& 2$ further show the differences in levels of mean log IL-6 and log CRP with MetS by ethnicity using ANOVA followed by Tukey post hoc test. Haitian Americans with and without MetS had lower mean log IL-6 levels than African

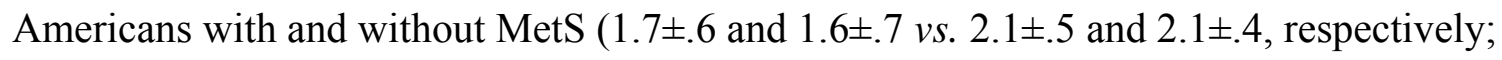
$P<0.001)$. Nevertheless, the mean log IL-6 levels of Haitian Americans with MetS were

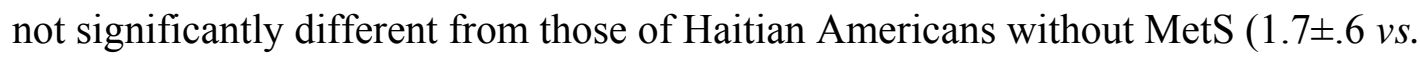
1.6 $\pm .7 ; P=0.123)$. This observation was also present among African Americans with and without MetS (2.1 \pm .5 vs. $2.1 \pm .4 ; P=1.000)$ (Fig. 1). Figure 2 shows that the mean log levels of CRP in Haitian Americans with MetS were lower than in African Americans with MetS $(0.6 \pm 1.0$ vs. $1.4 \pm 1.1 ; P<0.001)$, but not significantly different compared to African Americans without MetS (0.6 \pm 1.0 vs. $0.7 \pm 1.3 ; P=0.970)$. Haitian Americans without MetS had lower mean CRP levels compared to Haitian Americans with MetS $(0.2 \pm 1.1$ vs. $0.6 \pm 1.0 ; P=0.017)$, and African American with and without MetS $(0.2 \pm 1.1$ vs. $1.4 \pm 1.1$ and $0.7 \pm 1.3 ; P<0.001$ and $P=0.024$, respectively). African Americans with 
MetS had higher mean log CRP levels compared to African Americans without MetS (1.4 \pm 1.1 vs. $0.7 \pm 1.3 ; P<0.001)$.

Partial correlations between levels of $\log$ IL-6 and $\log$ CRP with MetS and each component of MetS by ethnicity and diabetes status controlled for age, gender and BMI are shown in Table 2. The levels of log IL-6 did not correlate with MetS in neither Haitian nor African Americans with and without T2D, whereas log CRP showed a positive correlation with MetS among Haitian Americans with T2D and African Americans with and without T2D. High levels of log IL-6 and log CRP corresponded with higher WC in all groups except for log IL-6 in African Americans without T2D. There was a positive correlation between $\log$ IL-6 and $\log$ CRP with TG only in Haitian Americans with T2D $(r=0.35, P<0.001$ and $r=0.18, P=0.046)$. In addition, $\log$ IL-6 was negatively correlated with HDL-C in only Haitian Americans with T2D $(r=-0.18, P$ $=0.048)$. Log insulin levels was positively correlated with log CRP in African Americans with and without T2D and Haitian Americans without T2D. There was no significant correlation between log IL-6 and log CRP with FPG, SBP and DBP in either Haitian or African Americans with and without T2D.

Multiple linear regression models performed to further test the secondary aim that MetS will be associated with higher levels of $\log$ IL- 6 and $\log$ CRP are illustrated in Tables 3 and 4 . The model was run with the primary variables and covariates: age, gender, BMI, smoking and intake of NSAIDs, lipid and oral hypoglycemic medications. After adjustment, the hypothesis was partially explained since log IL-6 was not significantly associated with MetS (Table 3), but MetS explained only log CRP (Table 4). Being African American and having a high BMI were positively associated with both log 
IL-6 and $\log$ CRP levels. High levels of $\log$ CRP levels were also significantly associated with being female, and higher age had a trend towards significant association with higher levels of $\log$ IL-6 levels. A test of the interaction effect between ethnicity and diabetes status showed that the interaction term was not significant. There was no relationship between T2D status, current smokers, intakes of NSAIDs, lipid and oral hypoglycemic medications with $\log$ IL-6 and $\log$ CRP.

\section{DISCUSSION}

The prevalence of metabolic syndrome (MetS), along with type 2 diabetes (T2D) and cardiovascular diseases (CVD), has increased steadily in the United States over the past decade and is considered as a national epidemic. ${ }^{2-4}$ MetS and obesity often coexist and corresponds to hyperinsulinemia and insulin resistance with increased levels of proinflammatory adipocytokines in persons with MetS. ${ }^{9}$ African Americans had higher IL-6 and CRP levels with or without MetS. This may be attributed to the fact that African Americans were more obese (higher BMI and WC) and had higher insulin levels. In addition, higher IL-6 and CRP levels were seen among participants with than without T2D, however, the difference was not significant for CRP. This might be due to only modest differences in BMI and insulin levels between the two groups. It is worth mentioning that although Haitian Americans had lower metabolic risk factors, their prevalence of MetS was similar to that of African Americans. This might be as a result of the similar prevalence of T2D among the two groups, since individuals with T2D are more likely to have higher prevalence of MetS, ${ }^{28}$ which is confirmed in our study. 
Chronic low-grade inflammation, as characterized by increased circulating levels of pro-inflammatory adipocytokines, is a key feature of chronic diseases including obesity, MetS, T2D and CVD. ${ }^{29}$ Several studies have associated circulating levels of proinflammatory adipocytokines such as IL-6 and CRP, with metabolic risk factors such as obesity and insulin resistance. ${ }^{30}$ Interleukin 6 is a pleiotropic adipocytokine that plays a key role in chronic inflammation. ${ }^{10}$ It is a central regulator of the acute-phase response and a major determinant of hepatic synthesis of CRP. ${ }^{11}$ IL- 6 is secreted by adipocytes and macrophages/monocytes recruited into the adipose tissue with increasing adiposity. ${ }^{10}$ Thus, IL-6 is considered to not only modulate glucose and lipid metabolism, but the innate immunity. IL-6 has been generally considered to play a role in developing insulin resistance by inhibiting insulin receptor signaling via expression of suppressor of cytokine signaling 3 (SOCS3) in hepatocytes ${ }^{31}$ and may provide the link between metabolic and immune system pathways in the development of MetS and eventually T2D. However, some studies have reported that IL-6 is not strongly associated with MetS as compared to CRP. ${ }^{32-34} \mathrm{C}$-reactive protein is the chief downstream mediator of the acute-phase response, and may account for the inflammatory and insulin resistance effects of IL-6. ${ }^{11,31}$ Alternatively, reverse causation has been implicated whereby decreased insulin sensitivity may enhance hepatic CRP production independent of IL-6 levels. ${ }^{35}$ This is because insulin has anti-inflammatory effect which counteracts the inflammatory effects of insulin resistance and increased synthesis of hepatic CRP. Recently CRP has been produced by adipocytes and may be considered as an adipocytokine. ${ }^{12}$ Among the inflammatory adipocytokines, CRP has been the main focus of previous investigations and has been shown to be strongly associated with MetS, T2D 
and CVD independent of traditional risk factors such as BMI and insulin resistance. ${ }^{12-}$ 13,16,32-34 Moreover compared to other pro-inflammatory adipocytokines, CRP measurements are more sensitive due to a relatively long half-life and no circadian variation.

The present study shows a predictable, but partially discordant association between MetS and increasing levels of IL-6 and CRP. Specifically, CRP showed a significant positive relationship with MetS, whereas a nonsignificant negative relationship was observed between MetS and IL-6, after adjusting for BMI and other IL-6 and CRP confounders. Interestingly, other studies have also shown that CRP, but not IL-6 is associated with MetS and that CRP seemed appropriate for detecting MetS among representative pro-inflammatory markers. ${ }^{32-34}$ However, the negative relationship in our study might be due to the influence of lipid lowering medications taken mainly by individuals with MetS to reduce adiposity. ${ }^{36}$ IL-6 is a direct product of adiposity, a major contributor to MetS, thus once adiposity is taken into account, this might have diminished association between having MetS and IL-6. On the other hand, CRP is a nonspecific proinflammatory marker which may not be directly affected by adiposity. ${ }^{37}$ In effect, CRP has been shown to be more strongly associated with MetS than IL-6 independent of obesity markers and is considered the best standardized pro-inflammatory marker of metabolic and cardiovascular disorders. ${ }^{38-40}$ Pro-inflammatory adipocytokines, particularly CRP has therefore been proposed to be considered a component of the classification of MetS. ${ }^{41}$ Moreover, the levels of IL-6 did not correlate with MetS in neither Haitian nor African Americans with and without T2D, whereas CRP showed a positive correlation with MetS among Haitian Americans with T2D and African 
Americans with and without T2D. On the other hand, IL-6 correlated with several components of the MetS: positively with WC except in African Americans with T2D, TG in Haitian Americans with T2D, and negatively correlated with HDL-C in Haitian Americans with T2D. This may be in support of the view that chronic inflammation is a component of the MetS and may act as the initial trigger to the development of MetS. ${ }^{9,41}$ CRP was also positively correlated with WC in Haitian and African Americans with and without T2D, TG in Haitian Americans with T2D and log insulin in African Americans with and without T2D and Haitian Americans without T2D. Both IL-6 and CRP were not correlated with FPG, SBP and DBP in either Haitian or African Americans with and without T2D. The lack of correlation of CRP with FPG has been previously reported. ${ }^{32}$ Because pancreatic $\beta$-cells compensate to increase insulin synthesis earlier on in impaired glucose tolerance, FPG levels may remain within normal limits.

We found ethnically-specific differences in IL-6 and CRP even when adjusting for BMI. One possible reason for the ethnic differences in the level of IL-6 is due to the presence of variants of cytokine gene single nucleotide polymorphisms. Delaney et al. ${ }^{42}$ discovered that allelic variation in the enhancer regions of the cytokine genes may modify the expression of some cytokines. The G/G genotype which causes high expression of IL-6 and as a result increases IL-6 production, has been predominantly found in African Americans, and may explain higher levels of IL-6 among this ethnic subgroup. Additionally, several studies have reported that the association between CRP and adiposity does not fully explain the higher CRP levels in populations of African ancestry. ${ }^{43-44}$ In a recent large genome-wide association study, Reiner and colleagues ${ }^{45}$ identified several CRP-associated alleles of triggering receptors expressed by myeloid 
cells 2 (TREM2) in African American women. The authors reported that the strongest of these alleles which is associated with higher levels of CRP is present only in African ancestral populations. Therefore, future studies should investigate the activities of these genes also in Haitian Americans to better distinguish inflammatory processes between the two non-Hispanic Black subgroups. Other nongenetic factors such as diet quality and lifestyle factors (including physical activity and smoking) which have been shown to be better in Haitian Americans than Africans Americans, ${ }^{46}$ may have accounted for the lower inflammatory status in Haitian Americans. Although, smoking was not significantly associated with levels of IL-6 and CRP in regression analysis, African Americans had a higher percentage of smokers in our study. Smoking has been found to be a strong risk factor for the chronic low-grade inflammation based on increased circulating levels of IL-6 and CRP. ${ }^{47-48}$

The association of inflammatory adipocytokines with diabetes are mixed. ${ }^{49-51}$ The nonsignificant association between IL-6 or CRP and T2D in our study was not expected. This could be due to the almost similar levels of BMI and insulin among participants with and without T2D. As such, the metabolic alterations and related changes in inflammation in participants with $\mathrm{T} 2 \mathrm{D}$ was not severe enough to make a significant difference between the two groups and difficult to detect. Krakoff et al. ${ }^{50}$ and Efstratiadis et al. ${ }^{51}$ investigated the association between diabetes and IL-6 or CRP levels and reported no significant association between these parameters after controlling for markers of obesity and other IL-6 and CRP confounders. However, a meta-analysis of ten studies, involving 19,709 participants have shown an association between diabetes and higher levels of IL-6 and CRP. ${ }^{52}$ These studies included either only women or only men or both and were 
conducted either within the US or outside the US. There is the need to further explore these findings to better understand the differing results. Despite the lack of association with T2D, IL-6 and CRP were strongly associated with known causal risk factors for diabetes such as BMI, WC and insulin levels. Thus, the positive relationship between chronic low-grade inflammation with adiposity measured by BMI and WC, and insulin was observed in our study.

The results further provide evidence of an association between gender and CRP, in congruence with previous investigations that have found higher CRP levels among females. ${ }^{53}$ While our study participants did not differ significantly by gender for ethnicity or diabetes status, African Americas and participants with T2D had higher percentages of females. Females have always had higher levels of CRP than men, ${ }^{53}$ a finding that is linked to higher BMI and WC, which was present in African Americans and participants with T2D in our study. Our findings also revealed that age had a slight tendency of significant association with IL-6 levels. IL-6 levels increase with age, apparently reflecting the higher inflammation levels as age advances. ${ }^{47}$ While Haitian Americans were older in our study, they had lower levels of IL-6 as compared to African Americans, suggesting that this observation may be due to other factors more significant than age in this population.

Strengths of our study include utilizing a gender-balanced, sample of two subgroups of non-Hispanic Blacks; that are not usually compared in most studies. There are limited studies to date on ethnic variations for MetS, T2D status and the inflammatory burden in nonwhite populations at risk for diabetes and cardiovascular diseases. This is the first study to the best of our knowledge that has specifically looked at MetS and its 
components, and assessed ethnic differences in the pro-inflammatory adipocytokines, IL6 and CRP within this non-Hispanic Black ethnicity with and without T2D. Our findings indicate significant differences in MetS components, obesity measures, and serum IL-6 and CRP levels among Haitian Americans and African Americans, thus, distinguishing the two non-Hispanic Black groups and yields important information particularly for Haitian Americans, a previously understudied ethnic minority subgroup.

The cross-sectional design of this is study is a limitation. As a result, causality between ethnicity, obesity measures, MetS, T2D and the levels of pro-inflammatory adipocytokines cannot be considered. In addition, the study population is a semiconvenience sample and not recruited by randomized selection. The sample may therefore not be representative of Haitian Americans and African Americans living in South Florida and as such, generalizability to the larger population may be limited. The IL- 6 concentration of 47 of the study participants was undetectable which might be that these participants were less predisposed to increased inflammation. Since IL-6 has a short half-life ( $\sim 6$ hours) and can be difficult to detect among particular populations using ELISA kits, future assessment of inflammation should use IL-6 receptor as a surrogate for IL-6 levels.

\section{CONCLUSION}

In summary, this study has important clinical and public health implications. Inflammatory based risk for metabolic conditions may vary according to ethnicity and other demographic variables in subgroups of non-Hispanic Blacks. The study indicates that African Americans with MetS have higher levels of IL-6 and CRP which might be 
explained by obesity with greater BMI and WC, and hyperinsulinemia. Ethnic-centered health interventions that focus on improving these metabolic parameters may therefore be the key to reducing the risk for T2D and cardiovascular diseases in this population. Future studies to determine genetic variants of the pro-inflammatory markers, and dietary and lifestyle factors of Haitian Americans and African Americans alongside their association with MetS may be beneficial. 


\section{REFERENCES:}

1. Grundy SM, Brewer HB Jr, Cleeman JI, Smith SC Jr, Lenfant C; American Heart Association; National Heart, Lung, and Blood Institute. Definition of metabolic syndrome: Report of the National Heart, Lung, and Blood Institute/American Heart Association conference on scientific issues related to definition. Circulation. 2004;109(3):433-438.

2. Alberti KG, Eckel RH, Grundy SM, Zimmet PZ, Cleeman JI, Donato KA, Fruchart JC, James WP, Loria CM, Smith SC Jr; Harmonizing the metabolic syndrome: a joint interim statement of the International Diabetes Federation Task Force on Epidemiology and Prevention; National Heart, Lung, and Blood Institute; American Heart Association; World Heart Federation; International Atherosclerosis Society; and International Association for the Study of Obesity. Circulation. 2009;120(16):1640-1645.

3. Ferrannini E, Haffner SM, Mitchell BD, Stern MP. Hyperinsulinaemia: the key feature of a cardiovascular and metabolic syndrome. Diabetologia. 1991;34(6):416-422.

4. Mozumdar A, Liguori G. Persistent increase of prevalence of metabolic syndrome among U.S. adults: NHANES III to NHANES 1999-2006. Diabetes Care. 2011;34(1):216-219.

5. Trujillo ME, Scherer PE. Adipose tissue-derived factors: impact on health and disease. Endocr Rev. 2006;27(7):762-778.

6. Hotamisligil GS. Inflammation and metabolic disorders. Nature. 2006;444(7121):860-867.

7. Ronti T, Lupattelli G, Mannarino E. The endocrine function of adipose tissue: an update. Clin Endocrinol (Oxf). 2006;64(4):355-365.

8. Ritchie SA, Connell JM. The link between abdominal obesity, metabolic syndrome and cardiovascular disease. Nutr Metab Cardiovasc Dis. 2007;(4):319326.

9. Dandona P, Aljada A, Chaudhuri A, Mohanty P, Garg R. Metabolic syndrome: a comprehensive perspective based on interactions between obesity, diabetes, and inflammation. Circulation. 2005;111(11):1448-1454. 
10. Glund S, Krook A. Role of interleukin-6 signalling in glucose and lipid metabolism. Acta Physiol (Oxf). 2008;192(1):37-48.

11. Heinrich PC, Castell JV, Andus T. Interleukin-6 and the acute phase response. Biochem J. 1990;265(3):621-636.

12. Calabro P, Chang DW, Willerson JT, Yeh ET. Release of C-reactive protein in response to inflammatory cytokines by human adipocytes: linking obesity to vascular inflammation. J Am Coll Cardiol. 2005;46(6):1112-1123.

13. Huffman FG, Gomez GP, Zarini GG. Metabolic syndrome and high-sensitivity Creactive protein in Cubans. Ethn Dis. 2009;19(2):115-120.

14. Indulekha K, Surendar J, Mohan V. High sensitivity C-reactive protein, tumor necrosis factor- $\alpha$, interleukin- 6 , and vascular cell adhesion molecule-1 levels in Asian Indians with metabolic syndrome and insulin resistance (CURES-105). J Diabetes Sci Technol. 2011;5(4):982-988.

15. Chen SJ, Yen CH, Huang YC, Lee BJ, Hsia S, Lin PT. Relationships between inflammation, adiponectin, and oxidative stress in metabolic syndrome. PLoS One. 2012;7(9):e45693.

16. Choi EY, Park EH, Cheong YS, Rheem I, Park SG, Yoo S. Association of Creactive protein with the metabolic risk factors among young and middle-aged Koreans. Metabolism. 2006;55(3):415-421.

17. Edalat B, Sharifi F, Badamchizadeh Z, Hossein-Nezhad A, Larijani B, Mirarefin M, Fakhrzadeh H. Association of metabolic syndrome with inflammatory mediators in women with previous gestational diabetes mellitus. J Diabetes Metab Disord. 2013;12(1):1-8.

18. Amato MC, Pizzolanti G, Torregrossa V, Misiano G, Milano S, Giordano C. Visceral adiposity index (VAI) is predictive of an altered adipokine profile in patients with type 2 diabetes. PLoS One. 2014;9(3):e91969.

19. Walker SE, Gurka MJ, Oliver MN, Johns DW, DeBoer MD. Racial/ethnic discrepancies in the metabolic syndrome begin in childhood and persist after adjustment for environmental factors. Nutr Metab Cardiovasc Dis. 2012;22(2):141-148.

20. Carnethon MR. Palaniappan LP. Burchfiel CM. Brancati FL. Fortmann SP. Serum insulin, obesity, and the incidence of type 2 diabetes in black and white 
adults: The atherosclerosis risk in communities study: 1987-1998. Diabetes Care. 2002;25:1358-1364.

21. Harris MI. Cowie CC. Gu K. Francis ME. Flegal K. Eberhardt MS. Higher fasting insulin but lower fasting C-peptide levels in African Americans in the US population. Diabetes Metab Res Rev. 2002;18:149-155.

22. Sumner AE. Vega GL. Genovese DJ. Finley KB. Bergman RN. Boston RC. Normal triglyceride levels despite insulin resistance in African Americans: role of lipoprotein lipase. Metabolism. 2005;54:902-909.

23. Mensah GA, Mokdad AH, Ford ES, Greenlund KJ, Croft JB. State of disparities in cardiovascular health in the United States. Circulation. 2005;111:1233-1241.

24. Paalani M, Lee JW, Haddad E, Tonstad S. Determinants of inflammatory markers in a bi-ethnic population. Ethn Dis. 2011;21(2):142-149.

25. Pearson TA, Mensah GA, Alexander RW, Anderson JL, Cannon RO 3rd, Criqui M, Fadl YY, Fortmann SP, Hong Y, Myers GL, Rifai N, Smith SC Jr, Taubert K, Tracy RP, Vinicor F; Centers for Disease Control and Prevention; American Heart Association. Markers of inflammation and cardiovascular disease: application to clinical and public health practice: A statement for healthcare professionals from the Centers for Disease Control and Prevention and the American Heart Association. Circulation. 2003;107(3):499-511.

26. Vimalananda,V. G., Rosenzweig, J. L., Cabral,H. J., David, M. M., Lasser,K. E. Comparison of diabetes control among Haitians, African Americans, and nonHispanic whites in an urban safety-net hospital. Diabetes Care.2011;34:58-60.

27. Huffman F, Vallasciani M, Vaccaro J, Exebio J, Zarini G, Nayer A, Ajabshir, S. The association of depression and perceived stress with beta cell function between African and Haitian Americans with and without type 2 diabetes. J of Diabetes Mellit. 2013;3:236-243.

28. Janghorbani M, Amini M. Metabolic syndrome in type 2 diabetes mellitus in isfahan, iran: prevalence and risk factors. Metab Syndr Relat Disord. 2007;5(3):243-254.

29. Duncan BB, Schmidt MI, Pankow JS, Ballantyne CM, Couper D, Vigo A, Hoogeveen R, Folsom AR, Heiss G; Atherosclerosis Risk in Communities Study. Low-grade systemic inflammation and the development of type 2 diabetes: the atherosclerosis risk in communities study. Diabetes. 2003;52(7):1799-1805. 
30. Abbatecola AM, Ferrucci L, Grella R, Bandinelli S, Bonafè M, Barbieri M, Corsi AM, Lauretani F, Franceschi C, Paolisso G. Diverse effect of inflammatory markers on insulin resistance and insulin-resistance syndrome in the elderly. J Am Geriatr Soc. 2004;52(3):399-404.

31. Senn JJ, Klover PJ, Nowak IA, Zimmers TA, Koniaris LG, Furlanetto RW, Mooney RA. Suppressor of cytokine signaling-3 (SOCS-3), a potential mediator of interleukin-6-dependent insulin resistance in hepatocytes. J Biol Chem. 2003;278(16):13740-13746.

32. Matsushita K, Yatsuya H, Tamakoshi K, Wada K, Otsuka R, Takefuji S, Sugiura $\mathrm{K}$, Kondo T, Murohara T, Toyoshima $\mathrm{H}$. Comparison of circulating adiponectin and proinflammatory markers regarding their association with metabolic syndrome in Japanese men. Arterioscler Thromb Vasc Biol. 2006;26(4):871-876.

33. Salmenniemi U, Ruotsalainen E, Pihlajamäki J, Vauhkonen I, Kainulainen S, Punnonen K, Vanninen E, Laakso M. Multiple abnormalities in glucose and energy metabolism and coordinated changes in levels of adiponectin, cytokines, and adhesion molecules in subjects with metabolic syndrome. Circulation. 2004;110(25):3842-3848.

34. Choi KM, Lee J, Lee KW, Seo JA, Oh JH, Kim SG, Kim NH, Choi DS, Baik SH. Comparison of serum concentrations of C-reactive protein, TNF-alpha, and interleukin 6 between elderly Korean women with normal and impaired glucose tolerance. Diabetes Res Clin Pract. 2004;64(2):99-106.

35. Bloomgarden ZT. Inflammation, atherosclerosis, and aspects of insulin action. Diabetes Care. 2005;28(9):2312-2319.

36. Pahan K. Lipid-lowering drugs. Cell Mol Life Sci. 2006:63(10):1165-1178.

37. Han TS, Sattar N, Williams K, Gonzalez-Villalpando C, Lean ME, Haffner SM. Prospective study of C-reactive protein in relation to the development of diabetes and metabolic syndrome in the Mexico City Diabetes Study. Diabetes Care. 2002;25(11):2016-2021.

38. Lim S, Lee HK, Kimm KC, Park C, Shin C, Cho NH. C-reactive protein level as an independent risk factor of metabolic syndrome in the Korean population. CRP as risk factor of metabolic syndrome. Diabetes Res Clin Pract. 2005;70(2):126133. 
39. Kip KE, Marroquin OC, Kelley DE, Johnson BD, Kelsey SF, Shaw LJ, Rogers WJ, Reis SE. Clinical importance of obesity versus the metabolic syndrome in cardiovascular risk in women: a report from the Women's Ischemia Syndrome Evaluation (WISE) study. Circulation. 2004;109(6):706-713.

40. Ridker, PM. Clinical application of C-reactive protein for cardiovascular disease detection and prevention. Circulation. 2003;107:363-369.

41. Rader DJ. Inflammatory markers of coronary risk. N Engl J Med. 2000;343(16):1179-1182.

42. Delaney NL, Esquenazi V, Lucas DP, Zachary AA, Leffell MS. TNF-alpha, TGFbeta, IL-10, IL-6, and INF-gamma alleles among African Americans and Cuban Americans. Report of the ASHI Minority Workshops: Part IV. Hum Immunol. 2004;65(12):1413-1419.

43. Shah T, Newcombe P, Smeeth L, Addo J, Casas J.P, Whittaker J, Miller M.A, Tinworth L, Jeffery S, Strazzullo P. Ancestry as a determinant of mean population C-reactive protein values: Implications for cardiovascular risk prediction. Circ Cardiovasc Genet. 2010;3:436-444.

44. Wee C.C, Mukamal K.J, Huang A, Davis R.B, McCarthy E.P, Mittleman M.A. Obesity and C-reactive protein levels among white, black, and hispanic US adults. Obesity (Silver Spring) 2008;16:875-880.

45. Reiner AP, Beleza S, Franceschini N, Auer PL, Robinson JG, Kooperberg C, Peters U, Tang H. Genome-wide association and population genetic analysis of Creactive protein in African American and Hispanic American women. Am J Hum Genet. 2012;91(3):502-512.

46. Huffman FG, De La Cera M, Vaccaro JA, Zarini GG, Exebio J, Gundupalli D, Shaban L. Healthy Eating Index and Alternate Healthy Eating Index among Haitian Americans and African Americans with and without Type 2 Diabetes. J Nutr Metab.2011;2011:1-8.

47. Helmersson J, Larsson A, Vessby B, Basu S. Active smoking and a history of smoking are associated with enhanced prostaglandin F(2alpha), interleukin- 6 and F2-isoprostane formation in elderly men. Atherosclerosis. 2005;181(1):201-207.

48. Wannamethee SG, Whincup PH, Rumley A, Lowe GD. Inter-relationships of interleukin-6, cardiovascular risk factors and the metabolic syndrome among older men. J Thromb Haemost. 2007;5(8):1637-1643. 
49. Liu S, Tinker L, Song Y, Rifai N, Bonds DE, Cook NR, Heiss G, Howard BV, Hotamisligil GS, Hu FB, Kuller LH, Manson JE. A prospective study of inflammatory cytokines and diabetes mellitus in a multiethnic cohort of postmenopausal women. Arch Intern Med. 2007;167(15):1676-1685.

50. Krakoff J, Funahashi T, Stehouwer CD, Schalkwijk CG, Tanaka S, Matsuzawa Y, Kobes S, Tataranni PA, Hanson RL, Knowler WC, Lindsay RS. Inflammatory markers, adiponectin, and risk of type 2 diabetes in the Pima Indian. Diabetes Care. 2003 ;26(6):1745-1751.

51. Efstratiadis G, Tsiaousis G, Athyros VG, Karagianni D, Pavlitou-Tsiontsi A, Giannakou-Darda A, Manes C. Total serum insulin-like growth factor-1 and Creactive protein in metabolic syndrome with or without diabetes. Angiology. 2006;57(3):303-311.

52. Wang X, Bao W, Liu J, Ouyang YY, Wang D, Rong S, Xiao X, Shan ZL, Zhang Y, Yao P, Liu LG. Inflammatory markers and risk of type 2 diabetes: a systematic review and meta-analysis. Diabetes Care. 2013;36(1):166-175.

53. Arcari A, Zito F, Di Castelnuovo A, De Curtis A, Dirckx C, Arnout J, Cappuccio FP, van Dongen MC, De Lorgeril M, Krogh V, Siani A, Donati MB, De Gaetano G, Iacoviello L; European Collaborative Group of Immidiet Project. C reactive protein and its determinants in healthy men and women from European regions at different risk of coronary disease: the IMMIDIET Project. J Thromb Haemost. 2008;6(3):436-443. 
TABLE 1. Characteristics of the Participants by Ethnicity and Diabetes Status

\begin{tabular}{|c|c|c|c|c|c|c|}
\hline \multirow[b]{2}{*}{ Variables } & \multicolumn{2}{|c|}{ Ethnicity } & \multicolumn{4}{|c|}{ Diabetes status } \\
\hline & $\begin{array}{c}\text { Haitian } \\
\text { American } \\
(\mathrm{n}=\mathbf{2 3 0})\end{array}$ & $\begin{array}{c}\text { African } \\
\text { American } \\
(\mathrm{n}=\mathbf{2 4 1})\end{array}$ & P-value & $\begin{array}{c}\text { With } \\
\text { T2D } \\
(n=231)\end{array}$ & $\begin{array}{c}\text { Without } \\
\text { T2D } \\
(n=240)\end{array}$ & $P$ value \\
\hline Age (years) & $56.3 \pm 10.5$ & $52.5 \pm 9.5$ & $<0.001$ & $55.9 \pm 10.2$ & $52.6 \pm 9.8$ & $<0.001$ \\
\hline Female (Yes) n \% & $120(52.2)$ & $125(51.9)$ & 0.947 & $130(54.2)$ & $115(49.8)$ & 0.341 \\
\hline Diabetes status (Yes) n \% & $120(52.2)$ & $120(49.8)$ & 0.605 & - & - & - \\
\hline Ethnicity & & & & & & 0.605 \\
\hline HA (Yes) n \% & - & - & - & $120(50.0)$ & $110(47.6)$ & - \\
\hline AA (Yes) n \% & - & - & - & $120(50.0)$ & $121(52.4)$ & - \\
\hline Smoke (Yes) n \% & $15(6.5)$ & $92(38.2)$ & $<0.001$ & $51(21.3)$ & $56(24.4)$ & 0.438 \\
\hline Lipid meds (Yes) n \% & $54(23.5)$ & $70(29.0)$ & 0.170 & $99(41.3)$ & $25(10.8)$ & $<0.001$ \\
\hline NSAIDs (Yes) n \% & $63(27.4)$ & $95(39.4)$ & 0.006 & $102(42.5)$ & $56(24.2)$ & $<0.001$ \\
\hline Oral hypoglycemic meds (Yes) $n \%$ & $106(46.1)$ & $92(38.2)$ & 0.082 & $198(82.5)$ & - & - \\
\hline $\mathrm{A} 1 \mathrm{C}(\%)$ & $7.3 \pm 2.3$ & $6.8 \pm 1.7$ & 0.004 & $8.0 \pm 2.4$ & $6.0 \pm .7$ & $<0.001$ \\
\hline BMI $\left(\mathrm{kg} / \mathrm{m}^{2}\right)$ & $29.4 \pm 5.3$ & $33.7 \pm 7.9$ & $<\mathbf{0 . 0 0 1}$ & $32.7 \pm 7.7$ & $30.4 \pm 6.1$ & $<0.001$ \\
\hline Obese $\left(\mathrm{BMI} \geq 30 \mathrm{~kg} / \mathrm{m}^{2}\right) \mathrm{n} \%$ & $101(43.9)$ & $157(65.1)$ & $<0.001$ & $148(61.7)$ & $110(47.6)$ & 0.002 \\
\hline $\mathrm{WC}(\mathrm{cm})$ & $98.5 \pm 12.5$ & $108.4 \pm 17.6$ & $<0.001$ & $107.3 \pm 16.9$ & $99.6 \pm 14.2$ & $<0.001$ \\
\hline FPG (mmol/L) & $130.4 \pm 60.7$ & $122.0 \pm 54.9$ & 0.114 & $151.8 \pm 69.7$ & $99.5 \pm 20.1$ & $<0.001$ \\
\hline $\mathrm{TG}(\mathrm{mg} / \mathrm{dL})$ & $106.7 \pm 56.0$ & $128.2 \pm 72.7$ & $<0.001$ & $114.3 \pm 64.5$ & $121.1 \pm 67.2$ & 0.269 \\
\hline HDL-C(mg/dL) & $53.1 \pm 14.5$ & $49.9 \pm 13.7$ & 0.017 & $51.8 \pm 14.7$ & $51.2 \pm 13.7$ & 0.660 \\
\hline $\mathrm{SBP}(\mathrm{mm} \mathrm{Hg})$ & $146.2 \pm 24.5$ & $136.9 \pm 19.5$ & $<0.001$ & $139.0 \pm 22.6$ & $143.7 \pm 22.1$ & 0.024 \\
\hline DBP (mm Hg) & $90.5 \pm 13.0$ & $89.0 \pm 12.1$ & 0.221 & $89.8 \pm 12.0$ & $89.6 \pm 13.1$ & 0.797 \\
\hline MetS (Yes) n \% & $160(69.6)$ & $176(73.0)$ & 0.406 & $215(89.6)$ & $121(52.4)$ & $<0.001$ \\
\hline $\log$ Insulin $(\mu \mathrm{IU} / \mathrm{mL})$ & $2.0 \pm .7$ & $2.4 \pm .8$ & $<0.001$ & $2.3 \pm .6$ & $2.1 \pm .9$ & 0.059 \\
\hline $\log$ IL-6 (pg/mL) & $1.69 \pm .7$ & $2.14 \pm .5$ & $<0.001$ & $1.85 \pm .7$ & $1.99 \pm .6$ & 0.028 \\
\hline $\log \mathrm{CRP}(\mathrm{mg} / \mathrm{L})$ & $0.50 \pm 1.1$ & $1.23 \pm 1.2$ & $<0.001$ & $0.80 \pm 1.3$ & $0.94 \pm 1.2$ & 0.239 \\
\hline
\end{tabular}

Data were expressed as mean \pm SD unless otherwise indicated. Abbreviations: T2D = type 2 diabetes; NSAIDs $=$ non-steroidal antiinflammatory drugs; BMI = body mass index; A1C = hemoglobin A1C; WC = waist circumference; FPG = fasting plasma glucose; TG $=$ triglycerides; HDL-C $=$ high density lipoprotein cholesterol; $\mathrm{SBP}=$ systolic blood pressure; $\mathrm{DBP}=$ diastolic blood pressure; MetS = metabolic syndrome; IL-6 = Interleukin 6; CRP $=$ C-reactive protein. P-value is considered significant at $<0.05$. 


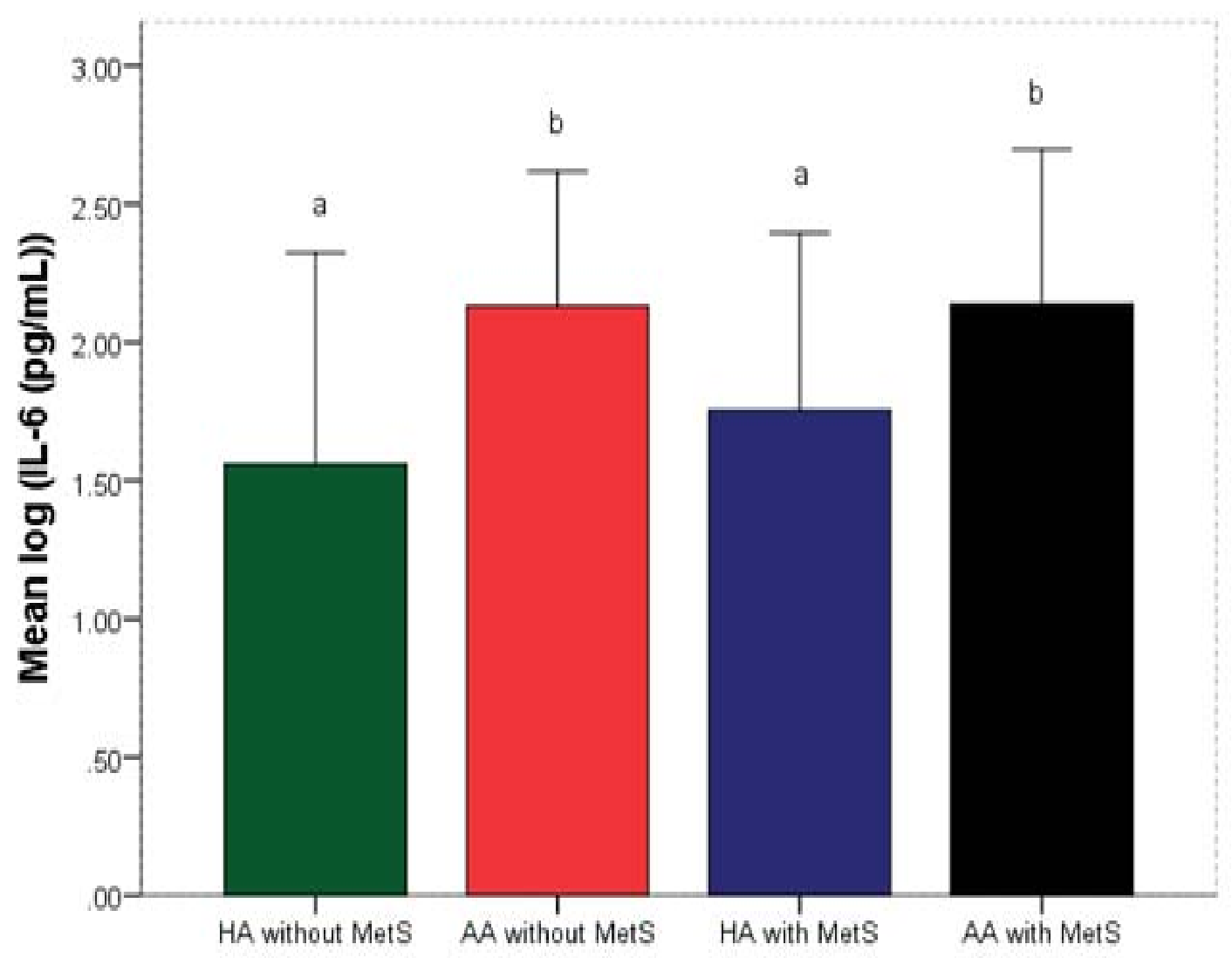

Fig 1. Comparison of levels of log IL-6 by metabolic syndrome and ethnicity Data were expressed as mean \pm SD. Groups with same superscript are not significantly different assessed by ANOVA, Tukey post hoc, $\mathrm{P}<0.05$. Abbreviations: $\mathrm{HA}=$ Haitian Americans; $\mathrm{AA}=$ African Americans; IL-6 = Interleukin-6; MetS = metabolic syndrome. 


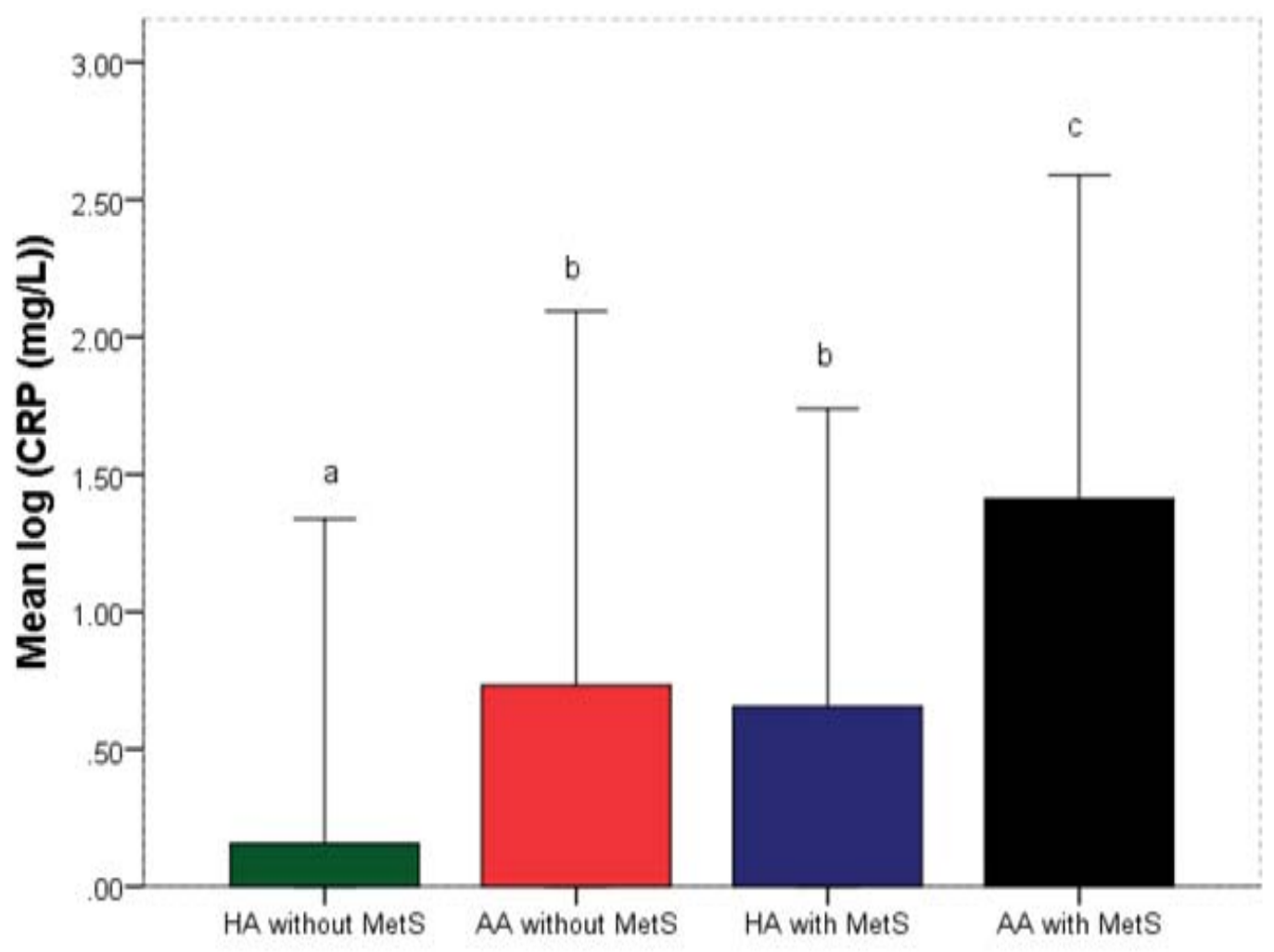

Fig 2. Comparison of levels of log CRP by metabolic syndrome and ethnicity Data were expressed as mean $\pm \mathrm{SD}$. Groups with same superscript are not significantly different assessed by ANOVA, Tukey post hoc, $\mathrm{P}<0.05$. Abbreviations: $\mathrm{HA}=$ Haitian Americans; $\mathrm{AA}=$ African Americans; $\mathrm{CRP}=\mathrm{C}$-reactive protein; MetS $=$ metabolic syndrome . 
TABLE 2. Partial Correlations of log IL-6 and log CRP with MetS and Components of MetS by Ethnicity and Diabetes Status

\begin{tabular}{|c|c|c|c|c|c|c|c|c|}
\hline \multirow[b]{2}{*}{ Variables } & \multicolumn{4}{|c|}{$\begin{array}{c}\log \text { IL-6 }(\mathrm{pg} / \mathrm{mL}) \\
\text { r (p-value) }\end{array}$} & \multicolumn{4}{|c|}{$\begin{array}{c}\log \text { CRP (mg/L) } \\
\text { r (p-value) }\end{array}$} \\
\hline & $\begin{array}{c}\text { HA } \\
\text { with T2D }\end{array}$ & $\begin{array}{c}\text { AA } \\
\text { with T2D }\end{array}$ & $\begin{array}{c}\text { HA } \\
\text { without T2D }\end{array}$ & $\begin{array}{c}\text { AA } \\
\text { without T2D }\end{array}$ & $\begin{array}{c}\text { HA } \\
\text { with T2D }\end{array}$ & $\begin{array}{c}\text { AA } \\
\text { with T2D }\end{array}$ & $\begin{array}{c}\text { HA } \\
\text { without T2D } \\
\end{array}$ & $\begin{array}{c}\text { AA } \\
\text { without T2D }\end{array}$ \\
\hline MetS & $0.14(0.122)$ & $0.04(0.663)$ & $0.03(0.758)$ & $-0.05(0.611)$ & $0.30(<\mathbf{0 . 0 0 1})$ & $0.27(\mathbf{0 . 0 0 3 )}$ & $0.13(0.189)$ & $0.23(\mathbf{0 . 0 1 1})$ \\
\hline $\mathrm{WC}(\mathrm{cm})$ & $0.20(\mathbf{0 . 0 3 1 )}$ & $0.26(\mathbf{0 . 0 0 4})$ & $0.22(\mathbf{0 . 0 2 3})$ & $0.09(0.354)$ & $0.40(<\mathbf{0 . 0 0 1})$ & $0.41(<\mathbf{0 . 0 0 1})$ & $0.23(\mathbf{0 . 0 1 4 )}$ & $0.39(<\mathbf{0 . 0 0 1})$ \\
\hline FPG (mmol/L) & $0.09(0.292)$ & $-0.14(0.142)$ & $0.09(0.314)$ & $0.04(0.660)$ & $-0.01(0.941)$ & $0.04(0.672)$ & $0.13(0.189)$ & $0.14(0.118)$ \\
\hline TG (mg/dL) & $0.35(<\mathbf{0 . 0 0 1 )}$ & $0.02(0.813)$ & $0.09(0.366)$ & $-0.07(0.467)$ & $0.18(\mathbf{0 . 0 4 6 )}$ & $0.05(0.623)$ & $0.03(0.774)$ & $0.08(0.375)$ \\
\hline HDL-C (mg/dL) & $-0.18(\mathbf{0 . 0 4 8 )}$ & $-0.14(0.135)$ & $-0.02(0.868)$ & $-0.04(0.683)$ & $-0.08(0.365)$ & $-0.11(0.227)$ & $0.05(0.574)$ & $-0.12(0.177)$ \\
\hline $\mathrm{SBP}(\mathrm{mm} \mathrm{Hg})$ & $-0.09(0.308)$ & $-0.04(0.675)$ & $-0.002(0.984)$ & $-0.11(0.235)$ & $-0.11(0.221)$ & $-0.09(0.316)$ & $-0.11(0.243)$ & $0.03(0.711)$ \\
\hline DBP (mm Hg) & $-0.06(0.498)$ & $-0.05(0.571)$ & $-0.03(0.727)$ & $0.05(0.621)$ & $0.01(0.940)$ & $0.06(0.535)$ & $-0.07(0.456)$ & $0.10(0.277)$ \\
\hline $\log$ insulin $(\mu \mathrm{IU} / \mathrm{mL})$ & $0.10(0.271)$ & $0.02(0.868)$ & $0.09(0.367)$ & $0.07(0.464)$ & $0.05(0.560)$ & $0.19(\mathbf{0 . 0 3 6 )}$ & $0.35(<\mathbf{0 . 0 0 1})$ & $0.33(<\mathbf{0 . 0 0 1})$ \\
\hline
\end{tabular}


TABLE 3. Multiple Linear Regression with log IL-6 as Dependent Variable

\begin{tabular}{|c|c|c|c|c|c|}
\hline \multirow{2}{*}{ Variables } & \multirow[t]{2}{*}{$\boldsymbol{\beta}$} & \multirow[t]{2}{*}{ SE } & \multirow{2}{*}{$P$-value } & \multicolumn{2}{|c|}{ CI\% } \\
\hline & & & & $\begin{array}{l}\text { Lower } \\
\text { bound }\end{array}$ & $\begin{array}{l}\text { Upper } \\
\text { bound }\end{array}$ \\
\hline Ethnicity & 0.37 & 0.07 & $<0.001$ & 0.24 & 0.50 \\
\hline T2D status & 0.07 & 0.10 & 0.518 & -0.14 & 0.27 \\
\hline MetS & -0.03 & 0.07 & 0.727 & -0.17 & 0.12 \\
\hline
\end{tabular}


TABLE 4. Multiple Linear Regression with log CRP as Dependent Variable

\begin{tabular}{|c|c|c|c|c|c|}
\hline \multirow[t]{2}{*}{ Variables } & \multirow[t]{2}{*}{$\boldsymbol{\beta}$} & \multirow[t]{2}{*}{ SE } & \multirow[t]{2}{*}{$P$-value } & \multicolumn{2}{|c|}{ CI\% } \\
\hline & & & & $\begin{array}{l}\text { Lower } \\
\text { bound }\end{array}$ & $\begin{array}{l}\text { Upper } \\
\text { bound }\end{array}$ \\
\hline Ethnicity & 0.47 & 0.12 & $<0.001$ & 0.24 & 0.71 \\
\hline T2D status & 0.09 & 0.19 & 0.651 & -0.29 & 0.46 \\
\hline MetS & 0.34 & 0.14 & 0.012 & 0.07 & 0.60 \\
\hline
\end{tabular}




\section{CHAPTER IV: SERUM CHEMERIN AND OMENTIN IN HAITIAN AND}

\section{AFRICAN AMERICANS WITH AND WITHOUT TYPE 2 DIABETES}

\section{ABSTRACT}

Background: Recently, chemerin and omentin have been identified as novel adipocytokines that are associated with obesity, insulin action and the development of type 2 diabetes (T2D). The circulating levels of chemerin and omentin and their association with T2D among non-Hispanic Black ethnic subgroups have not been studied. This study was conducted to determine whether the levels of chemerin and omentin are altered by ethnicity and diabetes status. Methods: The study included 429 participants, 225 without T2D and 204 with T2D (214 Haitian Americans and 215 African Americans). African Americans were recruited through mailing lists and Haitian Americans through multiple community sources. After informed consent, information on socio-demographic variables and clinical data were obtained. Serum levels of chemerin and omentin were measured by ELISA and the homeostasis model assessment version 2 was used to estimate insulin sensitivity (HOMA2-IS).

Results: Haitian Americans with T2D had significantly lower serum chemerin levels (P $<0.001)$ and significantly higher serum omentin levels $(\mathrm{P}=0.023)$ compared to African Americans with T2D. Diabetes status was negatively associated with chemerin $(B=-$ 41.35, $\mathrm{SE}=18.28, \mathrm{P}=0.024)$, but not significantly associated with omentin $(\mathrm{B}=-85.02$, $\mathrm{SE}=56.86, \mathrm{P}=0.136)$ in the separate models, after adjusting for covariates. HOMA2-IS was inversely associated with chemerin $(B=-0.229, \mathrm{SE}=0.11, \mathrm{P}=0.030)$, but not with omentin $(\mathrm{B}=0.11, \mathrm{SE}=0.33, \mathrm{P}=0.745)$. Conclusion: Haitian Americans with $\mathrm{T} 2 \mathrm{D}$ had lower chemerin and higher omentin levels compared to African Americans with T2D. 
The lower percentage of obesity in Haitian Americans may explain the lower chemerin and higher omentin. The unexpected inverse association of chemerin with diabetes status may have been due to the residual confounding effects of medications used mainly by participants with T2D. The relationship between chemerin and omentin in T2D should be further investigated in prospective studies and drug-naïve individuals.

\section{INTRODUCTION}

Type 2 diabetes (T2D) is a heterogeneous metabolic disorder characterized by impaired insulin sensitivity and/or action and a resulting chronic hyperglycemia. ${ }^{1-3}$ Worldwide, T2D has become a public health concern. In the United States (US) alone, about 29 million are diagnosed with the disease, accounting for 245 billion dollars in annual healthcare costs. ${ }^{4-5}$ Moreover, important ethnic disparities in T2D prevalence and outcomes have been reported..$^{6-7}$ While the rate of T2D has increased across all ethnic groups, non-Hispanic Blacks have had almost a doubling of prevalence of diagnosed diabetes since $1988 .^{8}$ According to the 2014 National Diabetes Statistics Report, the prevalence of T2D was 13.2\% among non-Hispanic Blacks in 2012; 1.1 times and 1.7 times higher than in Hispanics and non-Hispanic Whites, respectively. ${ }^{4}$ Thus, nowadays the focus on the effort to reduce the prevalence of T2D should be to conduct studies with respect to ethnic differences, particularly within the non-Hispanic Black population. ${ }^{9-10}$ It is suggested that a higher susceptibility to inflammation may account for the increased prevalence of T2D among non-Hispanic Blacks. ${ }^{11-12}$

Type 2 diabetes is considered a state of chronic low-grade inflammation, and that inflammation is suggested to initiate and contribute to the progression of T2D. ${ }^{12-14}$ It is 
well recognized that obesity and insulin resistance are prominent factors associated with the chronic low-grade inflammation and ultimately the development of T2D. ${ }^{12-15}$ The altered secretion of adipose-derived peptides (adipocytokines) have considerable influence on glucose metabolism in the main target tissues (adipose tissue, muscle and liver) of insulin. ${ }^{15-18}$ Chemerin is a recently discovered pro-inflammatory adipocytokine that have been shown to inhibit insulin signaling through the activation of key inflammatory modulators such as the nuclear factor- $\mathrm{B}$ signaling pathways. ${ }^{15-19}$ The consequences of these processes are perpetuation of inflammation and decreased insulin sensitivity. Chemerin is secreted as an inactive prochemerin and cleaved through serine protease activity to the active chemerin. ${ }^{20}$ Chemerin levels are increased in obese individuals and states of impaired insulin sensitivity, insulin resistance and metabolic syndrome. ${ }^{20-21}$ Thus, the role of chemerin in these processes, may explain the relationship between obesity, insulin action and T2D. Another candidate, omentin, a newly identified adipocytokine is involved in glucose and lipid metabolism. ${ }^{22-23}$ Omentin is a novel adipocytokine with insulin-sensitizing effects similar to adiponectin. ${ }^{23}$ Obesity, decreases visceral adipose tissue expression of the anti-inflammatory adipocytokine omentin. ${ }^{24}$ In several studies, omentin was shown to be significantly decreased in obese individuals and those with T2D. ${ }^{24-25}$

Previous studies on adipocytokines and obesity-related disorders have been focused on TNF- $\alpha$, leptin, resistin and adiponectin. ${ }^{26-27}$ Moreover, studies involving chemerin and omentin have been conducted mostly among non-Hispanic Whites and other Hispanic ethnic subgroups. ${ }^{20,28-29}$ To our knowledge, to date no studies have assessed the novel adipocytokines, chemerin and omentin among non-Hispanic Black 
subgroups. Considering the burden of disease among non-Hispanic Blacks with regards to T2D, it is worth understanding the levels of chemerin and omentin and identify other factors associated with T2D in this population. The purpose of this study was to determine whether the levels of chemerin and omentin differ by ethnicity and diabetes status and we also investigated the relationship of diabetes status with chemerin and omentin.

\section{STUDY SUBJECTS AND DESIGN}

This study was an ancillary study which generated data on adipocytokines from stored blood samples of the parent study that compared cardiovascular risk factors in non-Hispanic Blacks with and without T2D. The objective of this cross-sectional study was to determine the levels of chemerin and omentin in Haitian Americans and African Americans with and without T2D and to investigate their relationship to diabetes status. Between the period of 2008-2010, study subjects were recruited in South Florida, from the Miami- Dade and Broward Counties. African American participants were recruited randomly from two mailing lists provided by Knowledge Base Marketing, Inc.,

Richardson, TX, USA. The company generated the list of addresses from several databases of African Americans with and without T2D. Approximately 7550 letters were mailed to African Americans to request their participation. From the letters that were delivered, $4 \%(n=256)$ of the participants responded. Recruitment of Haitian Americans $(\mathrm{n}=259)$ was from multiple community based sources since a similar database of mailing addresses was unavailable for this group. The recruitment strategies included: i) placement of print advertisements in local Haitian supermarkets, churches, and restaurants ii) distribution of flyers to Florida International University (FIU) community 
iii) request to local diabetes educators and community health professionals and iv) airing of announcements on Creole radio stations. Telephone interviews were conducted for respondents who expressed interest in the study. During the phone calls, the purpose of the study was fully explained and final eligibility was assessed (i.e., age $-\geq 35$ years, gender and self-identified ethnicity - African American and Haitian American). Additionally, T2D status was ascertained based on fasting plasma glucose and hemoglobin A1C, diabetes duration and initial treatment modalities. Respondents with the following conditions were excluded: kidney failure, hepatitis, HIV and cancer. The study protocol obtained ethical approval from the Institutional Review Board (IRB) at FIU. Eligible respondents were invited for an enrollment visit at the Human Nutrition Laboratory at FIU. Participants were instructed to complete an overnight fast (at least 8 hours) prior to blood collection, during which they could drink only water, refrain from smoking and any unusual exercise. Informed consent in English or Creole with IRB ethical clearance was obtained from participants after they understood and agreed to the terms on the form. Eight Haitian Americans and 4 African Americans who self-reported as having no T2D, yet whose laboratory results showed high values of fasting plasma glucose (FPG) and glycated hemoglobin (A1C) for diabetes were reclassified as having diabetes and referred to their physicians. Participants $(n=87)$ with missing values and outliers for chemerin, omentin and HOMA2-IS were excluded. Data was available for 429 participants, 225 without T2D and 204 with T2D (214 Haitian and 215 African Americans) for final statistical analysis. 


\section{METHODS}

Study participants responded to a validated self-reported questionnaire. Trained interviewers administered in depth standardized questionnaires to participants to complete. Socio-demographic information comprised questions related to age, gender, smoking status, and medications used. Height and weight were measured using a SECA balance scale (Seca Corp, Columbia, MD). Body mass index (BMI) was calculated as weight in $\mathrm{kg}$ divided by height in $\mathrm{m}^{2}$.

\section{Clinical and laboratory assessments}

Following an 8-hour overnight fast, twenty milliliters of venous blood was collected in a Vaccutainer Serum Separator tube by a trained and certified phlebotomist using standard methods. Blood samples were centrifuged at 2500 RPM for half an hour after coagulation. The separated serum was aliquoted into 3 labeled plastic tubes. Two were designated for glucose determination and lipid panel analysis. The third aliquot was stored at $-70^{0} \mathrm{C}$ for subsequent analyses. Glucose levels were measured by hexokinase enzymatic methods (Laboratory Corporation of America, FL, USA). Hemoglobin A1C percentages were assayed in whole blood samples applying the Roche Tina Quant method (Laboratory Corporation of America, FL, USA). Fasting serum insulin levels were determined with enzyme-linked immunosorbent assay (ELISA) using commercially available kits (Millipore, St Charles, MS, USA).

Chemerin levels in serum were measured at the Human Nutrition Laboratory at FIU with ELISA using microtitration plates pre-coated with polyclonal anti-human chemerin antibody according to manufacturer's protocol (BioVendor LLC, Candler, NC, USA). Briefly, $100 \mu 1$ of standards, quality controls, dilution buffer (blank) and diluted 
samples $(100 \mathrm{x}-5 \mu 1$ sample plus $495 \mu 1$ dilution buffer) were pipetted in duplicates into wells on the microplate. After an hour of incubation at room temperature (shaking at 300 RPM) followed by washing, $100 \mu$ biotin labelled antibody solution was added and incubated with the bound chemerin for another hour. After a second washing step, $100 \mu \mathrm{l}$ streptavidin-HRP conjugate was added and incubated for half an hour at room temperature (shaking at $300 \mathrm{RPM}$ ). The last washing step was performed and the residual conjugate was allowed to react with the $100 \mu 1$ of substrate solution (tetramethylbenzidine). The reaction process was stopped by addition of $100 \mu \mathrm{l}$ of an acidic stop solution. The absorbance of the resulting product was measured at $450 \mathrm{~nm}$ with a spectrophotometer. A microplate reader capable of creating a standard curve plotted the mean absorbance values against the chemerin concentrations of standards. The software used the standard curve to determine the concentrations of the unknown diluted samples multiplied by the dilution factor to obtain the actual amount of serum chemerin. The sensitivity of the ELISA assay was $0.1 \mathrm{ng} / \mathrm{ml}$ and the range was $0.1-8 \mathrm{ng} / \mathrm{ml}(10-800$ $\mathrm{ng} / \mathrm{ml}$ with dilution factor). The intraassay and interassay coefficients of variation were both less than $10 \%$.

Serum omentin levels were determined in the Human Nutrition Laboratory at FIU using human omentin-1 detection kit (ELISA, BioVendor LLC, Candler, NC, USA) according to manufacturer's protocol. Serum samples were diluted and assayed using microplates pre-coated with polyclonal anti-human omentin-1 antibody. Briefly, $100 \mu 1$ of standards, quality controls, dilution buffer (blank) and diluted samples (40x $-6 \mu 1$ sample plus $234 \mu 1$ dilution buffer, or 60x further dilution for samples that exceeded $2560 \mathrm{ng} / \mathrm{ml}$ ) were pipetted in duplicates into wells on the microplate. After 2 hours of incubation at 
$37^{\circ} \mathrm{C}$ followed by washing, $100 \mu 1$ biotin labelled antibody solution was added and incubated with the bound omentin for half an hour. After a second washing step, $100 \mu 1$ streptavidin-HRP conjugate was added and incubated at $37^{\circ} \mathrm{C}$ for half an hour at room temperature. The last washing step was performed and the residual conjugate was allowed to react with the $100 \mu \mathrm{l}$ of substrate solution (tetramethylbenzidine). The reaction process was stopped by addition of $100 \mu 1$ of an acidic stop solution. The absorbance of the resulting product was measured at $450 \mathrm{~nm}$ with a spectrophotometer. A microplate reader capable of creating a standard curve plotted the mean absorbance values against the omentin concentrations of standards. The software used the standard curve to determine the concentrations of the unknown diluted samples multiplied by the dilution factor to obtain the actual amount of serum omentin. The intraassay and interassay coefficients of variation were both less than $10 \%$. The sensitivity of the ELISA assay was $0.5 \mathrm{ng} / \mathrm{ml}$ and the range was $0.5-64 \mathrm{ng} / \mathrm{ml}(80-2560 \mathrm{ng} / \mathrm{ml}$ with dilution factor).

\section{Calculation of insulin sensitivity (HOMA2-IS)}

The Oxford University HOMA2 calculator was used to calculate insulin sensitivity index as previously described. ${ }^{30}$ The model determines insulin sensitivity index (HOMA2-IS) from paired fasting plasma glucose and radioimmunoassay insulin across a range of 1-2,200 pmol/1 for insulin, and 1-25 mmol/1 for glucose.

\section{Data Analysis}

Statistical analyses were conducted with SPSS version 21 (IBM Corporation, Chicago, IL, USA). The Kolmogorov-Smirnov test was used to assess the normality of

the distribution of the data. A Student's t-test was used for continuous variables and $\chi^{2}$ 
tests for categorical variables to compare participants by ethnicity and diabetes status. The analysis of variance (ANOVA) was used to compare serum levels of chemerin and omentin according to BMI categories (normal weight: $\mathrm{BMI}<25 \mathrm{~kg} / \mathrm{m}^{2}$, overweight: BMI $25 \mathrm{~kg} / \mathrm{m}^{2}-<30 \mathrm{~kg} / \mathrm{m}^{2}$ and obese: BMI $\geq 30 \mathrm{~kg} / \mathrm{m}^{2}$ ), followed by Tukey’s post hoc tests. The relationships between variables were analyzed by multiple linear regression controlling for the covariates including age, gender, BMI, ethnicity (Haitian Americans/African Americans), smoke (yes/no), lipid lowering drugs (yes/no), nonsteroidal anti-inflammatory drugs $\{$ NSAIDs $\}$ (yes/no), oral hypoglycemic medications (yes/no) and HOMA2-IS. The serum concentrations of chemerin and omentin were used as dependent variables in separate models. A P-value of $<0.05$ was considered to be statistically significant.

\section{RESULTS}

Tables 1 and 2 show for the characteristics of the participants included in this study according to diabetes status and diabetes status by ethnicity.

The mean age of participants with T2D was 56.0 \pm 10.2 years and those without T2D was 52.1 \pm 9.7 years (Table 1). The percentages for the three BMI categories were significantly different between participants with T2D as compared to participants without T2D. The use of medications (lipid lowering drugs and NSAIDs) in participants with T2D were highly significant than in participants without T2D $(P<0.001)$. Fasting plasma glucose and A1C in participants with T2D were significantly higher $(P<0.001)$ than in participants without T2D. Moreover, fasting insulin levels and HOMA2-IS were not significantly different between participants with and without T2D. Serum chemerin and 
omentin levels were not significantly different in participants with T2D as compared to participants without T2D. There was no significant difference by gender between participants with T2D as compared to participants without T2D. The percentage of smokers in participants with T2D was comparable to that of participants without T2D.

Table 2 shows that in the group with diabetes, Haitian Americans with T2D were significantly older $(\mathrm{P}=0.009)$, had lower $\mathrm{BMI}(\mathrm{P}<0.001)$, lower percentage of smokers ( $\mathrm{P}<0.001)$, higher intake of oral hypoglycemic medications $(\mathrm{P}=0.002)$, higher $\mathrm{A} 1 \mathrm{C}$ $(\mathrm{P}<0.009)$, higher HOMA2-IS $(\mathrm{P}<0.001)$, lower chemerin levels $(\mathrm{P}<0.001)$ and higher omentin levels $(\mathrm{P}=0.023)$ than did African Americans with T2D. There were significant differences also in age, BMI, FPG, A1C, insulin levels, HOMA2-IS and medication use by diabetes status and ethnicity. African Americans without T2D were significantly younger $(P=0.013)$, had higher insulin levels $(P=0.006)$ and higher percentage of smokers $(P<0.001)$. Haitian Americans without T2D had significantly higher mean FPG $(105.1 \pm 29.0)$ and $\mathrm{A} 1 \mathrm{C}(6.2 \pm 0.9)$. Serum chemerin levels were significantly lower in Haitian Americans without T2D $(P<0.001)$, whereas omentin levels were slightly higher in African Americans without T2D, however not significantly. There was no significant differences in BMI and HOMA2-IS between Haitian and African Americans without T2D. Moreover, African Americans without T2D had higher, but not significantly intake of lipid medications and NSAIDs compared to Haitian Americans without T2D.

We further used ANOVA to analyze the difference in means of serum chemerin and omentin levels among participants with and without T2D by BMI categories; the data was classified as normal weight: BMI $<25 \mathrm{~kg} / \mathrm{m}^{2}$, overweight: BMI $25 \mathrm{~kg} / \mathrm{m}^{2}-<30 \mathrm{~kg} / \mathrm{m}^{2}$ and obese: BMI $\geq 30 \mathrm{~kg} / \mathrm{m}^{2}$ (Table 3). Among participants with T2D, those with normal 
weight had significantly lower chemerin and higher omentin levels compared with those who were obese. There was no significant difference in chemerin and omentin levels between normal and overweight and overweight and obese individuals. Among participants without T2D, there was no significant difference in mean serum chemerin and omentin levels with BMI categories.

Tables 4 and 5 show the multiple linear regressions run with chemerin and omentin as dependent variables in separate models. Diabetes status was negatively associated with chemerin $(\mathrm{B}=-41.35, \mathrm{SE}=18.28, \mathrm{P}=0.024)$, but not associated with omentin levels $(\mathrm{B}=-85.02, \mathrm{SE}=56.86, \mathrm{P}=0.136)$. African American $(\mathrm{B}=38.48, \mathrm{SE}=$ 11.59, $\mathrm{P}=0.001)$, having a lower HOMA2-IS $(\mathrm{B}=-0.23, \mathrm{SE}=0.11, \mathrm{P}=0.030)$, being older $(\mathrm{B}=1.37, \mathrm{SE}=0.51, \mathrm{P}=0.008)$ and being female $(\mathrm{B}=-21.14, \mathrm{SE}=10.15, \mathrm{P}=$ 0.038 ) were associated with chemerin. Omentin levels were negatively associated with $\mathrm{BMI}(\mathrm{B}=-6.64, \mathrm{SE}=2.66, \mathrm{P}=0.013)$ and positively associated with age $(\mathrm{B}=6.69, \mathrm{SE}=$ $1.59, \mathrm{P}<0.001)$. A test of the interaction effect between ethnicity and diabetes status showed that the interaction term was not significant.

\section{DISCUSSION}

To date, no studies have characterized the novel adipocytokines, chemerin and omentin, among non-Hispanic Black subgroups, a high-risk population for the development of type 2 diabetes (T2D). Thus, in this study, we determined the levels of serum chemerin and omentin in Haitian Americans and African Americans with and without $\mathrm{T} 2 \mathrm{D}$ and assessed their relationship with $\mathrm{T} 2 \mathrm{D}$, controlling for important covariates. The results of the present study surprisingly revealed a significant negative 
association between diabetes status and chemerin. Nonsignificant negative association was found with omentin and diabetes status. Chemerin is an adipose-tissue derived adipocytokine that has been shown to be elevated in states of obesity-related disorders such as T2D. ${ }^{19,31-32}$ Recently, chemerin was identified as a pro-inflammatory adipocytokine that plays a role in inflammation and metabolism. ${ }^{33-34}$ It is therefore suggested that chemerin may provide a link between chronic low-grade inflammation and T2D. Our findings on chemerin are in contrast to that of El-Mesallamy et al. ${ }^{35}$ who reported that chemerin levels were significantly increased in participants with T2D compared to participants without T2D. However, our findings are in line with that of Bozaoglu et al. ${ }^{19}$ which failed to show a significant difference in chemerin levels in adults with compared to without T2D. The non-significant difference in chemerin levels between participants with and without T2D and the greater effect of association for participants without T2D than participants with T2D may be due to the fact that a higher proportion of the participants with $\mathrm{T} 2 \mathrm{D}$ were on diabetes medications. The medications for diabetes have been reported to significantly decrease chemerin levels in diabetic patients. For example in a study among women with polycystic ovarian syndrome, metformin, an oral hypoglycemic agent, was shown to decrease circulating chemerin levels with a simultaneous decrease in insulin resistance. ${ }^{36}$

Omentin is a novel polypeptide hormone which triggers Akt/protein kinase B phosphorylation and insulin stimulated glucose uptake in human adipocytes in vitro. ${ }^{23}$ Omentin is considered an anti-inflammatory modulator and may have a protective role in T2D. ${ }^{37}$ Although our findings demonstrated that participants without T2D had higher omentin levels, this association was not significant and might be that a lowering of 
chemerin levels by diabetes medications caused a reciprocal increase in omentin levels in participants with T2D. However, the levels may not have been pronounced to detect a significant difference. However, previous studies showed that omentin levels were increased in healthy individuals compared with adults with T2D and found a significant negative association. ${ }^{35,37-38}$ The roles of omentin and chemerin in regulating metabolic function still need to be fully elucidated in future investigations among drug-free subjects to exclude any residual confounding effects of medications.

Chemerin levels are positively associated with obesity, but negatively associated with insulin sensitivity. ${ }^{31,34,39}$ Chemerin is secreted by mature adipocytes within adipose tissue. ${ }^{19}$ Obesity leads to hypertrophy of adipocytes which in turn increases chemerin secretion and contributes to inflammation. Previous studies have shown that chemerin may regulate insulin signaling and glucose metabolism. ${ }^{40-41}$ In vitro studies in 3T3-L1 adipocytes revealed that chemerin impaired insulin sensitivity and induced insulin resistance in muscle cells. ${ }^{41}$ Impaired insulin sensitivity is a major risk factor for the development of T2D. In addition, administration of chemerin to obese diabetic mice resulted in decreased tissue glucose uptake and worsened glucose intolerance. ${ }^{32}$ In accordance, serum chemerin levels were positively associated with BMI, although a nonsignificant one which might be due to the effect of medications on chemerin levels as already discussed above, since most of the obese individuals in our sample also had T2D. Other earlier studies also reported no significant association between serum chemerin and BMI. ${ }^{34}$ Additionally, in the present study, chemerin was negatively associated with insulin sensitivity, a finding in line with the studies by Kim et al. ${ }^{31}$ that showed a negative association between chemerin and insulin sensitivity in adults with T2D. Other studies 
have demonstrated conflicting results, with the study by Takahashi et al. ${ }^{41}$ reporting that increased levels of chemerin stimulated insulin sensitivity. Thus, these conflicting findings warrants a need to clarify the mechanisms by which chemerin regulates glucose homeostasis. ${ }^{31,41}$ Omentin was negatively associated with BMI and positively associated with insulin sensitivity in the present study. Omentin is secreted by the visceral adipose tissue and is decreased in obese patients, while it is involved in improving insulin sensitivity. ${ }^{23}$ Recently, in a study conducted by El-Mesallamy ${ }^{35}$ in Egyptian adults comparing omentin levels between those with T2D and healthy controls, omentin levels were negatively associated with obesity. Similarly, Tan et al. ${ }^{42}$ found a negative correlation between BMI and omentin levels. However, the nonsignificant differences for chemerin and omentin levels found between normal weight, overweight or obese in participants without T2D and between overweight and obese individuals in participants with T2D might be due to the smaller sample sizes for the normal weight and overweight group. It is possible that the significant differences in chemerin and omentin levels found between normal weight and obese patients among participants with T2D may have occurred by chance.

We have also demonstrated that Haitian Americans with T2D had significantly lower levels of chemerin and significantly higher levels of omentin compared with African Americans with T2D. This could be due to the lower BMI and higher insulin sensitivity observed in Haitian Americans compared to a higher BMI and impaired insulin sensitivity in African Americans. A lower BMI has been associated with increased insulin sensitivity which results in lowered insulin resistance. ${ }^{31}$ Haitian Americans without T2D compared to African Americans without T2D, had significantly 
lower levels of chemerin and surprisingly, slightly lower, but nonsignificant levels of omentin. Also in regression analysis, chemerin was associated with African American ethnicity which is expected. It is not surprising that the association of Haitian American ethnicity with omentin was not significant, which may have been due to low levels of omentin found among Haitian Americans. An explanation may be the higher percentage of lipid lowering drugs and NSAIDs use by African Americans which decreased possibility of significant differences being observed. An alternative explanation may be due to differences in particular metabolic characteristics between Haitian Americans and African Americans. The influence of certain unique characteristics such as acculturation, genetics and other environmental factors cannot be ruled out. The lack of existing data on the two ethnicities with regards to chemerin and omentin make it difficult to compare and contrast our findings with the literature and draw substantial conclusions. It is necessary for additional studies to be conducted in order to make further conclusions.

The limitation of this study is the cross-sectional nature which did not allow causality to be considered. In addition, the study population is a semi-convenience sample and not recruited by randomized selection. Moreover, genetic and acculturation factors may be possible influential variables on chemerin and omentin that were not considered. As such, the sample may not be representative of Haitian Americans and African Americans and generalizability to the general population may be limited. The serum chemerin levels measured are a reflection of the total level since the ELISA did not allow for the chemerin variants to be distinguished. Despite the limitations, this study has for the first time assessed novel adipocytokines, chemerin and omentin in two distinct non-Hispanic subgroups, which allows important ethnic differences in metabolic 
processes to be revealed. These results provide new opportunities for designing ethnic centered preventive strategies and targets for the treatment of T2D, particularly in nonHispanics who are at high risk for T2D and its related complications. The serum levels of chemerin and omentin in this study are similar to those found in other studies using the same ELISA kit or studies conducted in participants with and without T2D and other disorders. $^{35,43-44}$

\section{CONCLUSION}

In conclusion, Haitian Americans with T2D had lower chemerin and higher omentin levels compared to African Americans with T2D. These findings support the need to conduct studies of metabolic disorders based on ethnicity, particularly for nonHispanic Blacks who are highly susceptible to T2D and its associated outcomes. Moreover, important factors such as acculturation, genetics and other environmental factors may be unique to each ethnic subgroup and influence disease risk factors and progression of T2D. The relationship of chemerin and omentin with T2D should be further investigated in prospective studies. 


\section{REFERENCES:}

1. Vital P, Larrieta E, Hiriart M. Sexual dimorphism in insulin sensitivity and susceptibility to develop diabetes in rats. J Endocrinol. 2006;190(2):425-432.

2. Wolfs MG, Hofker MH, Wijmenga C, van Haeften TW. Type 2 Diabetes Mellitus: New Genetic Insights will Lead to New Therapeutics. Curr Genomics. 2009;10(2):110-118.

3. Genuth S, Alberti KG, Bennett P, Buse J, Defronzo R, Kahn R, Kitzmiller J, Knowler WC, Lebovitz H, Lernmark A, Nathan D, Palmer J, Rizza R, Saudek C, Shaw J, Steffes M, Stern M, Tuomilehto J, Zimmet P; Expert Committee on the Diagnosis and Classification of Diabetes Mellitus. Follow-up report on the diagnosis of diabetes mellitus. Diabetes Care. 2003;26(11):3160-3167.

4. American Diabetes Association. National Diabetes Statistics Report, 2014. Statistics About Diabetes. Available at: http://www.diabetes.org/diabetesbasics/statistics/. Accessed on August 04, 2014.

5. World Health Organization. Diabetes 2013. Fact Sheet \#312. Available at: http://www.who.int/mediacentre/factsheets/fs312/en/. Accessed on August 04, 2014.

6. Centers for Disease Control and Prevention. Diabetes Public Health Resource 2010. Available at: http://www.cdc.gov/diabetes/consumer/groups.htm. Accessed on August 04, 2014.

7. Lanting LC, Joung IM, Mackenbach JP, Lamberts SW, Bootsma AH. Ethnic differences in mortality, end-stage complications, and quality of care among diabetic patients: a review. Diabetes Care. 2005;28(9):2280-2288.

8. Centers for Disease Control and Prevention. National diabetes fact sheet: national estimates and general information on diabetes and prediabetes in the United States, 2011. Atlanta, GA: U.S. Department of Health and Human Services, Centers for Disease Control and Prevention, 2011. Available at: http://www.cdc.gov/diabetes/pubs/pdf/ndfs_2011.pdf. Accessed on August 07, 2014.

9. Centers for Disease Control and Prevention. Diabetes Successes and Opportunities for Population-Based Prevention and Control At A Glance 2011. Available at: 
http://www.cdc.gov/chronicdisease/resources/publications/aag/ddt.htm. Accessed on August 07, 2014.

10. Peek ME, Cargill A, Huang ES. Diabetes health disparities: a systematic review of health care interventions. Med Care Res Rev. 2007;64(5 Suppl):101S-156S.

11. Paalani M, Lee JW, Haddad E, Tonstad S. Determinants of inflammatory markers in a bi-ethnic population. Ethn Dis. 2011;21(2):142-149.

12. Duncan BB, Schmidt MI, Pankow JS, Ballantyne CM, Couper D, Vigo A, Hoogeveen R, Folsom AR, Heiss G; Atherosclerosis Risk in Communities Study. Low-grade systemic inflammation and the development of type 2 diabetes: the atherosclerosis risk in communities study. Diabetes. 2003;52(7):1799-1805.

13. Wellen KE, Hotamisligil GS. Inflammation, stress, and diabetes. J Clin Invest. 2005;115(5):1111-1119.

14. Bertoni AG, Burke GL, Owusu JA, Carnethon MR, Vaidya D, Barr RG, Jenny NS, Ouyang P, Rotter JI. Inflammation and the incidence of type 2 diabetes: the Multi-Ethnic Study of Atherosclerosis (MESA). Diabetes Care. 2010;33(4):804810.

15. Zeyda M, Stulnig TM. Obesity, inflammation, and insulin resistance-a minireview. Gerontology. 2009;55(4):379-386.

16. Yang M, Yang G, Dong J, Liu Y, Zong H, Liu H, Boden G, Li L. Elevated plasma levels of chemerin in newly diagnosed type 2 diabetes mellitus with hypertension. J Investig Med. 2010;58(7):883-886.

17. Trayhurn P, Beattie JH. Physiological role of adipose tissue: white adipose tissue as an endocrine and secretory organ. Proc Nutr Soc. 2001;60(3):329-339.

18. Taniguchi CM, Emanuelli B, Kahn CR. Critical nodes in signalling pathways: insights into insulin action. Nat Rev Mol Cell Biol. 2006;7(2):85-96.

19. Bozaoglu K, Bolton K, McMillan J, Zimmet P, Jowett J, Collier G, Walder K, Segal D. Chemerin is a novel adipokine associated with obesity and metabolic syndrome. Endocrinology. 2007;148(10):4687-4694.

20. Stejskal D, Karpisek M, Hanulova Z, Svestak M. Chemerin is an independent marker of the metabolic syndrome in a Caucasian population--a pilot study. 
Biomed Pap Med Fac Univ Palacky Olomouc Czech Repub. 2008;152(2):217221.

21. Chu SH, Lee MK, Ahn KY, Im JA, Park MS, Lee DC, Jeon JY, Lee JW. Chemerin and adiponectin contribute reciprocally to metabolic syndrome. PLoS One. 2012;7(4):e34710.

22. de Souza Batista CM, Yang RZ, Lee MJ, Glynn NM, Yu DZ, Pray J, Ndubuizu K, Patil S, Schwartz A, Kligman M, Fried SK, Gong DW, Shuldiner AR, Pollin TI, McLenithan JC. Omentin plasma levels and gene expression are decreased in obesity. Diabetes. 2007;56(6):1655-1661.

23. Yang RZ, Lee MJ, Hu H, Pray J, Wu HB, Hansen BC, Shuldiner AR, Fried SK, McLenithan JC, Gong DW. Identification of omentin as a novel depot-specific adipokine in human adipose tissue: possible role in modulating insulin action. Am J Physiol Endocrinol Metab. 2006;290(6):E1253-E1261.

24. Shibata R, Ouchi N, Takahashi R, Terakura Y, Ohashi K, Ikeda N, Higuchi A, Terasaki H, Kihara S, Murohara T. Omentin as a novel biomarker of metabolic risk factors. Diabetol Metab Syndr. 2012;4(1):37-41.

25. Pan HY, Guo L, Li Q. Changes of serum omentin-1 levels in normal subjects and in patients with impaired glucose regulation and with newly diagnosed and untreated type 2 diabetes. Diabetes Res Clin Pract. 2010;88(1):29-33.

26. Dyck DJ, Heigenhauser GJ, Bruce CR. The role of adipokines as regulators of skeletal muscle fatty acid metabolism and insulin sensitivity. Acta Physiol (Oxf). 2006;186(1):5-16.

27. Scherer PE. Adipose tissue: from lipid storage compartment to endocrine organ. Diabetes. 2006;55(6):1537-1545.

28. Moreno-Navarrete JM, Catalán V, Ortega F, Gómez-Ambrosi J, Ricart W, Frühbeck G, Fernández-Real JM. Circulating omentin concentration increases after weight loss. Nutr Metab (Lond). 2010;7(1):27-33.

29. Bozaoglu K, Segal D, Shields KA, Cummings N, Curran JE, Comuzzie AG, Mahaney MC, Rainwater DL, VandeBerg JL, MacCluer JW, Collier G, Blangero $\mathrm{J}$, Walder K, Jowett JB. Chemerin is associated with metabolic syndrome phenotypes in a Mexican-American population. J Clin Endocrinol Metab. 2009;94(8):3085-3088. 
30. Wallace TM, Levy JC, Matthews DR. Use and abuse of HOMA modeling. Diabetes Care. 2004;27(6):1487-1495.

31. Kim SH, Lee SH, Ahn KY, Lee DH, Suh YJ, Cho SG, Choi YJ, Lee DH, Lee SY, Hong SB, Kim YS, Jeon JY, Nam M. Effect of lifestyle modification on serum chemerin concentration and its association with insulin sensitivity in overweight and obese adults with type 2 diabetes. Clin Endocrinol (Oxf). 2014;80(6):825833.

32. Ernst MC, Issa M, Goralski KB, Sinal CJ. Chemerin exacerbates glucose intolerance in mouse models of obesity and diabetes. Endocrinology. 2010;151(5):1998-2007.

33. Ernst MC, Sinal CJ. Chemerin: at the crossroads of inflammation and obesity. Trends Endocrinol Metab. 2010;21(11):660-667.

34. Weigert J, Neumeier M, Wanninger J, Filarsky M, Bauer S, Wiest R, Farkas S, Scherer MN, Schäffler A, Aslanidis C, Schölmerich J, Buechler C. Systemic chemerin is related to inflammation rather than obesity in type 2 diabetes. Clin Endocrinol (Oxf). 2010;72(3):342-348.

35. El-Mesallamy HO, El-Derany MO, Hamdy NM. Serum omentin-1 and chemerin levels are interrelated in patients with Type 2 diabetes mellitus with or without ischaemic heart disease. Diabet Med. 2011;28(10):1194-1200.

36. Tan BK, Chen J, Farhatullah S, Adya R, Kaur J, Heutling D, Lewandowski KC, O'Hare JP, Lehnert H, Randeva HS. Insulin and metformin regulate circulating and adipose tissue chemerin. Diabetes. 2009;58(9):1971-1977.

37. Pan HY, Guo L, Li Q. Changes of serum omentin-1 levels in normal subjects and in patients with impaired glucose regulation and with newly diagnosed and untreated type 2 diabetes. Diabetes Res Clin Pract. 2010;88(1):29-33.

38. Yoo HJ, Hwang SY, Hong HC, Choi HY, Yang SJ, Seo JA, Kim SG, Kim NH, Choi KM, Choi DS, Baik SH. Association of circulating omentin-1 level with arterial stiffness and carotid plaque in type 2 diabetes. Cardiovasc Diabetol. 2011;10(1):103-111.

39. Kralisch S, Weise S, Sommer G, Lipfert J, Lossner U, Bluher M, Stumvoll M, Fasshauer M. Interleukin-1beta induces the novel adipokine chemerin in adipocytes in vitro. Regul Pept. 2009;154(1-3):102-106. 
40. Sell H, Laurencikiene J, Taube A, Eckardt K, Cramer A, Horrighs A, Arner P, Eckel J. Chemerin is a novel adipocyte-derived factor inducing insulin resistance in primary human skeletal muscle cells. Diabetes. 2009;58(12):2731-2740.

41. Takahashi M, Takahashi Y, Takahashi K, Zolotaryov FN, Hong KS, Kitazawa R, Iida K, Okimura Y, Kaji H, Kitazawa S, Kasuga M, Chihara K. Chemerin enhances insulin signaling and potentiates insulin-stimulated glucose uptake in 3T3-L1 adipocytes. FEBS Lett. 2008;582(5):573-578.

42. Tan BK, Pua S, Syed F, Lewandowski KC, O'Hare JP, Randeva HS. Decreased plasma omentin-1 levels in Type 1 diabetes mellitus. Diabet Med. 2008;25(10):1254-1255.

43. Canan F, Yildirim O, Tosun M, Kayka N, Tuman TC, Alcelik A. Serum levels of omentin are not altered in drug-naive patients with major depression: a pilot study. Psychiatr Danub. 2014;26(1):34-38.

44. Mona M. Osman, Abeer I. Abd El-mageed, Eman El-hadidi, Rania S. K. Shahin, and Nanees A. Adel A. Mageed. Clinical Utility of Serum Chemerin as a Novel Marker of Metabolic Syndrome and Type 2 Diabetes Mellitus. Life Sci J. 2012;9(2):1098-1108. 
TABLE 1. Characteristics of the Participants by Diabetes Status

\begin{tabular}{|c|c|c|c|c|}
\hline \multirow[b]{2}{*}{ Variables } & \multicolumn{2}{|c|}{ Diabetes status } & \multirow[b]{2}{*}{ P-value } & \multirow[b]{2}{*}{$\begin{array}{l}\text { Overall } \\
(n=429)\end{array}$} \\
\hline & $\begin{array}{c}\text { With } \\
\text { T2D } \\
(\mathrm{n}=\mathbf{2 0 4})\end{array}$ & $\begin{array}{c}\text { Without } \\
\text { T2D } \\
(\mathrm{n}=225)\end{array}$ & & \\
\hline Age (years) & $56.0 \pm 10.2$ & $52.1 \pm 9.7$ & $<0.001$ & $53.9 \pm 10.1$ \\
\hline Female n $(\%)$ & $110(53.9)$ & $114(50.7)$ & 0.500 & $224(52.2)$ \\
\hline Ethnicity & & & 0.593 & - \\
\hline HA n $(\%)$ & $99(48.5)$ & $115(51.1)$ & - & $214(49.9)$ \\
\hline $\mathrm{AA} n(\%)$ & $105(51.5)$ & $110(48.9)$ & - & $215(50.1)$ \\
\hline *BMI categories $\left(\mathrm{kg} / \mathrm{m}^{2}\right)$ & & & 0.009 & - \\
\hline Normal weight n $(\%)$ & $25(12.3)$ & $36(16.0)$ & - & $61(14.2)$ \\
\hline Overweight n $(\%)$ & $58(28.4)$ & $89(39.6)$ & - & $147(34.3)$ \\
\hline Obese n $(\%)$ & $121(59.2)$ & $100(44.4)$ & - & $221(51.5)$ \\
\hline Smoke n (\%) & $42(20.6)$ & $51(22.7)$ & 0.602 & $93(21.7)$ \\
\hline Lipid lowering drugs n (\%) & $85(41.7)$ & $24(10.7)$ & $<0.001$ & $109(25.4)$ \\
\hline NSAIDs n $(\%)$ & $84(41.2)$ & $55(24.4)$ & $<0.001$ & $139(32.4)$ \\
\hline Oral hypoglycemic meds n (\%) & $168(82.4)$ & - & - & $168(39.2)$ \\
\hline $\mathrm{A} 1 \mathrm{C}(\%)$ & $8.1 \pm 2.3$ & $6.0 \pm 0.8$ & $<0.001$ & $7.0 \pm 1.9$ \\
\hline FPG (mmol/L) & $150.9 \pm 65.1$ & $101.0 \pm 23.9$ & $<0.001$ & $124.8 \pm 54.2$ \\
\hline Insulin $(\mu \mathrm{IU} / \mathrm{mL})$ & $11.8 \pm 9.2$ & $11.4 \pm 8.2$ & 0.666 & $11.6 \pm 8.7$ \\
\hline HOMA2-IS & $86.9 \pm 50.1$ & $93.6 \pm 51.9$ & 0.181 & $90.5 \pm 51.1$ \\
\hline Chemerin (ng/mL) & $334.3 \pm 103.2$ & $348.5 \pm 110.1$ & 0.170 & $341.7 \pm 107.0$ \\
\hline Omentin $(\mathrm{ng} / \mathrm{mL})$ & $723.1 \pm 327.4$ & $752.2 \pm 315.0$ & 0.349 & $738.3 \pm 320.9$ \\
\hline
\end{tabular}


TABLE 2. Characteristics of the Participants by Ethnicity and Diabetes Status

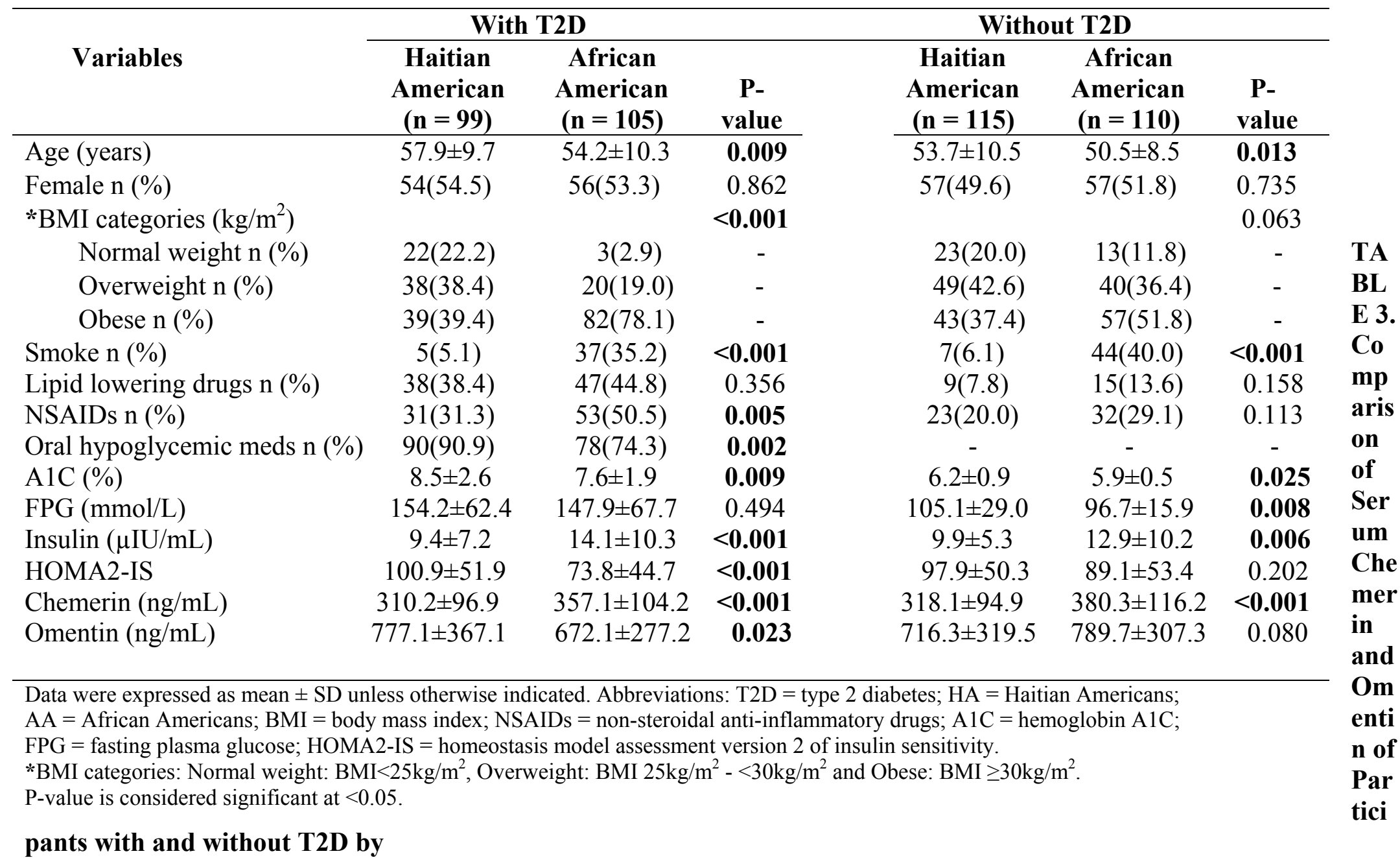




\section{BMI Categories}

\section{Participants with T2D}

\begin{tabular}{|c|c|c|c|c|}
\hline Variables & $\begin{array}{l}\text { Normal weight } \\
(\mathrm{n}=\mathbf{2 5})\end{array}$ & $\begin{array}{c}\text { Overweight } \\
(n=58)\end{array}$ & $\begin{array}{r}\text { Obese } \\
(\mathrm{n}=\mathbf{1 2 1}) \\
\end{array}$ & P-value \\
\hline BMI categories $\left(\mathrm{kg} / \mathrm{m}^{2}\right)$ & $<25$ & $25-<30$ & $\geq 30$ & - \\
\hline Chemerin (ng/mL) & $292.6 \pm 102.1^{\mathrm{a}}$ & $320.0 \pm 107.5^{\mathrm{ab}}$ & $349.8 \pm 98.7^{b}$ & 0.030 \\
\hline Omentin (ng/mL) & $913.1 \pm 467.7^{\mathrm{a}}$ & $742.7 \pm 306.1^{\mathrm{ab}}$ & $674.4 \pm 288.1^{\mathrm{b}}$ & 0.002 \\
\hline \multicolumn{5}{|c|}{ Participants without T2D } \\
\hline & $\begin{array}{c}\text { Normal weight } \\
(\mathrm{n}=36)\end{array}$ & $\begin{array}{l}\text { Overweight } \\
(n=89)\end{array}$ & $\begin{array}{r}\text { Obese } \\
(n=100) \\
\end{array}$ & P-value \\
\hline BMI categories $\left(\mathrm{kg} / \mathrm{m}^{2}\right)$ & $<25$ & $25-<30$ & $\geq 30$ & - \\
\hline Chemerin (ng/mL) & $336.7 \pm 105.4$ & $332.4 \pm 97.8$ & $367.2 \pm 119.9$ & NS \\
\hline Omentin $(\mathrm{ng} / \mathrm{mL})$ & $825.6 \pm 367.8$ & $764.1 \pm 303.1$ & $715.1 \pm 302.6$ & NS \\
\hline
\end{tabular}

Data are expressed as mean $\pm \mathrm{SD}$ unless otherwise indicated. P-value is considered significant at $<0.05$. Abbreviations: T2D $=$ type 2 diabetes; $\mathrm{BMI}=$ body mass index; NS = no significant differences between normal weight, overweight and obese or overweight and obese individuals. 
TABLE 4. Association between Chemerin and Diabetes Status - Multiple Linear Regression Analysis

\begin{tabular}{lccccc}
\hline \multicolumn{1}{c}{ Variables } & B & SE & $\boldsymbol{\beta}$ & $\mathbf{t}$ & P-value \\
\hline Diabetes status & -41.35 & 18.28 & -0.19 & -2.26 & $\mathbf{0 . 0 2 4}$ \\
Ethnicity & 38.48 & 11.59 & 0.18 & 3.32 & $\mathbf{0 . 0 0 1}$ \\
HOMA2-IS & -0.23 & 0.11 & -0.11 & -2.18 & $\mathbf{0 . 0 3 0}$ \\
BMI & 1.22 & 0.86 & 0.08 & 1.43 & 0.153 \\
Age & 1.37 & 0.51 & 0.13 & 2.68 & $\mathbf{0 . 0 0 8}$ \\
Gender & -21.14 & 10.15 & -0.09 & -2.08 & $\mathbf{0 . 0 3 8}$ \\
Smoke & 24.81 & 13.24 & 0.09 & 1.87 & 0.062 \\
Lipid lowering drugs & 15.56 & 12.89 & 0.06 & 1.21 & 0.228 \\
NSAIDs & 21.31 & 11.39 & 0.09 & 1.87 & 0.062 \\
Oral hypoglycemic meds & 9.39 & 19.06 & 0.04 & 0.49 & 0.622 \\
\hline
\end{tabular}

Adjusted $\mathrm{R}^{2}$ of model: $12.9 \%$ of independent contribution of diabetes status $(\mathrm{t}=-2.26, \mathrm{P}=0.024)$. Abbreviations: HOMA2-IS $=$

homeostasis model assessment version 2 of insulin sensitivity; BMI = body mass index; NSAIDs = non-steroidal anti-inflammatory drugs;

$\mathrm{B}=$ unstandardized coefficients; $\mathrm{SE}=$ standard error; $\beta=$ standardized coefficient. P-value is considered significant at $<0.05$. 
TABLE 5. Association between Omentin and Diabetes status - Multiple Linear Regression Analysis

\begin{tabular}{|c|c|c|c|c|c|}
\hline Variables & B & SE & $\boldsymbol{\beta}$ & $\mathbf{t}$ & P-value \\
\hline Diabetes status & -85.02 & 56.86 & -0.13 & -1.50 & 0.136 \\
\hline Ethnicity & 52.71 & 36.07 & 0.08 & 1.46 & 0.145 \\
\hline HOMA2-IS & 0.11 & 0.33 & 0.02 & 0.33 & 0.745 \\
\hline BMI & -6.64 & 2.66 & -0.14 & -2.49 & 0.013 \\
\hline Age & 6.69 & 1.59 & 0.21 & 4.19 & $<0.001$ \\
\hline Gender & 15.55 & 31.57 & 0.02 & 0.49 & 0.623 \\
\hline Smoke & -30.92 & 41.18 & -0.04 & -0.75 & 0.453 \\
\hline Lipid lowering drugs & 73.80 & 40.13 & 0.10 & 1.84 & 0.067 \\
\hline NSAIDs & 4.56 & 35.43 & 0.01 & 0.13 & 0.898 \\
\hline Oral hypoglycemic meds & 26.56 & 59.29 & 0.04 & 0.45 & 0.654 \\
\hline
\end{tabular}

Adjusted $\mathrm{R}^{2}$ of model: $6.3 \%$ of independent contribution of diabetes status $(\mathrm{t}=-1.50, \mathrm{P}=0.136)$. Abbreviations: HOMA2-IS $=$ homeostasis model assessment version 2 of insulin sensitivity; BMI = body mass index; NSAIDs = non-steroidal anti-inflammatory drugs; $\mathrm{B}=$ unstandardized coefficients; $\mathrm{SE}=$ standard error; $\beta=$ standardized coefficient. P-value is considered significant at $<0.05$. 


\section{CHAPTER V: ASSOCIATION OF LEPTIN WITH BMI AND INSULIN RESISTANCE \\ IN HAITIAN AND AFRICAN AMERICANS WITH AND WITHOUT TYPE 2 \\ DIABETES}

\section{ABSTRACT}

Background: Obesity has become a worldwide epidemic and non-Hispanic Blacks are disproportionately affected. Leptin is an adipose tissue derived peptide that is considered both structurally and functionally as a pro-inflammatory adipocytokine. Leptin has been associated with obesity, insulin resistance and type 2 diabetes (T2D). Ethnic differences in metabolic profile even within the same ethnicity may affect leptin levels and disease outcomes. The purpose of our study was to determine the variation in serum leptin levels in Haitian and African Africans and assess the association of leptin levels with body mass index (BMI) and insulin resistance. Methods: In 413 participants, 213 Haitian Americans and 200 African Americans (197 with T2D and 216 without T2D), fasting blood samples and clinical data were obtained, and socio-demographic data were collected using standardized questionnaires. Serum leptin levels and insulin resistance measures were analyzed by ELISA and HOMA-2-IR, respectively. Results: The serum log leptin levels in Haitian American males and females were significantly lower $(P<0.05)$ than those in African American males and females. Haitian Americans with T2D had significantly lower serum log leptin levels $(P=0.024)$ than did African Americans with T2D. Log leptin levels were significantly associated with BMI $(P<0.001)$ and HOMA2-IR $(P=0.015)$ in males without T2D, whereas in males with T2D and females with and without T2D, leptin was associated with only BMI $(P<0.001)$ as a primary independent variable. Conclusion: The lower leptin levels in Haitian Americans may be due to 
favorable metabolic profile including lower obesity and insulin resistance. The ethnic differences may also be attributable to genetic variation and differences in lifestyle, environmental and acculturation factors which may affect risk of disease. Future studies should focus on the association of these factors with leptin levels in the two ethnic subgroups. In addition, these findings may help identify individuals at risk for T2D across adiposity and make an important contribution in designing ethnic centered interventions to prevent T2D.

\section{INTRODUCTION}

Obesity, defined as body mass index (BMI) of $\geq 30 \mathrm{~kg} / \mathrm{m}^{2}$, has become a major health concern. ${ }^{1-3}$ Approximately, one-third of the United States adult population is obese. ${ }^{3}$ Between 1997-2007 and 2011-2012, there has been a significant increase in the prevalence of obesity from $27 \%$ to $35 \%$ for both men and women and across all age groups. ${ }^{3-4}$ Obesity is one of the major causes of preventable death and is closely related to insulin resistance, which may lead to type 2 diabetes (T2D). ${ }^{2,5-7}$ Type 2 diabetes is a major cause of morbidity and mortality in the United States. ${ }^{8}$ Type 2 diabetes and its health-related outcomes pose an immense burden both on individuals with the disease and on public health systems. ${ }^{9}$ The prevention of T2D and its associated outcomes, particularly cardiovascular risk has become a public health priority. Anti-diabetes efforts to reverse the increasing prevalence of T2D is threatened by a growing epidemic of obesity. ${ }^{2}$ While insulin resistance is widely accepted as the core process in the development of T2D, new concepts indicate initial inflammatory responses. ${ }^{10-11}$ Several peptides released from white adipose tissue with excess adiposity have been implicated in 
the coexistence of obesity and T2D. Leptin is one of the peptides that influences energy intake, inflammation and insulin resistance. ${ }^{12-13}$

Leptin an adipocytokine and a product of the $o b$ gene regulates body weight by acting centrally to reduce energy intake. ${ }^{14-17}$ Additionally, leptin modulates glucose and fat homeostasis. ${ }^{12,15}$ In humans, circulating levels of leptin are directly proportional to BMI or body fat percentage and high levels of leptin in obese individuals suggests leptin resistance in the central nervous system. ${ }^{15,18}$ Previous studies show that obesity-induced leptin resistance activates the c-Jun $\mathrm{NH}(2)$-terminal kinase (JNK) and inhibitor of nuclear factor kappa-B kinase subunit beta (IKK $\beta$ ) inflammatory pathways. ${ }^{13}$ Moreover, leptin has structural similarity to interleukin-6 (IL-6) and may subsequently increase C-reactive protein (CRP) levels. ${ }^{19-21}$ Further, leptin stimulates macrophages and monocytes to produce IL- 6 and TNF- $\alpha$, pro-inflammatory adipocytokines well-recognized to affect insulin sensitivity and induce insulin resistance. ${ }^{20}$ The reports of associations of leptin with other pro-inflammatory adipocytokines, insulin resistance and prevalence of T2D indicate leptin as a strong determinant of obesity and its complications. ${ }^{22}$ Serum leptin levels also show marked gender differences, with higher concentrations in women than in men at all levels of BMI. ${ }^{23}$ Apart from gender, existing studies also show that lifestyle factors such as diet and smoking may affect serum leptin levels. ${ }^{22,24-25}$ For example, vitamin $\mathrm{D}$ is an immune-modulator which may attenuate inflammation, enhance insulin sensitivity and thus is inversely associated with leptin levels. ${ }^{25}$ Cigarette smokers, on the other hand have lower leptin levels compared to their non-smoking counterparts. ${ }^{22,24}$ A number of population-based studies have consistently shown that compared with non-Hispanic Whites, non-white ethnicities, particularly non-Hispanic Blacks have 
high prevalence of obesity, insulin resistance and T2D. ${ }^{26}$ It is suggested that the ethnic differences in these metabolic-related factors is partly explained by differences in adiposity and body composition. ${ }^{1-3}$ Extensive research on ethnic differences in proinflammatory adipocytokines such as CRP and IL-6 linking adiposity, insulin resistance and T2D have been conducted. ${ }^{27-29}$ Moreover, only a few epidemiological studies have reported ethnic differences in leptin levels ${ }^{24,30-31}$ and such studies are yet to be conducted among non-Hispanic Blacks. In addition, previous studies on leptin levels in individuals with T2D are also controversial. ${ }^{32-34}$ Leptin levels were found to be lower in obese individuals with T2D, whereas other data show increased or unchanged levels in these individuals.

In the current study, we investigated; 1) ethnic variation of leptin levels in Haitian and African Americans with and without T2D and 2) the association of leptin with BMI and insulin resistance controlling for important confounders including diet and lifestyle factors.

\section{METHODS}

\section{Participants and Study Design}

This was a cross-sectional study conducted in Haitian and African Americans with $(\mathrm{n}=197)$ and without $(\mathrm{n}=216)$ T2D. The study protocol was approved by the Institutional Review Board at Florida International University (FIU). Within a period of one year, about 7550 letters were mailed to African Americans in South Florida, from the Miami-Dade and Broward Counties to request their participation. The list of mailing addresses for African Americans with and without T2D was purchased from the 
Knowledge Base Marketing, Inc., Richardson, TX, USA. Of the letters mailed, 4\% ( $\mathrm{n}=$ 256) of the participants responded. Due to unavailability of similar database of mailing addresses for Haitian Americans, recruitment for this group was done through multiple community based sources. These sources included local diabetes educators and community health practitioners, and staff, faculty and students of FIU. In addition, advertisements were placed in local Haitian supermarkets, churches, and restaurants and announcements were aired on Creole radio stations. Respondents were interviewed on phone. The purpose of the study was fully explained and the age ( $\geq 35$ years), gender and self-identified ethnicity (Haitian American or African American) were assessed. For respondents who self-reported as having T2D, initial treatment modalities, duration of diabetes and fasting plasma glucose (FPG) and glycated hemoglobin levels (A1C) were obtained. Exclusion criteria included kidney failure, hepatitis, HIV and cancer. Eligible participants were requested to enroll in the study at the Human Nutrition Laboratory at FIU. Participants to enroll in the study were instructed to fast at least 8 hours prior to their blood collection. Additionally, they were instructed to refrain from smoking and any unusual exercise, but could drink only water. Written informed consent in English or Creole was obtained from each participant after they understood the requirements on the form. The laboratory results of twelve participants (8 Haitian Americans and 4 African Americans) who reported not having T2D revealed high values for FPG and A1C and were reclassified as having T2D. These individuals were referred to their physicians. Participants $(\mathrm{n}=103)$ with missing values and outliers for leptin, HOMA2-IR, serum vitamin $\mathrm{D}\{25(\mathrm{OH}) \mathrm{D}\}$ and energy intake were excluded. A total of 413 participants, 197 
with T2D and 216 without T2D (213 Haitian and 200 African Americans) were included in all data analysis.

\section{Socio-demographic data}

A standardized self-reported questionnaire was used to obtain information regarding age, gender, smoking status, and medications used. Self-reported information on ethnicity was confirmed during interview. Anthropometric measures were obtained at the Human Nutrition Laboratory. Height and weight were measured with the SECA balance scale (Seca Corp, Columbia, MD). Body mass index (BMI) was calculated as weight in $\mathrm{kg}$ divided by height in $\mathrm{m}^{2}$.

\section{Assessment of dietary intake}

The validated and standardized Harvard semi-quantitative food frequency questionnaire was used to obtain information on macro- and micro-nutrients from foods and vitamins consumed. Participants self-reported average intake of specified quantities of foods over the past year. Daily servings for food groups were calculated by totaling frequency scores for all food items. The output of these calculations were used to obtain the energy intake (kcal) of participants.

\section{Blood collection and laboratory measurements}

Twenty milliliters of venous blood was collected in a Vaccutainer Serum Separator tubes by a trained and certified phlebotomist using standard methods, following an 8-hour overnight fast. Blood samples were centrifuged at 2500 RPM for half an hour after coagulation. The separated serum was aliquoted into 3 labeled plastic tubes. Two were designated for analysis of glucose and vitamin D. The third aliquot was stored at - 
$70^{\circ} \mathrm{C}$ for subsequent analyses. Glucose levels were measured by hexokinase enzymatic methods (Laboratory Corporation of America, FL, USA). Hemoglobin A1C percentages were assayed in whole blood samples applying the Roche Tina Quant method (Laboratory Corporation of America, FL, USA). Serum vitamin D (25(OH)D) levels were determined with a commercial enzyme linked immunosorbent assay kit (ELISA) from Immunodiagnostic Systems Limited (Scottsdale, AZ, U.S.).

Leptin levels in serum were measured at the Human Nutrition Laboratory at FIU using ELISA developed with monoclonal antibody specific for leptin pre-coated onto a microplate, according to manufacturer's protocol (R\&D Systems, Minneapolis, MN, USA). Briefly, $100 \mu$ l of Assay Diluent RD1-19 was added to each well followed by $100 \mu 1$ of standards, dilution buffer (blank) and diluted samples $(100 \mathrm{x}-10 \mu 1$ sample plus $990 \mu 1$ dilution buffer). After 2 hours of incubation at room temperature followed by washing, $200 \mu 1$ of leptin conjugate was added and incubated with the bound leptin for an hour. After a second washing step, $200 \mu 1$ substrate solution was added and incubated for half an hour to allow reaction with the residual conjugate. The reaction process was stopped by addition of $50 \mu \mathrm{l}$ of $\mathrm{N}$ sulfuric acid stop solution. The absorbance of the resulting product was measured at $450 \mathrm{~nm}$ with a spectrophotometer. A microplate reader capable of creating a standard curve plotted the mean absorbance values against the leptin concentrations of standards. The software used the standard curve to determine the concentrations of the unknown diluted samples multiplied by the dilution factor to obtain the actual amount of serum leptin. The sensitivity of the ELISA assay was $7.8 \mathrm{pg} / \mathrm{ml}$ and the range was $7.8-1000 \mathrm{pg} / \mathrm{ml}(78-100000 \mathrm{pg} / \mathrm{ml}$ with dilution factor). The intraassay and interassay coefficients of variation were both less than $10 \%$. 


\section{Calculation of insulin resistance (HOMA2-IR)}

The Oxford University HOMA2 calculator was used to calculate insulin resistance as previously described. ${ }^{35}$ The model determines insulin resistance (HOMA2IR) from paired fasting plasma glucose and radioimmunoassay insulin across a range of $1-2,200 \mathrm{pmol} / \mathrm{l}$ for insulin, and 1-25 $\mathrm{mmol} / 1$ for glucose.

\section{Data Analysis}

All statistical analyses were conducted with SPSS version 21 (IBM Corporation, Chicago, IL, USA). The Kolmogorov-Smirnov test was used to assess the normality of the distribution of the data. The distributions of leptin and insulin resistance (HOMA2IR) were natural log-transformed to improve normality. All data analyses were separated by gender because the mean serum leptin levels differed by gender in our sample. Moreover, gender was an independent predictor of leptin levels in previous studies. ${ }^{23}$ Differences in mean values between ethnicity and diabetes status were compared by Student's t-test for continuous variables and $\chi^{2}$ tests for categorical variables. The relationships between variables were analyzed by multiple linear regression using log leptin as the dependent variable. The models were generated separately for diabetes status and gender. Independent variables including BMI and HOMA2-IR as primary predictors, age, ethnicity (Haitian American/African American), smoke status (yes/no), energy intake, serum 25(OH)D, lipid lowering drugs (yes/no), nonsteroidal anti-inflammatory drugs (NSAIDs) (yes/no) were forced into the model. For all analyses, a P-value of $<0.05$ was considered to be statistically significant. 


\section{RESULTS}

Of the 413 Haitian and African Americans with and without T2D, 49.9\% were males and $50.1 \%$ were females. The general demographic and health-related characteristics of the study population by ethnicity are shown in Table 1. Compared with Haitian Americans, African Americans were younger $(P<0.05)$ and had a higher percentage of smokers $(P<0.001)$. African American females had higher mean BMI (35.1 \pm 8.3 vs. $29.9 \pm 5.0, P<0.001)$, were more obese $(P=0.003)$, had higher energy intake $(P=0.045)$, lower serum vitamin D levels $(P=0.005)$, higher log HOMA2-IR $(P=0.014)$ and higher log leptin levels $((P=0.029)$ than did Haitian American females. While the mean serum vitamin $\mathrm{D}$ levels $(60.3 \pm 26.9$ vs. $54.0 \pm 19.7, P=0.060)$ were higher in African American males, although not significantly, the mean BMI (31.2 \pm 6.0 vs. 28.1 \pm 4.2 , $P<0.001)$, obesity $(P<0.001)$, energy intake $(P<0.001), \log$ HOMA2-IR $(P=0.004)$ and $\log$ leptin levels $(P=0.001)$ were significantly lower in Haitian American males. With the exception of significantly higher use of NSAIDs $(P<0.001)$ among African American females compared to Haitian American females, there was no significant ethnic difference in the use of lipid lowering drugs and oral hypoglycemic medications between males and females.

The general demographic and health-related characteristics of the study population by diabetes status are shown in Table 2 . BMI was significantly higher in males and females with T2D compared to those without T2D $(P<0.05)$, however, no significant difference was observed for percentages of obese males and females with and without T2D. Energy intake was significantly lower among males with T2D compared to males without T2D $(P<0.001)$, but no difference was seen in females. Although low 
serum vitamin D levels were common in females with compared to those without T2D $(P=0.045)$, no significant difference was observed in males. As expected, the use of lipid lowering drugs $(P<0.001)$, NSAIDs $(P<0.05)$ and oral hypoglycemic medications $(P<0.001)$ were significantly higher among males and females with T2D compared to males and females without T2D. Both males and females with and without T2D had similar tendencies to smoke. The mean log leptin and mean log HOMA2-IR were not significantly different between males and females with and without T2D.

A test of the means by Student's t-test showed a significant difference in serum log leptin levels by males and females, obesity and ethnicity/diabetes status in the entire sample (data not shown). Males had significantly lower mean log leptin levels as compared to females $(9.3 \pm 0.9$ vs. $10.4 \pm 0.8, P<0.001)$. Obese individuals had significantly higher mean log leptin levels compared with non-obese individuals (10.4 \pm 0.8 vs. 9.4 \pm 0.9 , $P<0.001)$. In addition, Haitian Americans with T2D, contrary to our earlier hypothesis, had lower mean log leptin levels compared to African Americans with T2D (9.6 \pm 1.2 vs. $10.1 \pm 0.8, P=0.001)$.

Tables 3 and 4 show the results of multiple linear regression analyses conducted using serum log leptin levels as the dependent variable. In males with T2D, log levels of leptin were predicted by ethnicity, age and BMI, whereas in males without T2D, BMI and $\log$ HOMA2-IR were the major determinants. In females with T2D, changes in log leptin levels were explained by BMI and log HOMA2-IR had a slight trend towards significance. However, in females without T2D, BMI and smoking explained serum log leptin levels, and ethnicity had a slight trend towards significance. Overall, BMI was the strongest predictor of serum log leptin levels across all groups. These results reinforce 
existing evidence that serum $\log$ leptin levels in males are altered differently from those of females. The differences in predictors of serum leptin levels between participants with and without T2D may suggest T2D as an influential factor in our sample. Independent variables for males with $\mathrm{T} 2 \mathrm{D}$ and without $\mathrm{T} 2 \mathrm{D}$, females with $\mathrm{T} 2 \mathrm{D}$ and without $\mathrm{T} 2 \mathrm{D}$ explained $44 \%, 61 \%, 18 \%$ and $33 \%$ of the variance of log leptin levels in separate regression models, respectively. Energy intake, serum vitamin D and medications were not significantly associated with log leptin levels.

\section{DISCUSSION}

In the present study, we evaluated serum leptin levels in Haitian and African Americans with and without T2D. We observed significant differences in serum leptin levels across ethnic groups by gender, but not with diabetes status by gender. Haitian American males and females had lower serum leptin levels compared to African American males and females. Among the diabetes groups, the nonsignificant difference in serum leptin levels in participants with and without T2D is consistent with other research. ${ }^{36}$ A number of factors may explain the nonsignificant difference observed: firstly, advancing disease may cause continuing loss of the normal processes of leptin regulation. ${ }^{36}$ Secondly, adiposity and gender are the main predictors of leptin levels in both individuals with and without T2D. A difference in distribution of adipose tissue accumulation, where subcutaneous fat has been shown to produce more leptin compared

to visceral fat. ${ }^{37-38}$ Individuals with T2D have been shown to have more visceral and less subcutaneous adipocytes; ${ }^{38}$ although this was not determined in our study. Females with T2D had lower leptin levels compared to females without T2D, whereas males with T2D 
had higher leptin levels than males without T2D, although nonsignificantly in both instances. Thirdly, medications used in the treatment of T2D may reduce the leptin levels in individuals with T2D. For instance, in a randomized clinical trial, metformin and pioglitazone, two commonly used oral hypoglycemic medications reduced leptin levels in individuals with newly diagnosed T2D. ${ }^{39}$ The lack of conclusive data regarding the levels of leptin in individuals with T2D warrants further research among newly diagnosed drugfree T2D individuals.

As expected, in our study, we found that leptin was strongly associated with BMI, a globally accepted surrogate of general adiposity, in all groups. Our sample was made up of overweight (on the higher side) and obese individuals, thus the results observed is not unexpected. Leptin is primarily an adipose-tissue derived peptide and the first identified adipocytokine. ${ }^{13}$ Leptin regulates food behavior and energy expenditure and interacts with inflammatory pathways and immune function. ${ }^{12,14,18-21}$ An autosomal recessive mutation of the obese gene $(o b)$ results in increased food intake and obesity. ${ }^{15}$ Thus, increased levels of leptin signifying leptin resistance in obesity is the key feature of the strong positive relationship between leptin with BMI and adipose mass. Leptin resistance and the accumulation of adipose mass results in inflammatory responses in adipose tissue. Leptin induces inflammation through key inflammatory pathways including JNK and IKK $\beta .{ }^{18}$ Moreover, with a similar structure to IL-6, leptin induces inflammatory response through its proximal Janus kinase 2 (JAK2) signaling pathway and as such may modulate C-reactive protein. ${ }^{19-21}$ Leptin also activates innate and adaptive immunity which causes macrophages and monocytes to produce the pro-inflammatory adipocytokines, IL- 6 and TNF- $\alpha .{ }^{20}$ Together, all these processes of leptin lead to insulin 
resistance in peripheral tissues. Various researchers have suggested that leptin may actually be the link between obesity, insulin resistance and the development of T2D. ${ }^{22}$ In our entire sample, obese individuals had significantly higher levels of leptin than nonobese individuals. The strong positive relationship of leptin with BMI found in our sample is in agreement with those reported by previous studies for overweight/obese participants with and without T2D. ${ }^{33-34,36,40}$

Type 2 diabetes is a disease of leptin and insulin-mediated signaling pathways. ${ }^{41}$ Leptin and insulin levels are directly interrelated with body weight and adipose mass. Leptin attenuates insulin action and insulin signaling. ${ }^{18-21}$ However, the literature is inconsistent regarding circulating leptin levels and insulin resistance. As mentioned, gender difference may partially contribute to the discrepancies in our results. While some studies have shown significance for the association between leptin and insulin resistance in both males and females ${ }^{42}$ others reported that leptin levels are associated with insulin resistance independently of BMI only in males. ${ }^{43-44}$ Our study demonstrated that leptin levels were significantly associated with insulin resistance (assessed by HOMA2-IR), independently of BMI in males without T2D. However, in males with T2D and females with and without T2D, only BMI was associated with levels of leptin after controlling for confounders. Similarly, Hattori et al. ${ }^{45}$ reported that in a sample of 64 Japanese with and without T2D, leptin levels were associated with insulin resistance independently of BMI in both males with and without T2D. The authors stated that in females, only BMI was associated with leptin levels. They concluded that the association between insulin resistance and leptin levels in females is dependent on BMI since insulin resistance was highly correlated with BMI in their sample. The reason of the differences by gender is 
proposed to be due to the regulation of leptin levels by the effect of sex hormones which are triggered to control body weight. ${ }^{44,46}$ The nonsignificant association of HOMA2-IR with leptin levels in males with T2D in our study, contrary to that observed by Hattori et al. ${ }^{45}$ may be due to the use of diabetes medications in males with T2D. An alternative explanation may be the nonsignificant difference in obesity, comparable serum vitamin D levels and the higher dietary energy intake among males without T2D.

Leptin levels were significantly higher in African American men and there was a slight trend toward significance $(P=0.088)$ in African American women in regression analysis. Higher proportions of BMI, higher HOMA2-IR, higher dietary energy intake and lower serum levels of vitamin D among African American males and females compared to Haitian American males and females may account for the observed higher levels of leptin in African American males and females. Ethnic comparative studies have demonstrated higher levels of leptin in ethnic populations with the highest prevalence of metabolic risk factors. ${ }^{24,30-31}$ African Americans have consistently been shown to have higher obesity and insulin resistance compared to non-Hispanic Whites and other minorities including the non-Hispanic Black subgroup of Haitian Americans. ${ }^{26,47}$ The greater influence of adiposity in ascertaining the levels of leptin in females, particularly among African American women who had the highest proportion of obesity in the current study may be applicable to the gender-based difference. Among African Americans, particularly African American women, obesity is well accepted and their view of an ideal body weight has been significantly higher compared to non-Hispanic Whites. ${ }^{48-49}$ Although data is lacking in Haitian Americans, available evidence shows that they are less obese and moreover have fewer metabolic abnormalities compared to African 
Americans. ${ }^{47}$ The observed ethnic subgroup differences in the risk factors may also reflect an interplay of behavioral and lifestyle, genetic and acculturation factors which warrant further investigations.

Regression analyses revealed that socio-demographic and lifestyle factors such as age and smoking were positively and inversely associated with leptin levels in men with T2D and women without T2D, respectively. Similar to the study conducted by Schautz et

al. ${ }^{50}$ leptin levels were increased as an individual ages. A possible explanation may be the age-related metabolic decline which alters fat distribution, obesity and insulin resistance. The inverse association between smoking and leptin levels may be due to a possibility of nicotine to increase sensitivity of insulin dependent tissues to leptin. ${ }^{22,24}$

The cross-sectional design of our study limits us from establishing causality between ethnicity, obesity, insulin resistance and T2D with leptin levels. In addition, genetic variation and differences in lifestyle, environmental and acculturation factors which have the possibility to alter leptin levels between Haitian and African Americans were not determined in this study. Although this study used HOMA2-IR an estimate of insulin resistance rather than the gold standard of hyperinsulinemic-euglycemic clamp, the HOMA2-IR has been used in several cross-sectional studies and has been shown to be a reliable surrogate in determining measures of insulin resistance. ${ }^{51}$ The semiconvenience nature of our sample is not representative of Haitian and African Americans and thus, limits generalizability to the larger population.

The strength of our study is that we are the first to report gender differences in leptin levels in two non-Hispanic Black ethnic subgroups. Our results show that serum leptin levels are influenced differently in women compared to men. While the 
relationship between metabolic risk factors and leptin levels in African Americans have been extensively reported in the literature, however, information for Haitian Americans is lacking. Thus, this study has not only generated data on this relationship in Haitian Americans, but also highlights the need to target these non-Hispanic Black ethnic subgroups separately considering the profound differences in metabolic risk factors.

\section{CONCLUSION}

In conclusion, our results showed that in males without $\mathrm{T} 2 \mathrm{D}$, both BMI and HOMA2-IR were independently associated with leptin levels while in males with T2D and females with and without T2D, only BMI one of the primary independent variables was associated with leptin levels. Further, contrary to our earlier hypothesis, we found leptin levels to be lower in Haitian Americans with T2D irrespective of gender compared to African Americans with T2D. The lower leptin levels in Haitian Americans may be due to favorable metabolic profile including lower obesity and insulin resistance. The ethnic differences may also be attributable to genetic variation and differences in lifestyle, environmental and acculturation factors which may affect risk of disease. Future studies should focus on the association of these factors with leptin levels in the two subethnic groups. In addition, these findings may help identify individuals at risk for T2D across adiposity level and make an important contribution in designing ethnic centered interventions to prevent $\mathrm{T} 2 \mathrm{D}$ in this population. 


\section{REFERENCES:}

1. Flegal KM, Carroll MD, Kit BK, Ogden CL. Prevalence of obesity and trends in the distribution of body mass index among US adults, 1999-2010. JAMA. 2012;307(5):491-497.

2. Centers for Disease Control and Prevention. Overweight and Obesity. Adult Obesity Facts 2014. Available at: http://www.cdc.gov/obesity/data/adult.html. Accessed on August 18, 2014.

3. Ogden CL, Carroll MD, Kit BK, Flegal KM. Prevalence of childhood and adult obesity in the United States, 2011-2012. JAMA. 2014;311(8):806-814.

4. Centers for Disease Control and Prevention. Early Release of Selected Estimates Based on Data From the 2007 National Health Interview Survey. Available at: http://www.cdc.gov/nchs/data/nhis/earlyrelease/200712 06.pdf. Accessed on August 18, 2014.

5. Mokdad AH, Marks JS, Stroup DF, Gerberding JL. Actual causes of death in the United States, 2000. JAMA. 2004;291(10):1238-1245.

6. Haslam DW, James WP. Obesity. Lancet. 2005;366(9492):1197-1209.

7. Wellen KE, Hotamisligil GS. Inflammation, stress, and diabetes. J Clin Invest. 2005;115(5):1111-1119.

8. Narayan KM, Gregg EW, Fagot-Campagna A, Engelgau MM, Vinicor F. Diabetes - a common, growing, serious, costly, and potentially preventable public health problem. Diabetes Res Clin Pract. 2000;50 Suppl 2:S77-84.

9. American Diabetes Association. National Diabetes Statistics Report, 2014. Statistics About Diabetes. Available at: http://www.diabetes.org/diabetesbasics/statistics/. Accessed on August 18, 2014.

10. Bertoni AG, Burke GL, Owusu JA, Carnethon MR, Vaidya D, Barr RG, Jenny NS, Ouyang P, Rotter JI. Inflammation and the incidence of type 2 diabetes: the Multi-Ethnic Study of Atherosclerosis (MESA). Diabetes Care. 2010;33(4):804810 .

11. Pradhan AD, Manson JE, Rifai N, Buring JE, Ridker PM. C-reactive protein, interleukin 6 , and risk of developing type 2 diabetes mellitus. JAMA. 2001;286(3):327-334.

12. Mantzoros CS. The role of leptin in human obesity and disease: a review of current evidence. Ann Intern Med. 1999;130(8):671-680. 
13. Zhang X, Zhang G, Zhang H, Karin M, Bai H, Cai D. Hypothalamic IKKbeta/NFkappaB and ER stress link overnutrition to energy imbalance and obesity. Cell. 2008;135(1):61-73.

14. Blüher S, Mantzoros CS. Leptin in humans: lessons from translational research. Am J Clin Nutr. 2009;89(3):991S-997S.

15. Friedman JM, Halaas JL. Leptin and the regulation of body weight in mammals. Nature. 1998;395(6704):763-770.

16. Zhang Y, Proenca R, Maffei M, Barone M, Leopold L, Friedman JM. Positional cloning of the mouse obese gene and its human homologue. Nature. 1994;372(6505):425-432.

17. Halaas JL, Gajiwala KS, Maffei M, Cohen SL, Chait BT, Rabinowitz D, Lallone RL, Burley SK, Friedman JM. Weight-reducing effects of the plasma protein encoded by the obese gene. Science. 1995;269(5223):543-546.

18. Mahabir S, Baer D, Johnson LL, Roth M, Campbell W, Clevidence B, Taylor PR. Body Mass Index, percent body fat, and regional body fat distribution in relation to leptin concentrations in healthy, non-smoking postmenopausal women in a feeding study. Nutr J. 2007;6:3.

19. Lam QL, Lu L. Role of leptin in immunity. Cell Mol Immunol. 2007;4(1):1-13.

20. Gainsford T, Willson TA, Metcalf D, Handman E, McFarlane C, Ng A, Nicola NA, Alexander WS, Hilton DJ. Leptin can induce proliferation, differentiation, and functional activation of hemopoietic cells. Proc Natl Acad Sci. 1996;93(25):14564-14568.

21. Chen K, Li F, Li J, Cai H, Strom S, Bisello A, Kelley DE, Friedman-Einat M, Skibinski GA, McCrory MA, Szalai AJ, Zhao AZ. Induction of leptin resistance through direct interaction of C-reactive protein with leptin. Nat Med. 2006;12(4):425-432.

22. Considine RV, Sinha MK, Heiman ML, Kriauciunas A, Stephens TW, Nyce MR, Ohannesian JP, Marco CC, McKee LJ, Bauer TL, et al. Serum immunoreactiveleptin concentrations in normal-weight and obese humans. N Engl J Med. 1996;334(5):292-295.

23. Hickey MS, Israel RG, Gardiner SN, Considine RV, McCammon MR, Tyndall GL, Houmard JA, Marks RH, Caro JF. Gender differences in serum leptin levels in humans. Biochem Mol Med. 1996;59(1):1-6. 
24. Wei M, Stern MP, Haffner SM. Serum leptin levels in Mexican Americans and non-Hispanic whites: association with body mass index and cigarette smoking. Ann Epidemiol. 1997;7(2):81-86.

25. Belenchia AM, Tosh AK, Hillman LS, Peterson CA. Correcting vitamin D insufficiency improves insulin sensitivity in obese adolescents: a randomized controlled trial. Am J Clin Nutr. 2013;97(4):774-781.

26. Dagogo-Jack S. Ethnic disparities in type 2 diabetes: pathophysiology and implications for prevention and management. J Natl Med Assoc. 2003;95(9):774,779-789.

27. Bertoni AG, Burke GL, Owusu JA, Carnethon MR, Vaidya D, Barr RG, Jenny NS, Ouyang P, Rotter JI. Inflammation and the incidence of type 2 diabetes: the Multi-Ethnic Study of Atherosclerosis (MESA). Diabetes Care. 2010;33(4):804810.

28. Duncan BB, Schmidt MI, Pankow JS, Ballantyne CM, Couper D, Vigo A, Hoogeveen R, Folsom AR, Heiss G; Atherosclerosis Risk in Communities Study. Low-grade systemic inflammation and the development of type 2 diabetes: the atherosclerosis risk in communities study. Diabetes. 2003;52(7):1799-1805.

29. Paalani M, Lee JW, Haddad E, Tonstad S. Determinants of inflammatory markers in a bi-ethnic population. Ethn Dis. 2011;21(2):142-149.

30. Zimmet P, Hodge A, Nicolson M, Staten M, de Courten M, Moore J, Morawiecki A, Lubina J, Collier G, Alberti G, Dowse G. Serum leptin concentration, obesity, and insulin resistance in Western Samoans: cross sectional study. BMJ. 1996;313(7063):965-969.

31. Haffner SM, Stern MP, Miettinen H, Wei M, Gingerich RL. Leptin concentrations in diabetic and nondiabetic Mexican-Americans. Diabetes. 1996;45(6):822-824.

32. Al-Daghri N, Al-Rubean K, Bartlett WA, Al-Attas O, Jones AF, Kumar S. Serum leptin is elevated in Saudi Arabian patients with metabolic syndrome and coronary artery disease. Diabet Med. 2003;20(10):832-837.

33. Abdelgadir M, Elbagir M, Eltom M, Berne C, Ahrén B. Reduced leptin concentrations in subjects with type 2 diabetes mellitus in Sudan. Metabolism. 2002;51(3):304-306.

34. Ozata M, Gungor D, Turan M, Ozisik G, Bingol N, Ozgurtas T, Ozdemir IC. Improved glycemic control increases fasting plasma acylation-stimulating protein and decreases leptin concentrations in type II diabetic subjects. J Clin Endocrinol Metab. 2001;86(8):3659-3664. 
35. Wallace TM, Levy JC, Matthews DR. Use and abuse of HOMA modeling. Diabetes Care. 2004;27(6):1487-1495.

36. Tatti P, Masselli L, Buonanno A, Di Mauro P, Strollo F. Leptin levels in diabetic and nondiabetic subjects. Endocrine. 2001;15(3):305-308.

37. Van Gaal LF, Wauters MA, Mertens IL, Considine RV, De Leeuw IH. Clinical endocrinology of human leptin. Int J Obes Relat Metab Disord. 1999;23 Suppl $1: 29-36$.

38. Lefebvre AM, Laville M, Vega N, Riou JP, van Gaal L, Auwerx J, Vidal H. Depot-specific differences in adipose tissue gene expression in lean and obese subjects. Diabetes. 1998;47(1):98-103.

39. Esteghamati A, Noshad S, Rabizadeh S, Ghavami M, Zandieh A, Nakhjavani M. Comparative effects of metformin and pioglitazone on omentin and leptin concentrations in patients with newly diagnosed diabetes: a randomized clinical trial. Regul Pept. 2013;182:1-6.

40. Zuo H, Shi Z, Yuan B, Dai Y, Wu G, Hussain A. Association between serum leptin concentrations and insulin resistance: a population-based study from China. PLoS One. 2013;8(1):e54615.

41. Kulkarni RN, Wang ZL, Wang RM, Hurley JD, Smith DM, Ghatei MA, Withers DJ, Gardiner JV, Bailey CJ, Bloom SR. Leptin rapidly suppresses insulin release from insulinoma cells, rat and human islets and, in vivo, in mice. J Clin Invest. 1997;100(11):2729-2736.

42. de Courten M, Zimmet P, Hodge A, Collins V, Nicolson M, Staten M, Dowse G, Alberti KG. Hyperleptinaemia: the missing link in the, metabolic syndrome? Diabet Med. 1997;14(3):200-208.

43. Vettor R, De Pergola G, Pagano C, Englaro P, Laudadio E, Giorgino F, Blum WF, Giorgino R, Federspil G. Gender differences in serum leptin in obese people: relationships with testosterone, body fat distribution and insulin sensitivity. Eur J Clin Invest. 1997;27(12):1016-1024.

44. Kennedy A, Gettys TW, Watson P, Wallace P, Ganaway E, Pan Q, Garvey WT. The metabolic significance of leptin in humans: gender-based differences in relationship to adiposity, insulin sensitivity, and energy expenditure. J Clin Endocrinol Metab. 1997;82(4):1293-1300.

45. Hattori A, Uemura K, Miura H, Ueda M, Tamaya N, Iwata F, Muraguchi M, Ohmoto Y, Iguchi A. Gender-related difference in relationship between insulin 
resistance and serum leptin level in Japanese type 2 diabetic and non-diabetic subjects. Endocr J. 2000;47(5):615-621.

46. Rosenbaum M, Nicolson M, Hirsch J, Heymsfield SB, Gallagher D, Chu F, Leibel RL. Effects of gender, body composition, and menopause on plasma concentrations of leptin. J Clin Endocrinol Metab. 1996;81(9):3424-3427.

47. Huffman F, Vallasciani M, Vaccaro J, Exebio J, Zarini G, Nayer A, Ajabshir, S. The association of depression and perceived stress with beta cell function between African and Haitian Americans with and without type 2 diabetes. J of Diabetes Mellit. 2013;3:236-243.

48. Latner JD, Stunkard AJ, Wilson GT. Stigmatized students: age, sex, and ethnicity effects in the stigmatization of obesity. Obes Res. 2005;13(7):1226-1231.

49. Becker DM, Yanek LR, Koffman DM, Bronner YC. Body image preferences among urban African Americans and whites from low income communities. Ethn Dis. 1999;9(3):377-386.

50. Schautz B, Later W, Heller M, Peters A, Müller MJ, Bosy-Westphal A. Impact of age on leptin and adiponectin independent of adiposity. $\mathrm{Br} \mathrm{J}$ Nutr. 2012;108(2):363-370.

51. Exebio JC, Ajabshir S, Zarini GG, Vaccaro J, Huffman FG. Use of Homeostatic Model Assessment Indexes for the Identification of Metabolic Syndrome and Insulin Resistance among Cuban-Americans: A Cross Sectional Study. Br J Med Med Res. 2014;4(29): 4824-4833. 
TABLE 1. Characteristics of the Participants by Sex and Ethnicity

\begin{tabular}{|c|c|c|c|c|c|c|}
\hline \multirow[b]{2}{*}{ Variables } & \multicolumn{2}{|c|}{ Male } & \multicolumn{4}{|c|}{ Female } \\
\hline & $\begin{array}{l}\text { Haitian } \\
\text { American } \\
(n=104)\end{array}$ & $\begin{array}{c}\text { African } \\
\text { American } \\
(\mathrm{n}=\mathbf{1 0 2})\end{array}$ & $\begin{array}{c}\text { P- } \\
\text { value }\end{array}$ & $\begin{array}{l}\text { Haitian } \\
\text { American } \\
(\mathrm{n}=\mathbf{1 0 9})\end{array}$ & $\begin{array}{l}\text { African } \\
\text { American } \\
(\mathrm{n}=98)\end{array}$ & $\begin{array}{c}\text { P- } \\
\text { value }\end{array}$ \\
\hline Age (years) & $54.9 \pm 9.8$ & $51.9 \pm 7.8$ & 0.014 & $56.9 \pm 10.9$ & $53.8 \pm 10.8$ & 0.043 \\
\hline Diabetes status & & & 0.582 & & & 0.924 \\
\hline With T2D n (\%) & $47(45.2)$ & $50(49.0)$ & & $53(48.6)$ & $47(48.0)$ & \\
\hline Without T2D n (\%) & $57(54.8)$ & $52(51.0)$ & & $56(51.4)$ & $51(52.0)$ & \\
\hline BMI $\left(\mathrm{kg} / \mathrm{m}^{2}\right)$ & $28.1 \pm 4.2$ & $31.2 \pm 6.0$ & $<0.001$ & $29.9 \pm 5.0$ & $35.1 \pm 8.3$ & $<0.001$ \\
\hline Obese $\left(\mathrm{BMI} \geq 30 \mathrm{~kg} / \mathrm{m}^{2}\right)$ & & & $<0.001$ & & & 0.003 \\
\hline Yes $n(\%)$ & $32(30.8)$ & $58(56.9)$ & & $56(51.4)$ & $70(71.4)$ & \\
\hline No $n(\%)$ & $72(69.2)$ & $44(43.1)$ & & $53(48.6)$ & $28(28.6)$ & \\
\hline Smoke n $(\%)$ & $11(10.6)$ & $51(50.0)$ & $<0.001$ & $1(0.9)$ & $30(30.6)$ & $<0.001$ \\
\hline Energy intake (kcal/d) & $1844.0 \pm 1161.3$ & $2759.0 \pm 1846.1$ & $<0.001$ & $1821.3 \pm 1074.4$ & $2201.7 \pm 1561.6$ & 0.045 \\
\hline 25(OH)D (nmol/L) & $54.0 \pm 19.7$ & $60.3 \pm 26.9$ & 0.060 & $56.2 \pm 18.3$ & $48.6 \pm 19.8$ & 0.005 \\
\hline Lipid lowering drugs $\mathrm{n}(\%)$ & $22(21.2)$ & $27(26.5)$ & 0.370 & $25(22.9)$ & $32(32.7)$ & 0.118 \\
\hline NSAIDs n (\%) & $26(25.0)$ & $33(32.4)$ & 0.243 & $26(23.9)$ & $46(46.9)$ & $<0.001$ \\
\hline Oral hypoglycemic meds n $(\%)$ & $42(40.4)$ & $35(34.3)$ & 0.368 & $48(44.0)$ & $40(40.8)$ & 0.640 \\
\hline $\mathrm{A} 1 \mathrm{C}(\%)$ & $7.4 \pm 2.4$ & $6.7 \pm 1.7$ & 0.028 & $7.1 \pm 1.9$ & $6.8 \pm 1.7$ & 0.294 \\
\hline $\mathrm{FPG}(\mathrm{mmol} / \mathrm{L})$ & $130.2 \pm 58.6$ & $122.7 \pm 53.5$ & 0.343 & $125.6 \pm 48.1$ & $121.8 \pm 55.0$ & 0.600 \\
\hline Insulin $(\mu \mathrm{IU} / \mathrm{mL})$ & $8.8 \pm 5.1$ & $12.9 \pm 11.1$ & 0.001 & $10.8 \pm 7.1$ & $13.9 \pm 9.8$ & 0.011 \\
\hline $\log$ HOMA2-IR & $0.1 \pm 0.5$ & $0.3 \pm 0.7$ & 0.004 & $0.2 \pm 0.5$ & $0.5 \pm 0$ & 0.014 \\
\hline $\log \operatorname{Leptin}(\mathrm{pg} / \mathrm{mL})$ & $9.1 \pm 0.9$ & $9.6 \pm 0.9$ & 0.001 & $10.3 \pm 0.9$ & $10.7 \pm 0.7$ & 0.029 \\
\hline
\end{tabular}

Data were expressed as mean \pm SD unless otherwise indicated. Abbreviations: $\mathrm{T} 2 \mathrm{D}=$ type 2 diabetes; $\mathrm{BMI}=$ body mass index;

NSAIDs $=$ nonsteroidal anti-inflammatory drugs; $\mathrm{A} 1 \mathrm{C}=$ hemoglobin $\mathrm{A} 1 \mathrm{C} ; \mathrm{FPG}=$ fasting plasma glucose; HOMA2-IR $=$ homeostasis

model assessment version 2 of insulin resistance. P-value is considered significant at $<0.05$. 
TABLE 2. Characteristics of the Participants by Sex and Diabetes Status

\begin{tabular}{|c|c|c|c|c|c|c|}
\hline \multirow[b]{2}{*}{ Variables } & \multicolumn{2}{|l|}{ Male } & \multicolumn{4}{|c|}{ Female } \\
\hline & $\begin{array}{c}\text { With } \\
\text { T2D } \\
(n=97)\end{array}$ & $\begin{array}{c}\text { Without } \\
\text { T2D } \\
(n=109)\end{array}$ & $\begin{array}{c}\mathbf{P}- \\
\text { value }\end{array}$ & $\begin{array}{c}\text { With } \\
\text { T2D } \\
(n=100)\end{array}$ & $\begin{array}{c}\text { Without } \\
\text { T2D } \\
(n=107)\end{array}$ & $\begin{array}{c}\text { P- } \\
\text { value }\end{array}$ \\
\hline Age (years) & $55.9 \pm 9.1$ & $51.1 \pm 8.2$ & $<0.001$ & $57.1 \pm 11.0$ & $53.9 \pm 10.7$ & 0.035 \\
\hline Ethnicity & & & 0.582 & & & 0.924 \\
\hline HA n $(\%)$ & $47(48.5)$ & $57(52.3)$ & & $53(53.0)$ & $56(52.3)$ & \\
\hline AA n $(\%)$ & $50(51.5)$ & $52(47.7)$ & & $47(47.0)$ & $51(47.7)$ & \\
\hline $\operatorname{BMI}\left(\mathrm{kg} / \mathrm{m}^{2}\right)$ & $30.4 \pm 5.6$ & $28.9 \pm 5.1$ & 0.043 & $33.9 \pm 8.2$ & $30.9 \pm 5.9$ & 0.004 \\
\hline Obese $\left(\mathrm{BMI} \geq 30 \mathrm{~kg} / \mathrm{m}^{2}\right)$ & & & 0.062 & & & 0.081 \\
\hline Yes n $(\%)$ & $49(50.5)$ & $41(37.6)$ & & $67(67.0)$ & $59(55.1)$ & \\
\hline No $n(\%)$ & $48(49.5)$ & $68(62.4)$ & & $33(33.0)$ & $48(44.9)$ & \\
\hline Smoke n $(\%)$ & $27(27.8)$ & $35(32.1)$ & 0.504 & $14(14.0)$ & $17(15.9)$ & 0.704 \\
\hline Energy intake (kcal/d) & $1885.65 \pm 1254.8$ & $2663.2 \pm 1784.9$ & $<0.001$ & $1826.9 \pm 1147.8$ & $2164.4 \pm 1480.6$ & 0.070 \\
\hline $25(\mathrm{OH}) \mathrm{D}(\mathrm{nmol} / \mathrm{L})$ & $55.8 \pm 22.9$ & $58.3 \pm 24.5$ & 0.445 & $49.8 \pm 21.5$ & $55.2 \pm 16.9$ & 0.045 \\
\hline Lipid lowering drugs $n(\%)$ & $38(39.2)$ & $11(10.1)$ & $<0.001$ & $44(44.0)$ & $13(12.1)$ & $<0.001$ \\
\hline NSAIDs n $(\%)$ & $37(38.1)$ & $22(20.2)$ & 0.004 & $44(44.0)$ & $28(26.2)$ & 0.007 \\
\hline Oral hypoglycemic meds $\mathrm{n}(\%)$ & o) 77(79.4) & - & - & $88(88.0)$ & - & - \\
\hline $\mathrm{A} 1 \mathrm{C}(\%)$ & $8.2 \pm 2.5$ & $6.0 \pm 0.8$ & $<0.001$ & $7.9 \pm 2.2$ & $6.1 \pm 0.7$ & $<\mathbf{0 . 0 0 1}$ \\
\hline FPG (mmol/L) & $154.5 \pm 67.6$ & $101.6 \pm 24.2$ & $<0.001$ & $148.1 \pm 61.0$ & $101.0 \pm 23.9$ & $<\mathbf{0 . 0 0 1}$ \\
\hline Insulin $(\mu \mathrm{IU} / \mathrm{mL})$ & $10.6 \pm 8.9$ & $11.1 \pm 8.8$ & 0.688 & $12.7 \pm 9.4$ & $11.8 \pm 7.8$ & 0.429 \\
\hline $\log$ HOMA2-IR & $0.2 \pm 0.6$ & $0.2 \pm 0.6$ & 0.599 & $0.4 \pm 0.6$ & $0.3 \pm 0.6$ & 0.115 \\
\hline $\log$ Leptin $(\mathrm{pg} / \mathrm{mL})$ & $9.4 \pm 0.9$ & $9.3 \pm 0.8$ & 0.532 & $10.4 \pm 0.9$ & $10.5 \pm 0.7$ & 0.302 \\
\hline
\end{tabular}

Data were expressed as mean \pm SD unless otherwise indicated. Abbreviations: T2D = type 2 diabetes; HA = Haitian Americans; $\mathrm{AA}=$ African Americans; BMI = body mass index; NSAIDs = nonsteroidal anti-inflammatory drugs; A1C = hemoglobin A1C; $\mathrm{FPG}=$ fasting plasma glucose; HOMA2-IR = homeostasis model assessment version 2 of insulin resistance. P-value is considered significant at $<0.05$. 
TABLE 3. Relationship of Leptin with BMI and HOMA2-IR in Participants with T2D - Multiple Linear Regression Analysis

\begin{tabular}{lcccccc}
\hline & \multicolumn{3}{c}{ Male $(\mathbf{n = 9 7 )}$} & & Female (n= 100) \\
\hline Variables & $\mathbf{B}$ & SE & P-value & B & SE & P-value \\
& & & & & & \\
\hline BMI & 0.113 & 0.017 & $<\mathbf{0 . 0 0 1}$ & 0.055 & 0.013 & $<\mathbf{0 . 0 0 1}$ \\
HOMA2-IR & -0.217 & 0.134 & 0.109 & -0.268 & 0.142 & 0.063 \\
Ethnicity & 0.548 & 0.212 & $\mathbf{0 . 0 1 1}$ & -0.006 & 0.206 & 0.977 \\
Age & 0.035 & 0.010 & $\mathbf{0 . 0 0 1}$ & -0.002 & 0.008 & 0.838 \\
Smoke & -0.093 & 0.200 & 0.644 & 0.077 & 0.255 & 0.762 \\
Energy intake & 0.000 & 0.001 & 0.178 & 0.000 & 0.001 & 0.986 \\
25(OH)D & -0.005 & 0.003 & 0.133 & 0.001 & 0.004 & 0.948 \\
Lipid lowering drugs & 0.334 & 0.168 & 0.050 & 0.079 & 0.177 & 0.656 \\
NSAIDs & -0.235 & 0.172 & 0.176 & 0.104 & 0.183 & 0.572 \\
\hline
\end{tabular}

Abbreviations: BMI = body mass index; HOMA2-IR = homeostasis model assessment version 2 of insulin resistance; NSAIDs = nonsteroidal anti-inflammatory drugs; $\mathrm{B}=$ unstandardized coefficients; $\mathrm{SE}=$ standard error. Leptin and HOMA2-IR were natural log transformed.

$\mathrm{P}$-value is considered significant at $<0.05$. 
TABLE 4. Relationship of Leptin with BMI and HOMA2-IR in Participants without T2D - Multiple Linear Regression Analysis

\begin{tabular}{|c|c|c|c|c|c|c|}
\hline \multirow[b]{2}{*}{ Variables } & \multicolumn{3}{|c|}{ Male $(n=109)$} & \multicolumn{3}{|c|}{ Female $(n=107)$} \\
\hline & B & SE & P-value & B & SE & P-value \\
\hline BMI & 0.111 & 0.012 & $<0.001$ & 0.058 & 0.011 & $<0.001$ \\
\hline HOMA2-IR & 0.240 & 0.097 & 0.015 & -0.032 & 0.118 & 0.786 \\
\hline Ethnicity & 0.125 & 0.127 & 0.326 & 0.225 & 0.131 & 0.088 \\
\hline Age & 0.012 & 0.007 & 0.110 & 0.005 & 0.005 & 0.397 \\
\hline Smoke & -0.186 & 0.132 & 0.162 & -0.712 & 0.184 & $<0.001$ \\
\hline Energy intake & 0.000 & 0.001 & 0.311 & 0.000 & 0.001 & 0.239 \\
\hline $25(\mathrm{OH}) \mathrm{D}$ & -0.002 & 0.002 & 0.448 & 0.003 & 0.003 & 0.440 \\
\hline Lipid lowering drugs & 0.130 & 0.200 & 0.516 & 0.108 & 0.189 & 0.569 \\
\hline NSAIDs & 0.105 & 0.152 & 0.489 & -0.048 & 0.140 & 0.732 \\
\hline
\end{tabular}

Abbreviations: BMI = body mass index; HOMA2-IR = homeostasis model assessment version 2 of insulin resistance; NSAIDs = nonsteroidal anti-inflammatory drugs; $\mathrm{B}=$ unstandardized coefficients; $\mathrm{SE}=$ standard error. Leptin and HOMA2-IR were natural log transformed. P-value is considered significant at $<0.05$. 


\section{CHAPTER VI: SUMMARY AND FUTURE RESEARCH}

The overall primary purpose of the current study was to examine the relationship of adipocytokines with metabolic syndrome (MetS), anthropometric and HOMA2 measures by ethnicity and diabetes status in Haitian and African Americans. The involvement of adipocytokines in inflammatory response and metabolic regulation, the association of adipocytokines with adiposity and consequently development of MetS and T2D, and the high susceptibility of non-Hispanic Blacks for inflammation illustrated in the literature initiated this research assessing the effects of adipocytokines in processes leading to metabolic disorders such as T2D.

The altered levels of pro- and anti-inflammatory adipocytokines due to constant stimulation of the innate immune system has been suggested as the basis for chronic lowgrade inflammation. It is proposed that this alteration is pronounced with increasing adiposity as seen in obese individuals and restored with weight loss. Although the mechanisms accountable for adipocytokines in metabolic disorders are not completely elucidated, it is thought that altered adipocytokine levels which favor pro-inflammatory adipocytokines impair insulin secretion in pancreatic $\beta$ cells, in addition to perturbation of insulin signaling pathways leading to development of T2D. The measurement of adipocytokine levels allowed an assessment of inflammation, and their relationship to obesity, insulin resistance, MetS and T2D. The dissertation comprised of three studies that were built on data from the parent study.

Explorations of the associations of the pro-inflammatory adipocytokines IL-6 and CRP with MetS and its components showed that CRP, but not IL-6 was positively associated with MetS after adjusting for important confounders. This partially supported 
our hypothesis that higher levels of IL-6 and CRP will be associated with having MetS. Notwithstanding, the current findings support others that have shown the uniqueness of $\mathrm{CRP}$ as an established and strong predictor of MetS. A lack of association between IL-6 and MetS has been reported in previous studies. However, the inverse direction found in our study may be due to the tight connection of IL-6 with adiposity. Where, lipid lowering drugs may have caused a decrease in adiposity and dampened the association of IL-6 with MetS. Our earlier hypothesis that Haitian Americans with T2D will have higher IL-6 and CRP levels compared to African Americans was found to be the reverse. Higher levels of both IL-6 and CRP were associated with African American ethnicity, however there was no association with diabetes status. Favorable metabolic factors such as lower BMI, waist circumference, insulin resistance and others including acculturation, genetic and lifestyle factors in Haitian Americans may have contributed to these findings.

Findings of the relationship between novel adipocytokines, chemerin and omentin with insulin sensitivity, ethnicity and diabetes status showed significant ethnic differences for chemerin between ethnic groups, with Haitian Americans having the lowest chemerin levels compared to African Americans. Omentin levels did not differ significantly between Haitian and African Americans. Moreover, there was no significant difference in either chemerin or omentin levels by diabetes status. However, analyses of these adipocytokines stratified by both ethnicity and diabetes status showed that Haitian Americans with T2D had lower chemerin and higher omentin levels than African Americans with T2D. Linear regression models generated with chemerin and omentin as separate dependent variables showed that chemerin was inversely associated with insulin sensitivity and positively associated with African American ethnicity and diabetes status. 
Omentin on the other hand was positively associated with insulin sensitivity and negatively associated with being African American and diabetes status. Apart from a most likely explanation of Haitian Americans possessing advantageous characteristics to have accounted for the results observed, the intake of medications by a majority of our participants may have also affected the study outcome despite controlling for medication use.

The assessment of the relationship between leptin with BMI and insulin resistance by ethnicity and diabetes status was also conducted. Since leptin levels differed by gender in our study, analysis were stratified in line with this difference. Leptin levels were not statistically different between males and females, regardless of diabetes status. However, with further classification by ethnicity and diabetes status, both Haitian American males and females were found to have lower leptin levels compared to African Americans. Additionally BMI and insulin resistance were predictors of higher leptin levels only in males without T2D.

The novel finding of our study is the differences shown in chemerin and omentin levels and their association with metabolic parameters in two non-Hispanic Black ethnic subgroups which has previously not being studied. Other strengths of our study include the use of a gender-balanced cohort and for the first time has generated data on established and novel adipocytokines particularly in Haitian Americans, a group undersampled in diabetes studies.

Several limitations of this research are important to mention. Failure of our study to support some of the hypotheses stated is again believed to be due to the high use of medications that have been shown to influence adipocytokines levels by majority of our 
study subjects. Moreover, we could not control for relevant lifestyle factors such as physical activity and detailed dietary factors which also affect adipocytokine levels. The cross-sectional design of this study did not allow the determination of temporal and causal associations. In addition, the study population is a semi-convenience sample and may therefore not be representative of Haitian Americans and African Americans living in South Florida. As a result, generalizability to the larger population may be limited. The use of surrogate markers such as serum IL- 6 concentrations in lieu of IL-6 receptor and HOMA-IR instead of the hyperinsulinemic-euglycemic clamp may have also influenced the results of this study.

The current study reveals important differences between Haitian and African Americans and further establishes a need for future research to consider these two nonHispanic Black ethnic subgroups as unique in order to design effective ethnic-focused interventions to reduce the disparities and the high incidence of T2D and its outcomes. A better understanding of the role of adipocytokines in the regulation of glucose and lipid homeostasis through insulin secretion and signaling is needed. To fully understand the ethnic specific effect on the role of adipocytokines, further investigation among Haitian and African Americans should be performed. 
VITA

\section{JANET ANTWI}

2005

2010

2010-2014
BPharm., Bachelor of Pharmacy

Kwame Nkrumah University of Science and Technology

Kumasi, Ghana

M.S., Master in International Healthcare Management, Economics and Policy

SDA Bocconi School of Management

Milan, Italy

Teaching Assistant

Florida International University

Miami, Florida

\section{PUBLICATIONS AND PRESENTATIONS}

Cheema AK, Zarini GG, Exebio J, Ajabshir S, Shaban L, Antwi J, Vaccaro, Huffman FG. Ethnic Differences in Insulin Resistance Adiponectin Levels and Abdominal Obesity: Haitian Americans and African Americans, with and without Type 2 Diabetes Mellitus. Br J Med Med Res. 2014;4(26):4455-4469.

Zarini GG, Vaccaro JA, Terris MC, Exebio J, Tokayer L, Antwi J, Ajabshir S, Cheema AK, Huffman FG. Lifestyle Behaviors and Self-Rated Health: The Living for Health Program. J Environ Public Health. Accepted for publication on 10/08/2014. Available at downloads.hindawi.com/journals/jeph/raa/315042.pdf.

Exebio JC, Zarini GG, Ajabshir Sahar, Antwi J, Huffman FG. Validation of Sun Exposure Questionnaire among Subjects with Type 2 Diabetes Residing in South Florida. Under Review. J Immigr Minor Health.

Janet Antwi, Gustavo G. Zarini, Joel Exebio, Amanpreet K. Cheema, Sahar Ajabshir, Vijaya Narayanan, Joan A. Vaccaro, Fatma G. Huffman. Serum inflammatory adipocytokine levels differ by diabetes status and ethnicity and are associated with body mass index in individuals with type 2 diabetes. July 2014. Poster presentation at the International Conference on Diabetes for Physicians Committee for Responsible Medicine. Washington, DC.

Antwi J, Cheema A, Zarini GG, Exebio JC, Vaccaro JA, Huffman FG. Relationship of levels of triglyceride with $\mathrm{HbAl} \mathrm{c}$ and adiponectin in Haitian Americans with type 2 diabetes. FASEB J April 2014, 28:1029.4. 
Zarini G, Vaccaro JA, Sahar Ajabshir, Antwi J, Cheema A, Huffman FG. Abnormal pulse pressure and microalbuminuria in Hiatians with type 2 diabetes. FASEB J April 2014, 28:1029.6.

Exebio JC, Zarini G, Vaccaro JA, Ajabshir S, Cheema A, Antwi J, Huffman FG.

Relationship between serum vitamin D and insulin resistance in African Americans with type 2 diabetes. FASEB J April 2014, 28:1030.3.

Huffman FG, Friere T, McClean M, Exebio JC, Zarini G, Antwi J, Ajabshir S, Vaccaro JA. Relationship between serum vitamin $\mathrm{D}$ and insulin resistance in African Americans with type 2 diabetes. FASEB J April 2014, 28:1029.5.

Vivas A, Exebio JC, Zarini G, Vaccaro JA, Ajabshir S, Antwi J, Cheema A, Vaccaro JA, Huffman FG. The relationship between self-rated health and the dietary choices of African Americans. FASEB J April 2014, 28:806.6.

Antwi J, Baum MK, Martinez SS, Gracia D, Greer P, Barr S, Campa A. Quality of Life (QOL), Depression and Physical and Gastrointestinal (GI) Symptoms in HIV-Infected Patients on ART. FASEB J April 2013, 27:840.4. 